\title{
Entrepreneurship, Labor Market Mobility and the Role of Entrepreneurial Insurance*
}

\author{
Alexandre Gaillard ${ }^{\dagger} \quad$ Sumudu Kankanamge ${ }^{\ddagger}$ \\ First version: February 2017 \\ This version: January 2019
}

\begin{abstract}
This paper introduces a quantitative model with risky entrepreneurship and search frictions matching the occupational flows between entrepreneurship, paid-employment, and unemployment. We account for the general shape of these flows and key entrepreneurial and labor market features based mostly on micro CPS and SCF data. Using this model, we show that an insurance providing Self-Employment Assistance (SEA) policy mitigates the bias disfavoring self-employment inherent in unemployment insurance programs. Moreover, ability-dependent SEA programs select more productive and wealthier new entrepreneurs out of unemployment. Finally, we show that the interaction between UI design and SEA programs has a significant impact on entrepreneurship.
\end{abstract}

Keywords: entrepreneurship, labor market mobility, unemployment, insurance, SEA. JEL classification: E24, J68, E61

*This paper supersedes a previous version titled "Insuring Entrepreneurial Downside Risk". We are indebted in no specific order to Arpad Abraham, Mark Bils, Patrick Fève, Christian Hellwig, Dirk Krueger, Tim Lee, Franck Portier and José Víctor Ríos Rull for their useful discussions. We are also very grateful for constructive comments from participants at the 2017 SED in Edinburgh, the XXII Workshop on Dynamic Macroeconomics in Vigo, the 23rd CEF conference in New York, the 22nd T2M conference in Paris, the 2018 spring Midwest Macroeconomics Meetings in Madison, the 2018 ESEM in Cologne and the ADEMU conferences in Toulouse and Prague. The authors are solely responsible for any remaining errors or omissions.

${ }^{\dagger}$ Toulouse School of Economics, University of Toulouse Capitole, Toulouse, France.

¥Toulouse School of Economics, University of Toulouse Capitole, Toulouse, France. Corresponding author: sumudu.kankanamge@tse-fr.eu. Toulouse School of Economics, University of Toulouse Capitole, office MF501, 21 allée de Brienne, 31000 Toulouse - France. Tel: +33 (0)5 61128549. 


\section{Introduction}

Many countries have instated programs promoting entrepreneurship as policymakers have been increasingly acknowledging their potential virtues as Active Labor Market Policies (ALMP). This subject has found a large echo in the academic literature, but two important issues have so far drawn little attention: (i) the existence of a distortion arising from the current unemployment insurance (UI) system favoring the search for paid-employment rather than self-employment and, (ii) the related question of insuring the downside risk inherent to any entrepreneurial activity as a means to reduce the above distortion. By enforcing the requirements that unemployed individuals are available for work and actively searching for a job in order to obtain regular benefits, many UI programs implicitly prevent the pursuit of an entrepreneurial project. At the same time, the downside risk, defined as the risk supported by an entrepreneur on her income stream because of bad performances, is a stark reality. The potential insurance of this risk is subject to a trade-off: on the one hand, this risk could be an important selection mechanism of the ablest entrepreneurs. On the other hand, it could prevent many potentially successful individuals from engaging in an entrepreneurial activity. The papers by Hombert et al. (2017), Ejrnæs and Hochguertel (2014) and Caliendo and Künn (2011) have paved the way for empirically addressing this trade-off. The policy discussed in Hombert et al. (2017) maintains the UI rights of unemployed individuals when they start a business in order to alleviate the effects of adverse business shocks. Implementing such a reform is a step towards reducing the distortion arising from prevalent UI systems. However, addressing these issues first require a proper representation of endogenous occupational choices and the associated flows between occupations. The main contribution of this paper is thus to build a rich theoretical framework encompassing entrepreneurship and detailed occupational flows. To support this objective, we start by documenting a number of empirical facts about entrepreneurship and the labor market focusing on these flows. Our second contribution is to use our model to assess the interaction between UI and entrepreneurship, with a special focus on recently implemented entrepreneurial assistance programs. To the best of our knowledge, this paper is the first to tackle this agenda.

The basic building block of our economy is an incomplete markets general equilibrium model with heterogeneous agents, occupational choices, risky entrepreneurship and search frictions. Agents can be employed in a corporate sector, self-employed or unemployed. Employed 
agents face an unemployment risk and can search for a business idea on-the-job in order to become self-employed. Unemployed agents can either search for a job or an entrepreneurial idea. Self-employed agents, also referred to as entrepreneurs, can search for a corporate job on-thebusiness. They might experience an adverse shock to their business productivity, leading them to potentially default on a previously contracted debt. Importantly, they have to decide how much to invest in their activity before knowing this shock. Finally, the government runs a taxfinanced UI program. In our baseline economy, entrepreneurs that fall out of business cannot claim UI rights. All the ingredients above are crucial for our purpose: financial frictions, savings, and heterogenous abilities create a quantitatively credible framework to address our policy questions. Labor market frictions are key to reproducing the necessity self-employment, which is the pool of low earning entrepreneurs that would be better off in a corporate job, in order to avoid considering only the ablest entrepreneurs.

We use the Current Population Survey (CPS) to characterize occupational flows between paid-employment, unemployment, and entrepreneurship in our baseline economy. Using education or wages in the data and ability in the model and with a parsimonious set of assumptions, we capture most of the shapes of these flows, namely the hump-shape of the flow from unemployment to employment, the decreasing shapes from employment to unemployment and entrepreneurship to unemployment, the increasing shape between unemployment and entrepreneurship and the increasing part of the flow from entrepreneurship to employment. ${ }^{1}$ We also capture the high entrepreneurial exit rate into paid-employment and show that unemployed individuals are four times more likely to start a business than employed individuals. In contrast to the existing literature, we obtain these flows while scarcely using exogenous elements: for instance, we do not impose exogenous entrepreneurial exit. The model is also able to match a number of other entrepreneurial or individual characteristics found in the CPS and the Survey of Consumer Finances (SCF): the relative wealth between occupations, entrepreneurial earnings (including the zero or negative earnings fraction) or the fraction of people starting a business out of necessity. Our resulting entrepreneurial survival rate is consistent with the data, both in terms of magnitude and in replicating the large exit rate of young entrepreneurs and the low exit rate of older ones.

\footnotetext{
${ }^{1}$ We target the flow from employment to entrepreneurship by earnings quantiles and impose a decreasing job destruction rate with respect to ability.
} 
A crucial attribute of an entrepreneur is the idiosyncratic and possibly fundamental risk associated with her activity. In recent years, an increasing number of ALMPs in OECD countries have been providing financial assistance to unemployed individuals in order to help them start a business. These policies are referred to as Self-Employment Assistance (SEA) programs and target the risk faced by unemployed individuals when creating a business. Broadly speaking, a first class of SEA programs provides assistance to unemployed individuals in the form of monetary grants, loan guarantees or training, somewhat independently of the UI system. A second class extends the UI system to cover part of the entrepreneurial risk. This last class of policies can be type dependent when they rest on previous labor earnings and individual productivity and even business income dependent when the assistance is contingent on business outcomes. In the US, a type dependent policy called the Self-Employment Assistance Program (SEAP) waives regular UI beneficiaries from active job search and dispense an allowance of the same amount and duration as regular benefits, provided they engage in the establishment of a business. However, this policy is only active in less than ten states and is constrained by quotas. In Europe, a number of countries experimented SEA programs in the last decades. Hombert et al. (2017) describe a 2002 French type and business income dependent policy called Plan d'Aide au Retour à l'Emploi (PARE), that introduced a form of SEA designed to insure the downside risk: eligible entrepreneurs could use their UI benefits to bridge the gap between the original amount of benefits and their business income. ${ }^{2}$ Moreover, in the first three years after starting their businesses, they could also keep claiming their UI rights in case of failure. These authors estimate an increase of $12 \%$ of the number of newly created firms after this reform while the pool of entrepreneurs and their relative performances are unchanged. ${ }^{3}$

We extend our baseline economy to evaluate this second class of SEA policies. Our reference SEA policy mirrors the French type and business dependent program and includes two main mechanisms. First, upon business failure, eligible entrepreneurs can return to unemployment

\footnotetext{
${ }^{2}$ Only formerly unemployed individuals with UI rights are eligible.

${ }^{3}$ Related papers on European SEA policies include Ejrnæs and Hochguertel (2014) who use a Danish retirement reform incorporating entrepreneurial UI to study the effects of a downside risk insurance. They find that entry into entrepreneurship increases by $1.2-1.8 \%$ and that entrepreneurs are not any different in terms of performances. Caliendo and Künn (2011) estimate the effects of two different German programs helping unemployed individuals to start businesses. In the first program, individuals were given a lump-sum startup subsidy each month for three years, with the amount declining every year. Under the alternative bridging allowance (BA) program, individuals received their unemployment benefits for six months. The authors find that under the two experiments, new entrepreneurs tend to be less qualified, but are more qualified under the BA than under the start-up subsidy.
} 
and claim UI benefits. Second, operating eligible entrepreneurs are given partial insurance in the form of a supplementary income covering poor business outcomes. ${ }^{4}$ In comparative experiments, we study the effect of alternative SEA mechanisms found in policies implemented in various countries, such as non type dependency and non business income dependency. We find that all the SEA programs we study have important mobility effects. With our reference policy, the share of entrepreneurs increases by $1.5 \%$ and the fraction of unemployed individuals starting businesses rises by $11 \%$ as compared to the no policy baseline economy. In contrast to the previous literature that focuses on partial equilibrium, we do not find a significant effect of SEA programs on the unemployment rate but rather find that employment in the corporate sector is crowded out. Concerning unemployed individuals who would have entered entrepreneurship even in the absence of the policy, we show that eligible entrepreneurs survive longer, but invest and produce slightly less due to moral hazard effects. For those who entered because of the policy, a type dependent SEA program selects more skilled and richer new entrepreneurs, who therefore invest more than those selected under a non type dependent SEA providing a lump-sum compensation. After decomposing the reference SEA into components, we argue that the single mechanism of allowing business-starting unemployed individuals to return to the unemployment pool at some point and keep claiming their outstanding UI rights would significantly reduce the bias towards paid-employment of current UI systems at virtually no extra cost for the economy. Interestingly, all the reforms generate positive levels of steady-state welfare. However, relatively poor and unskilled individuals with low UI rights are borrowing constrained and do not benefit from the reform. At the same time, the predominant corporate workers support the costs of the policies. As a consequence, the welfare along the transition is on average negative, albeit only slightly, and around 30-40\% of the individuals benefit from the reforms. Finally, we show that the design of the UI system itself and the level of entrepreneurship is tightly linked. A more generous UI system has a negative effect on the propensity of becoming an entrepreneur: increasing UI benefits and/or extending UI duration imply a lower incentive for unemployed agents to start a business, amplified by the rising opportunity costs of abandoning their status. This adverse effect can significantly be mitigated using a SEA program and even reverted in the case of an increase in the UI duration.

\footnotetext{
${ }^{4}$ This income is subject to a specific rule depending on previous UI benefits. A third auxiliary mechanism can be activated to provide an extra income even in case of better outcomes. These privileges are all temporary.
} 
Related literature There is a substantial literature on entrepreneurship and many papers are concerned about the impact of existing barriers to entrepreneurship on the share of entrepreneurs in the economy. A number of contributions such as Landier and Thesmar (2008), Schoar (2010) or Hurst and Pugsley (2011) show that only focusing on this share might prevent us from understanding the vast amount of heterogeneity in the entrepreneurial pool and the rich composition or selection effects underneath. Our specification is able to capture a number of those effects: we, for instance, highlight a high quarterly flow from entrepreneurship to paid-employment. While this latter finding is not new (see for instance Cagetti and De Nardi (2006) at a yearly frequency), our model generates this flow as the result of only endogenous decisions. The recent literature introduces a distinction between entrepreneurs starting a business out-of-necessity and out-of-opportunity in order to understand the choice of becoming entrepreneurs with respect to the working ability (Poschke (2013)). Our model theoretically characterizes the related notion of necessity share, and show how insurance mechanisms affect its magnitude. This paper is also related to the quantitative literature on entrepreneurship in relation with mobility and wealth inequality issues pioneered for instance by Quadrini (2000) or Cagetti and De Nardi (2006) and to the many policy questions that have been addressed using this framework (Kitao (2008), Cagetti and De Nardi (2009) and Buera and Shin (2013) among others). Similarly to our contribution, some recent papers have begun addressing the question of insurance mechanisms in models with entrepreneurship. This literature has mainly focused on the effects of introducing health insurance (Fairlie, Kapur and Gates (2011)) or alternative bankruptcy laws (Mankart and Rodano (2015)) on the fraction of entrepreneurs and their performances.

While many papers often argue that improving entrepreneurial conditions could be a way to reduce unemployment (for instance, Caliendo and Künn (2011) or Thurik et al. (2008)), our results mitigate this argument based on entrepreneurial insurance. Some authors (Evans and Leighton (1989), Thurik et al. (2008), Røed and Skogstrøm (2013) among others) have studied the relationship between unemployment and UI benefits and the probability to start a business. In this respect our paper is closest to Hombert et al. (2017) and Ejrnæs and Hochguertel (2014), although their contributions are mostly empirical and use partial equilibrium models. To the best of our knowledge, none of these contributions have raised the question of entrepreneurial insurance or that of the distortive effect of the UI system in a general equilibrium model, especially one with realistic occupational flows. 
The remaining of the paper is organized as follows. Section 2 presents empirical facts concerning entrepreneurship and occupational flows. Our baseline model is developed in section 3 and our parameterization in section 4 . In section 5, we discuss the properties of our baseline economy while our policy experiments are conducted in section 6. Section 7 concludes.

\section{Stylized facts and definitions}

In this section, we first clarify our notion of entrepreneurship and highlight the potential relationship between entrepreneurial risk and business start-up rate. We hint at how assistance programs and insurance mechanisms could foster entrepreneurship, most notably for unemployed individuals. Second, we document a number of empirical facts about occupational flows in the US that motivate our modeling choices.

\subsection{Entrepreneurship and risk}

Definitions The definitions of an entrepreneur in the literature take into account three main dimensions: the self-employment status, business ownership, and the active management status. Depending on the definition and the survey used, the fraction of entrepreneurs in the US varies from $7 \%$ to $11 \%$. Surveys such as the SCF or CPS contain questions that let an individual define himself as self-employed according to her own perception. In this paper, we use the CPS to compute both the masses in each occupation and the corresponding flows between them. ${ }^{5}$ We define an entrepreneur as a self-employed individual owning her business. ${ }^{6}$ According to this definition, from 2001 to 2008 , we find an average fraction of entrepreneurs of $9.4 \%$. In the SCF, over the 2001, 2004 and 2007 waves, the corresponding number is $8.8 \% .^{7}$

Entrepreneurship and risk perception Using the 2007 SCF, we find substantial risks associated with entrepreneurial income: considering only income filed as business revenues, about $20 \%$ of the entrepreneurs report having zero or negative income. This number falls to $3 \%$ when

\footnotetext{
${ }^{5}$ We restrict our sample to the period from 2001 to 2008 and consider only the 20-65 old population. Ratios are computed with respect to the total number of entrepreneurs, unemployed individuals, and workers. Section B of the online appendix details our sample selection approach and additional details.

${ }^{6}$ Cagetti and De Nardi (2006) define an entrepreneur as a self-employed individual owning her business and actively managing it in the PSID. Unfortunately, we cannot control for an active management role in the CPS.

${ }^{7}$ Section B of the online appendix summarizes our reference SCF moments. We define an entrepreneur as a self-employed individual holding a positive share of their businesses in order to be consistent with our definition in the CPS.
} 
we account for entrepreneurial income filed as wages plus business revenues. ${ }^{8}$ This corroborates the findings in Herranz, Krasa and Villamil (2015) about income risks: they report that in a year, about $12 \%$ of the Survey of Small Business Finances firms lose more than $20 \%$ of assets invested in the firm (debt plus equity), $7.4 \%$ more than $40 \%$, and $3.8 \%$ more than $100 \%$. Similarly, using the Survey of Income and Program Participation (SIPP), Hamilton (2000) finds that $10 \%$ of self-employed reports zero or negative earnings. Furthermore, we find that entrepreneurial income is not distributed normally but is rather extremely right-skewed. ${ }^{9}$ Most entrepreneurs are concentrated below and around the median income but some of them perform extremely well while others have negative incomes. Whether we consider business or total income, the main idea is that there are potentially important risks associated with an entrepreneurial occupation. In particular, the entrepreneurial earnings distribution displays a much higher variance than the distribution for employees.

Finally, using data from the Global Entrepreneurship Monitor (GEM) project for 28 countries, Arenius and Minniti (2005) find that perceptual variables, such as alertness to opportunities, fear of failure, and confidence in one's own skills are significantly correlated with new business creation across all countries. ${ }^{10}$ The above evidence on perceived risk as a barrier to entry into entrepreneurship is an argument for the fact that insurance provision could foster entrepreneurship by lowering entrepreneurial risk.

Unemployment insurance (UI) and entrepreneurship In almost every state in the US, unemployed individuals lose their unemployment benefits when starting a business. ${ }^{11}$ Contrastingly, a number of OECD countries and a small number of US states have or had a SEA program in place, encouraging the pursuit of an entrepreneurial activity while unemployed. When available, SEA programs constitute one of the largest entrepreneurial subsidies. In France, the

\footnotetext{
${ }^{8}$ We distinguish between business income and wage plus business income because a number of entrepreneurs file their earnings either as wage or as business income. We also normalize incomes by the median entrepreneurial income. There are two main problems arising in most of the survey. First, entrepreneurial earnings are bottomcoded. Second, as argued by Astebro and Chen (2014), entrepreneurial earnings can be under-reported. In the end, SCF data concerning negative (due to loan repayment and interests, salary to employees and per-period variable and fixed costs) and zero income have to be taken with caution.

${ }^{9}$ We plot this distribution in section A of the online appendix using SCF data.

${ }^{10}$ We report in section $\mathrm{A}$ of the online appendix a figure that shows that the decline in the self-employment rate in the US since the 2000s is associated with an increase in the fear of failure index.

${ }^{11}$ For instance, in Pennsylvania, section 402(h) of the Pennsylvania Unemployment Compensation Law states that "a claimant is ineligible for any week in which he/she is engaged in self-employment. When a claimant is starting a new business, the claimant becomes self-employed with the first positive step toward starting the business".
} 
PARE reform concerns almost 50\% of all new entrepreneurs (Hombert et al. (2017)). In Germany, between 2002 and 2011, around 40-50\% of new entrepreneurs per year received this type of insurance. Concerning their implementation, some SEA policies are said to be type dependent with benefits tied to an agent's ability and calculated on the base of previous earnings. A non type dependent SEA, however, provides periodic lump-sum amounts irrespectively of UI benefits. Existing SEA programs can also be distinguished along the following dimensions. A first set of SEA programs is business income dependent and provides UI benefits only when eligible entrepreneurs experience bad outcomes. A second set allows eligible entrepreneurs to terminate their business activity and recover outstanding UI benefits as an unemployed agent. Table 1 provides a non-exhaustive overview of SEA programs around the world. ${ }^{12}$

\begin{tabular}{|c|c|c|c|}
\hline $\begin{array}{l}\text { Type dependent } \\
\text { policy }\end{array}$ & $\begin{array}{l}\text { Business income } \\
\text { dependent policy }\end{array}$ & $\begin{array}{l}\text { UI rights if } \\
\text { failure }\end{array}$ & Countries \\
\hline Yes & Yes & Yes & $\begin{array}{l}\text { France ACCRE (1998-2006), France ARE (2008-), Fin- } \\
\text { land (current), The Netherlands (current) }\end{array}$ \\
\hline Yes & No & Yes & $\begin{array}{l}\text { Ireland BTWEA (1999-), US SEAP (1998-) Sweden Self- } \\
\text { employment Grants, Germany Bridging Allowance (1986- } \\
\text { 2006), Germany new start-up subsidy (2006-) }\end{array}$ \\
\hline Yes & No & - & Canada SEA (1993-), Hungary SEA \\
\hline No & No & Yes & Finland Start-up Grant (1988-), UK EAS (1983-1991) \\
\hline No & No & No & $\begin{array}{l}\text { Australia NEIS (1985-), Denmark EAS (1989-1994) } \\
\text { Germany start-up subsidy (2003-2006), UK NEA (2010-) }\end{array}$ \\
\hline
\end{tabular}

Table. 1. Types of Self-employment Assistance programs around the world.

Financial frictions In the incomplete markets literature with entrepreneurship, the presence of borrowing constraints is documented (by Quadrini (2000) among others) and is used to generate heterogeneous firm sizes. The ability to borrow is essential for a business venture. According to Mankart and Rodano (2015), of the total credit backed by some real collateral, about $80 \%$ is backed by some business assets. ${ }^{13}$ But this ability can be damaged by the past history of defaults. Personal bankruptcy can be made under Chapter 7 (liquidation bankruptcy) and Chapter 13 (repayment reorganization bankruptcy), with the former accounting for $70 \%$ of total bankruptcy cases. Bankruptcy filing remains public information for ten years: this can exclude a potential entrepreneur from borrowing for a significant amount of time.

\footnotetext{
${ }^{12}$ It should be noted that the rules regulating these programs are in the details more complex than the simplified classification we provide here. Much of the complexity comes from the fact that many programs are entangled with other unemployment assistance programs.

${ }^{13}$ This includes inventory, account receivables, vehicles or other business equipment, business securities or deposits and business real estate.
} 


\subsection{Occupational flows}

We now document a number of empirical features of quarterly flows between occupations based on CPS data. Many of these flows have not been detailed in the literature and they constitute important factual elements for our modeling choices and calibration. Cagetti and De Nardi (2009) target a high annual entrepreneurship exit rate of about $22 \%$ in the US. With a different but related measure of entrepreneurship, we find a consistent quarterly entrepreneurship exit rate of $6 \%$, with roughly $1 \%$ toward unemployment. As shown in Table 2, if we consider the whole population of self-employed individuals ${ }^{14}$, the corresponding number is close to $7.5 \%$. This exit rate is much higher than the $1 \%$ to $3 \%$ of entrepreneurs filing for bankruptcy each year, corresponding to $0.25 \%$ to $0.75 \%$ each quarter. This suggests that many entrepreneurs voluntary quit their businesses for a job.

\begin{tabular}{rcccc}
\hline & \multicolumn{3}{c}{ Transition (\%) } & Mass (\%) \\
& Employment & Entrepreneurship & Unemployment & \\
\hline A. Self-employed business owner & & & & \\
Employment & $97.35(0.36)$ & $0.50(0.09)$ & $2.15(0.34)$ & 85.2 \\
Entrepreneurship & $4.80(0.82)$ & $94.22(0.89)$ & $0.99(0.34)$ & 9.4 \\
Unemployment & $47.36(5.86)$ & $2.40(0.88)$ & $50.25(6.0)$ & 5.4 \\
\hline B. All self-employed & & & & 84.3 \\
Employment & $97.20(0.36)$ & $0.69(0.1)$ & $2.11(0.34)$ & 10.3 \\
Entrepreneurship & $6.15(0.93)$ & $92.45(1.0)$ & $1.40(0.40)$ & 5.4 \\
\hline \hline
\end{tabular}

Table. 2. Flows between occupations for different definitions of entrepreneurship per quarter (std. deviations between braces). Data sources: authors' own computations using CPS data from 2001 to 2008.

On the entry side, roughly $2.4 \%$ of the unemployed individuals and $0.5 \%$ of the workers start a business each quarter. If we consider the whole self-employed population, these numbers rise respectively to $3.7 \%$ and $0.7 \%$. We find that unemployed individuals are 4 to 5 times more likely to enter entrepreneurship than workers. Concerning the flow from employment to entrepreneurship, we document a U-shaped relation with respect to earning quintiles in Table 3. We find that high earning (and potentially high skill) and low earning (and potentially low skill) workers tend to start their own businesses more often than the average worker. It is arguable that high earners tend to be more talented for running valuable businesses, making self-employment a better alternative than employment for those individuals. Similarly, low earning workers can

\footnotetext{
${ }^{14}$ This grouping comes from individual replies to the CPS survey questions across people clearly mentioning being self-employed and a business owner and people generally declaring being self-employed.
} 
view entrepreneurship as a way to improve their standards of living. Contrastingly, for average (and potentially mid-skill) earners, entrepreneurship seems to be a less viable alternative when compared to paid employment.

\begin{tabular}{lcccccc}
\hline \% of workers switching to & \multicolumn{3}{c}{ Quintile } & \multicolumn{2}{c}{ Mean } \\
& {$[0: 20]$} & {$[20: 40]$} & {$[40: 60]$} & {$[60: 80]$} & {$[80: 100]$} & \\
\hline A. Self-employment \& business owner & 0.68 & 0.38 & 0.44 & 0.41 & 0.61 & 0.50 \\
& $(0.13)$ & $(0.11)$ & $(0.11)$ & $(0.10)$ & $(0.11)$ & $(0.09)$ \\
B. Self-employment & 1.05 & 0.61 & 0.62 & 0.54 & 0.75 & 0.69 \\
& $(0.15)$ & $(0.13)$ & $(0.11)$ & $(0.12)$ & $(0.12)$ & $(0.10)$ \\
\hline \hline
\end{tabular}

Table. 3. Flows from employment to entrepreneurship by earning quintiles per quarter (std. deviations between braces). Data sources: authors' own computations using CPS data from 2001 to 2008.

Figure 1 gives a general picture of the shape of the flows between occupations with respect to educational attainment ${ }^{15}$ (and for flows out of employment with respect to wage quintile). One striking feature is that the $>C$ : higher college and professional school group can have a substantially different behavior with respect to other college graduates. This finding is quite recurrent and one explanation is the fact that this group has a less uniform definition in the data when compared to all the other groups (with the exception of maybe $<H S$ : less than a high school degree group at the other extreme). The U-shape described above for the employment to entrepreneurship flow by earnings persists with respect to educational attainment when taking into account only self-employment. ${ }^{16}$ We also find that other flow profiles are non-linear, such as the entrepreneurship to worker flow that displays a $S$ shape. Specifically, less educated entrepreneurs have a high flow out of entrepreneurship, reflecting potentially their higher risk of failure. Then as more educated groups can find high income and less risky paid jobs, the profile becomes increasing again. The $S$-shape is created by the $>C$ group that displays a very low disposition to quit entrepreneurship that mirrors the very high disposition of the same group to leave paid employment for entrepreneurship. We surmise that on top of education, other characteristics might explain this behavior, making this group especially prone to becoming and remaining entrepreneurs. We point out that the patterns above are robust to others time frames. We also obtain similar shapes when we exclude mobility toward and from part-time

\footnotetext{
${ }^{15}$ Educational attainment is divided between: $<H S$ : less than a high school degree, $H$ : high school degree, $<C$ : some college but no degree, $B$ : bachelor's degree, $M$ : master's degree, $>C$ : higher college and professional school degrees.

${ }^{16}$ In section A of the online appendix, we show that this flow with respect to education for any definition of entrepreneurship is $U$-shaped at the longer 2001-2015 horizon.
} 
jobs (fewer than 20 hours of work per week) ${ }^{17}$ and if we control for individual characteristics. ${ }^{18}$ In the end, what these flows show is that observing only aggregate occupational mobility might not be enough. The skill or ability of an individual, that we can not directly measure in the CPS data, could be an important determinant of mobility. Flows by education or income show significant non-linearities that should be captured in a model. On this subject, Poschke (2013) shows theoretically that a correlation between working ability and the opportunity of setting-up a valuable business can replicate the observed masses of self-employed workers among different ability groups (measured in terms of education). We stress that financial frictions are also an important requirement to generate heterogeneous entrepreneurship decisions within ability groups. We, therefore, build our model on the two minimal dimensions of individual capital and skill levels.

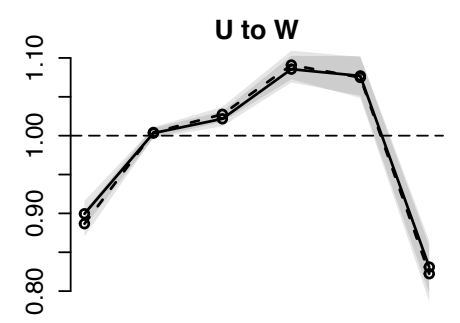

$\mathrm{U}$ to $\mathrm{E}$

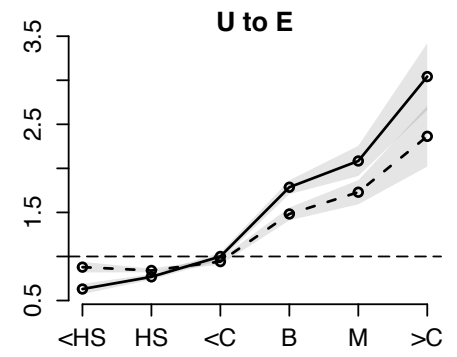

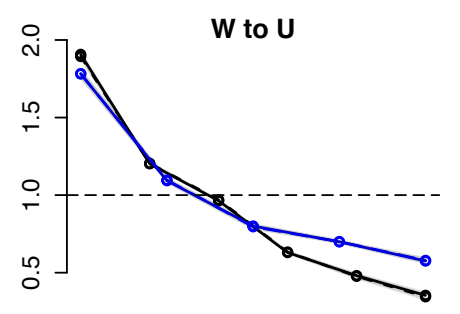

W to $E$

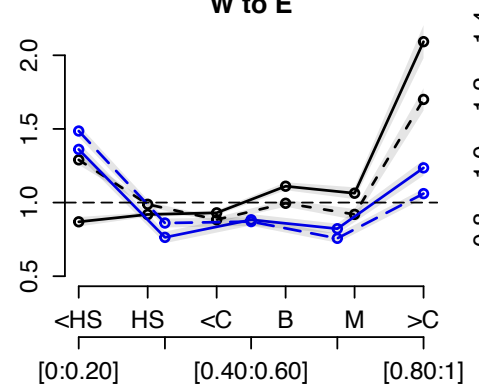

E to $U$

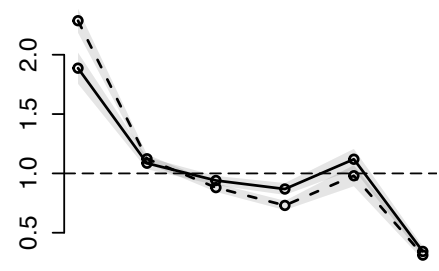

E to W

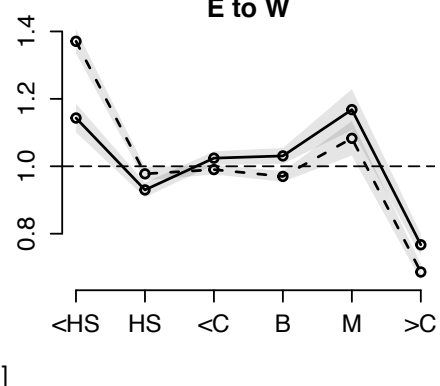

Figure 1. Quarterly occupational flows by educational attainment (black, top horizontal axis) and wage earnings (blue, bottom horizontal axis). The solid lines (resp. dashed lines) refer to self-employed business owners (resp. self-employment only). Legend: $U$ : unemployment, $W$ : paid-employment, $E$ : entrepreneurship. In grey: confidence interval for the mean at a $95 \%$ confidence level. Data sources: authors' own computations using CPS data from 2001 to 2008.

\footnotetext{
${ }^{17}$ These alternative flows are reported in the online appendix section A. In detail, we compute quarterly flows for the alternative period 2008-2015, quarterly flows for 2001-2008 selecting only full-time occupation and yearly flows for 2001-2008. We find that the patterns of the flows shown above are robust.

${ }^{18}$ Results of a linear probability model on the probability to exit a given occupation reveal similar shapes relative to educational attainment.
} 


\section{Model}

In this section, we describe a Bewley - Huggett - Aiyagari type general equilibrium model in incomplete markets, with occupational choices in the spirit of Cagetti and De Nardi (2006). We extend the latter paper by introducing risky entrepreneurial investment choices, occupational search frictions and the possibility to default in equilibrium. Our model accounts for a baseline economy and alternatives ones under various SEA programs, as it is our main policy concern.

\subsection{Corporate sector}

Our economy has two production sectors: a corporate one presented here and an entrepreneurial one discussed later. The corporate output $Y$ is produced by a single competitive representative firm using a Cobb-Douglas technology, with total factor productivity $A$, capital level $K$ and labor $L$, such that: $Y=F(K, L)=A K^{\alpha} L^{1-\alpha}$, where $\alpha \in(0,1)$ is the capital share. There is no aggregate uncertainty. Profit maximization produces the competitive prices: $r=A \alpha\left(\frac{L}{K}\right)^{1-\alpha}-\delta$ and $w=A(1-\alpha)\left(\frac{K}{L}\right)^{\alpha}$, with $w$ and $r$ the wage and interest rates, which by a no arbitrage condition are identical in the entrepreneurial sector, and $\delta$ the depreciation rate in both sectors.

\subsection{Households}

Occupations and preferences The economy is populated by a continuum of infinitely-lived households of unit mass. Every period, a household falls in one of three occupations $o \in$ $\mathcal{O} \equiv\left\{o_{e}, o_{w}, o_{u}\right\}$ : entrepreneurship $\left(o_{e}\right)$; unemployment $\left(o_{u}\right)$; or employment $\left(o_{w}\right)$ (worker in the corporate sector). An agent's occupation can change either exogenously or endogenously. Agents derive utility from consumption and disutility from search. The life-time utility of a household is given by $\mathbb{E}_{0} \sum_{t=0}^{\infty} \beta^{t} u\left(c, s_{e}, s_{w}\right)$, with $c$ the consumption, $s_{e}$ and $s_{w}$ respectively business and job search efforts, and $\beta$ the discount factor. We assume that labor is supplied inelastically. We denote $a \in \mathcal{A}$ the agent's wealth. Any wealth saved in the model pays the deposit rate $r^{d}$, with $r^{d}=r-v$. The competitive interest rate $r$ can thus be interpreted as a lending rate and $v$ as a wedge between the lending rate and the deposit rate.

Insurance status Depending on their previous occupation, agents can either be insured $(j=i)$ or uninsured $(j=n)$. In the baseline economy, only a worker falling in involuntary unemployment (i.e. when laid off) can claim any insurance in the form of a standard UI. In the alternative economy subject to a specific policy discussed below, eligible entrepreneurs are also insured 
during their entrepreneurial endeavor. Section 3.6 describes this policy in details.

Exclusion status Entrepreneurs can borrow from a creditor subject to an endogenous interest rate and use these amounts in their entrepreneurial venture. ${ }^{19}$ However, an agent who has defaulted in the past is excluded temporarily from the credit market. Such an agent cannot borrow and is labeled constrained, with credit flag $e=C$, but can still start a business. Following Chatterjee et al. (2007) and Mankart and Rodano (2015), we model exclusion in a probabilistic way. Upon recovering access to credit, her credit flag is $e=A$.

Exogenous processes The exogenous states of an agent are summarized by $\left(\theta, y, z_{-1}\right)$ and we assume that the three associated processes are AR(1) with orthogonal innovations. All individuals are endowed with a persistent component of individual productivity $\theta \in \Theta$ that we call ability. This component is initially determined according to the invariant distribution $\Pi_{\theta}$ and then evolves at a very slow rate. ${ }^{20}$ We stress that a working household's labor income, an unemployed individual's replacement income and an entrepreneurial household's business income all depend on this component. Workers are subject to an additional persistent idiosyncratic shock $y \in \mathcal{Y}$ on their labor income that we call match-quality. ${ }^{21}$ If an agent was not a worker in the previous period, she does not know her match-quality before receiving a job offer. In that case, this shock in initialized by drawing it from the invariant distribution $\Pi_{y}$ associated with the process for $y$. Otherwise, both individual productivity and match-quality shocks are realized at the beginning of the period before agents take any decision. Entrepreneurs face a within-period persistent idiosyncratic business shock $z \in \mathcal{Z}$. Contrastingly to the other shocks, only its previous value $z_{-1}$ is known at the beginning of the period, and the current shock is realized within the period after entrepreneurs have decided on their business investment. An individual not currently running a business, but starting one next period will initialize her shock $z$ according to the invariant distribution $\Pi_{z}$ associated with the process for $z{ }^{22}$

\footnotetext{
${ }^{19}$ The exact nature of the credit contract is explained in section 3.5.1.

${ }^{20} \mathrm{We}$ allow individual productivity to evolve in order to generate additional saving motives. Our model does not take into account life-cycle aspects, human capital accumulation at work, technological progress or health risks. Those elements can explain a large productivity dispersion along the life-cycle, but are unaccounted for here.

${ }^{21}$ This model does not include an explicit matching process but $y$ can be viewed as a match-quality component because it starts and ends with a specific job while not appearing as a state for the unemployed or the entrepreneur. Adding this process brings our earnings distribution closer to reality but our results are insensitive to it.

${ }^{22} \mathrm{We}$ assume that $z$ is observed only after experimenting the business idea. In our model as in the reality, an important fraction of new entrepreneurs experiments a business and exit if the project is not profitable enough.
} 
Value functions We denote $\mathbf{x}=(a, y, \theta, z, j, e)$ the full state vector of households over all occupations. We will sometimes use a subset $\mathbf{x}_{o}$ for a specific occupation $o$. We note $W$ the value function associated with a worker, $U$ with an unemployed individual and $E$ an entrepreneur. Future value functions are respectively denoted: $W^{\prime}=W\left(a^{\prime}, \theta^{\prime}, y^{\prime}, e^{\prime}\right), U_{j^{\prime}}^{\prime}=U\left(a^{\prime}, \theta^{\prime}, e^{\prime}, j^{\prime}\right)$ and $E_{j^{\prime}}^{\prime}=E\left(a^{\prime}, \theta^{\prime}, z, e^{\prime}, j^{\prime}\right)$. Finally, eligible unemployed individuals benefit from the entrepreneurial insurance. The value of being a new entrepreneur while uninsured is given by $\mathcal{E}_{n}^{\prime}=\mathbb{E}_{z}\left[E\left(a^{\prime}, \theta^{\prime}, z, e^{\prime}, j=n\right)\right]$. The value $\mathcal{E}_{i}^{\prime}$ of being a new insured entrepreneur depends on the economy considered. ${ }^{23}$ We specify this value in section 3.6. Note that in section $\mathrm{C}$ of the online appendix, we write a more detailed version of model equations, explicitly including transition probabilities that we omit below for readability.

\subsection{Workers}

In the corporate sector, a worker receives the labor income $h(\theta) y w$, where the function $h: \theta \mapsto \mathbb{R}$ transforms the individual productivity component into working ability. She has a probability $\eta(\theta)$ of getting laid off, depending on her individual productivity. In such a case, she falls in insured unemployment and can expect to get value $U_{i}^{\prime}{ }^{24}$ To finance UI benefits, a worker pays a proportional tax $\tau_{w}$ on their labor income. By providing effort $s_{e}$, a worker can search for a business idea on-the-job and start a business in the next period with probability $\pi_{e}\left(s_{e}\right) .{ }^{25}$ She then voluntary exits her current occupation, cannot claim UI benefits (i.e., $j=n$ ) and can expect to get value $\mathcal{E}_{n}^{\prime}$. If she gets laid off at the same time as getting a business idea, she can claim UI rights and start a business with value $\mathcal{E}_{i}^{\prime}$, which depends on the policy status: no insurance in the baseline case or entrepreneurial insurance otherwise. To simplify notations, let us denote $\eta \equiv \eta(\theta)$ and $\pi_{e} \equiv \pi_{e}\left(s_{e}\right)$. The recursive formulation of a worker is given by:

$$
\begin{array}{r}
W(a, \theta, y, e)=\max _{\substack{c>0, a^{\prime} \geq 0, s_{e} \geq 0}} u\left(c, 0, s_{e}\right)+\beta \mathbb{E}_{e^{\prime}, y^{\prime}, \theta^{\prime} \mid e, y, \theta}\left\{(1-\eta)\left[\left(1-\pi_{e}\right) W^{\prime}+\pi_{e} \max \left\{\mathcal{E}_{n}^{\prime}, W^{\prime}\right\}\right]\right. \\
\left.+\eta\left[\left(1-\pi_{e}\right) U_{i}^{\prime}+\pi_{e} \max \left\{\mathcal{E}_{i}^{\prime}, U_{i}^{\prime}\right\}\right]\right\}
\end{array}
$$

\footnotetext{
${ }^{23}$ We denote this value with the subscript $i$ even if no insurance policy is currently in place in the baseline model. The subscript can thus be interpreted as access to insurance in the alternative economy.

${ }^{24}$ Notice that in our model, value functions associated with unemployment are always lower than those associated to a worker. Therefore, we exclude any voluntary switch to unemployment. Conversely, an unemployed agent getting a job opportunity always exits.

${ }^{25}$ Business search effort can describe market research on the feasibility of an idea, competition assessment, business education, agency costs or the time needed to fill administrative forms, validate product norms, etc.
} 


$$
\text { s.t. } \quad c=\left(1-\tau_{w}\right) h(\theta) w y+\left(1+r^{d}\right) a-a^{\prime}
$$

where equation (2) is the worker's budget constraint. ${ }^{26}$

\subsection{Unemployed individual}

We assume that all unemployed individuals are endowed each period with a fixed amount $m$, that can be interpreted as domestic production. An unemployed individual can either claim $\mathrm{UI}(j=i)$ or not $(j=n)$. Insured unemployed agents receive UI benefits proportional to their individual productivity, with replacement rate $\mu$ and lose UI rights with probability $\rho$. An uninsured unemployed individual cannot claim any UI benefits and remains uninsured until finding a job. Unemployed agents search for a business idea and a job opportunity with respective efforts $s_{e}$ and $s_{w}$ and corresponding success probabilities $\pi_{e}$ and $\pi_{w} \equiv \pi_{w}\left(s_{w}\right)$. Upon finding a job, such an agent becomes a worker with value $W^{\prime}$. Similarly, when getting an idea, a business can be started in the next period. An insured agent $\left(j^{\prime}=i\right)$ do so with value $\mathcal{E}_{i}^{\prime}$, while an uninsured agent $\left(j^{\prime}=n\right)$ will have value $\mathcal{E}_{n}^{\prime}$. Finally, exclusion from credit market evolves similarly to a worker. The recursive program of an unemployed individual is:

$$
\begin{gathered}
U(a, \theta, e, j)=\max _{\substack{c>0, a^{\prime} \geq 0, s_{e} \geq 0, s_{w} \geq 0}} u\left(c, s_{w}, s_{e}\right)+\beta \mathbb{E}_{\theta^{\prime}, y^{\prime}, j^{\prime}, e^{\prime} \mid e, j, \theta}\left\{\pi_{w}\left[\left(1-\pi_{e}\right) W^{\prime}+\pi_{e} \max \left\{\mathcal{E}_{j^{\prime}}^{\prime}, W^{\prime}\right\}\right]\right. \\
\left.+\left(1-\pi_{w}\right)\left[\left(1-\pi_{e}\right) U_{j^{\prime}}^{\prime}+\pi_{e} \max \left\{\mathcal{E}_{j^{\prime}}^{\prime}, U_{j^{\prime}}^{\prime}\right\}\right]\right\} \\
\text { s.t. } \quad c=m+\mathbb{1}_{\{j=i\}}\left(1-\tau_{w}\right) h(\theta) w \mu+\left(1+r^{d}\right) a-a^{\prime}
\end{gathered}
$$

where equation (4) is the budget constraint.

\subsection{Entrepreneurs}

An entrepreneur raises revenues from her self-employed business venture. She decides to invest an number of resources $k$, that can be either her own or borrowed, in a decreasing returns to scale technology governed by the parameter $\nu \in(0,1)$, before knowing the current realization of the business shock $z \in \mathcal{Z}$. All entrepreneurs are subject to this within-period idiosyncratic shock affecting the firm's productivity. Entrepreneurial activity also depend on $g(\theta)$ where the function $g: \theta \mapsto \mathbb{R}$ transforms the individual productivity component into

\footnotetext{
${ }^{26}$ For simplicity, we assume that $w$ already internalizes other taxes not related to the UI financing. Relaxing this assumption would need to account for a more realistic set of taxes.
} 
entrepreneurial ability. ${ }^{27}$ The entrepreneurial technology is thus: $f(k, \theta, z)=z g(\theta)(k)^{\nu}$. We define entrepreneurial income as the entrepreneurial production net of capital depreciation and any interest repayment on borrowed entrepreneurial capital. Moreover, by providing effort $s_{w}$, an entrepreneur can search for a job opportunity on-the-business and change occupation in the next period with probability $\pi_{w}$. The sequence of choices an entrepreneur is facing is summarized in Figure 2. We now detail this sequence.

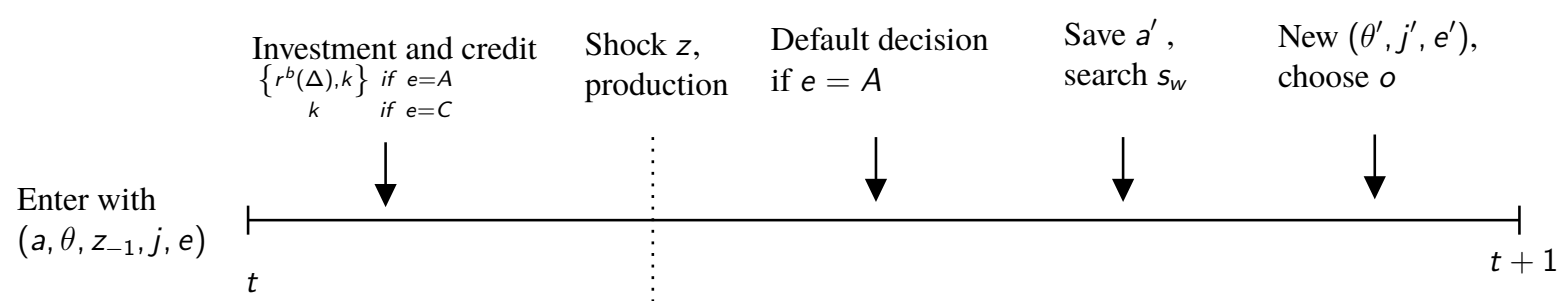

Figure 2. Timing for an entrepreneur.

\subsubsection{Non-excluded entrepreneur}

When an entrepreneur has access to the credit market, she is allowed to borrow from a financial intermediary an amount that can only be invested in her business. Recalling that $a$ is the agent's current wealth, an entrepreneur chooses whether to borrow $(k>a)$ or save $(k<a)$. If she borrows from a creditor the amount $(k-a)$, we assume that it is only up to a fixed fraction $\lambda$ of their total assets. ${ }^{28}$ The entrepreneur decides the amount $k$ invested in her firm in order to maximize her expected value with respect to the shock $z$, as expressed below:

$$
\begin{gathered}
E\left(a, \theta, z_{-1}, e=A, j\right)=\max _{k}\left\{\sum_{z \in \mathcal{Z}} \pi_{z}\left(z \mid z_{-1}\right) \max \{B(a, k, \theta, z, j), R(a, k, \theta, z, j)\}\right\} \\
\text { s.t. } \quad(k-a) \leq \lambda a
\end{gathered}
$$

The interior max operator in expression (5) corresponds to the choice the entrepreneur has to make between bankruptcy $(B)$ or repayment $(R)$ options once the realization of the shock $z$ is known.

Repayment The standard behavior of a borrowing entrepreneur is to repay her loan after production. In case of a bad shock, the entrepreneur will receive a low (possibly negative) en-

\footnotetext{
${ }^{27} g(\theta)$ could reflect the fact that individuals with different abilities (i.e educational attainment for instance) runs very different businesses.

${ }^{28}$ In principle, an entrepreneur could borrow an amount and then decide to invest none or only a part of it in her business. Such behavior is excluded in this model. In that sense, the entrepreneur pledges the totality of her business collateral amount $a$ invested in her firm before borrowing any amount. Alternatively, we could introduce an endogenous borrowing constraint as in Cagetti and De Nardi (2006). However, this considerably increases the computational time.
} 
trepreneurial income but can still decide to repay and thus not be excluded from the credit market in future periods. If she repays, the entrepreneur also has to cover the endogenous interest $r^{b}(\Delta)$ on her loan. The associated recursive problem is:

$$
\begin{array}{rl}
R(a, k, \theta, z, j)=\max _{\substack{c>0, a^{\prime} \geq 0, s_{w} \geq 0}} u\left(c, s_{w}, 0\right)+\beta_{\theta^{\prime}, y^{\prime}, j^{\prime} \mid \theta, j} & \mathbb{E} \\
\text { s.t. } \quad & c+a^{\prime}=\pi_{r}^{A}+\mathbb{1}_{\{j=i\}} b_{e}\left(\theta, \pi_{r}^{A}\right)+a+r^{d}(a-k) \mathbb{1}_{\{k \leq a\}} \\
& \left.\left.\pi_{r}^{A}=z g(\theta)(k)^{\nu}-\delta k-r^{b}(\Delta)(k-a) \mathbb{1}_{\{k \geq a\}}^{\prime}\right\}+\left(1-\pi_{w}\right) \max \left\{U_{j^{\prime}}^{\prime}, E_{j^{\prime}}^{\prime}\right\}\right\}
\end{array}
$$

where equation (9) is the profit function defined as total production minus depreciation and interest paid on debt. Equation (8) is the budget constraint. We emphasize that the baseline economy is only populated with uninsured entrepreneurs. Contrastingly, there are two groups of entrepreneurs in the alternative economy with SEA: the insured group $(j=i)$ and the uninsured group $(j=n)$. We stress here for clarity that insured entrepreneurs might receive an additional income $b_{e}\left(\theta, \pi_{r}\right)$ on top of their current entrepreneurial income $\pi_{r}$. Thus this entrepreneur's consumption and saving decision depend on her total income and assets, composed of her entrepreneurial income, possible SEA benefits, interests on savings not invested in her company for an amount $r^{d}(a-k) \mathbb{1}_{\{k \leq a\}}$ and personal assets $a .^{29}$

Bankruptcy When an entrepreneur chooses not to repay the borrowed amount or the interests, she defaults and goes bankrupts. Her firm is liquidated and her business idea is lost. ${ }^{30} \mathrm{We}$ assume, in the spirit of D'Erasmo and Boedo (2012), that after producing and observing her shock $z$, an entrepreneur can choose to renegotiate what is due through a judicial action in a court. Bankruptcy is characterized by the cost of the procedure $\chi$ (including court fees and the cost of insolvency practitioners), proportional to the invested business capital and the recovery rate $\xi$ referring to the portion of the original loan that the creditor can recover. ${ }^{31}$ This portion captures what can be recovered using different channels, including liquidation and reorganization.

\footnotetext{
${ }^{29}$ To see this, recall that the cash on hand of such an entrepreneur in the baseline economy can be written: $z g(\theta)(k)^{\nu}+(1-\delta) k-\left(1+r^{b}(\Delta)\right)(k-a) \mathbb{1}_{\{k \geq a\}}+\left(1+r^{d}\right)(a-k) \mathbb{1}_{\{k \leq a\}}$. Rearranging terms yield the profit and household's budget constraint equations.

${ }^{30}$ In that case, the entrepreneur has to exit entrepreneurship for at least one period: she can start searching for a new business idea in the next period and create a new business the period after that.

${ }^{31}$ Unlike Mankart and Rodano (2015), we abstract from Chapter 7 bankruptcy exemptions, as we do not distinguish secured and unsecured debt. They generate default with an iid investment shock inducing large capital losses. Here, we focus on productivity shocks impacting current profit. We, therefore, need a bankruptcy specification that implies a higher default incentive. Despite this potential limitation, our specification is able to capture the entrepreneur's income distribution as shown in section 5, which is our major concern for our policy experiment to be meaningful.
} 
After defaulting, the entrepreneur is excluded temporarily from the credit market in subsequent periods. The recursive formulation of such an entrepreneur is:

$$
\begin{aligned}
& B(a, k, \theta, z, j)=\max _{\substack{c>0, a^{\prime} \geq 0, s_{w} \geq 0}} u\left(c, s_{w}, 0\right)+\beta \mathbb{E}_{\theta^{\prime}, y^{\prime}, j^{\prime} \mid \theta, j}\left\{\pi_{w} W^{\prime}+\left(1-\pi_{w}\right) U_{j^{\prime}}^{\prime}\right\} \\
& \text { s.t. } \quad c+a^{\prime}=\max \left\{(1-\chi) k+\min \left\{\pi_{r}, 0\right\}-\xi(k-a), 0\right\}+\mathbb{1}_{\{j=i\}} b_{e}(\theta, 0) \\
& \quad \pi_{r}=z g(\theta)(k)^{\nu}-\delta k
\end{aligned}
$$

where we assume that banks recover all the positive profit. ${ }^{32}$ In our alternative economy with a SEA program, an insured but bankrupt entrepreneur can claim any outstanding UI rights $b_{e}(\theta, 0)$. This is consistent with the current bankruptcy law: public benefits, including unemployment compensation, are fully exempted from any debt recovery.

Credit contract Following the literature on entrepreneurial option to default, the interest rate $r^{b}(\Delta)$ on an entrepreneurial loan is chosen endogenously by the creditor. We assume the latter has perfect information about the entrepreneur's default probability based on the observable characteristics $\Delta=\left(a, \theta, z_{-1}, j\right) .{ }^{33}$ We also assume perfect competition and free entry in the credit market. Thus, an entrepreneur with a zero default probability will pay the competitive rate $r$. The creditor and the borrowing entrepreneur agree on the terms of the credit contract $\left\{k-a, r^{b}(\Delta, k)\right\}$, detailing the amount loaned and its cost. The interest rate applied to the loan is set such that the creditor makes zero profit in expectation given the entrepreneur's decision to default on a specific loan. When the entrepreneur chooses not to repay the debt, the creditor can recover a fraction $\xi$ of the original loan (plus the positive profit). The zero profit condition includes three elements: (i) the expected return in case of bankruptcy $\left(V_{B}\right)$, (ii) the expected return in case of repayment $\left(V_{R}\right)$ and (iii) on the right hand side, the amount that the creditor would get by investing the loaned amount in a project paying the safe interest rate of the economy, such that:

$$
V_{B}+V_{R} \geq\left(1+r^{d}+v\right)(k-a)
$$

\footnotetext{
${ }^{32}$ The entrepreneur starts the period with asset $a$, borrows $(k-a)$ and uses $k=a+(k-a)$ in production. She then pays depreciation $\delta k$ and recovers $k$ but decides to default on the borrowed amount. Thus her after production asset is indeed $k$, but she has to pay all her positive profits, cost of bankruptcy $\chi k$ and recovery $\xi(k-a)$. Creditor preempting profit is an assumption ensuring a better reproduction of the default rate.

${ }^{33} \mathrm{We}$ assume here that there is a sufficient relation between the creditor (bank) and the entrepreneur. In particular, we argue for instance that the creditor is able to observe enough elements (past entrepreneurial income, wage income, etc.) about the entrepreneur to infer this value. Concerning the literature see, among others, Herranz, Krasa and Villamil (2015), Mankart and Rodano (2015) or D'Erasmo and Boedo (2012).
} 
where $V_{B}$ and $V_{R}$ are given by:

$$
\begin{aligned}
& V_{B}=\sum_{z \in \mathcal{B}(\Delta)} \pi\left(z \mid z_{-1}\right)\left[\min \left\{\xi(k-a),(1-\chi) k+\min \left\{\pi_{r}, 0\right\}\right\}+\max \left\{\pi_{r}, 0\right\}\right] \\
& V_{R}=\sum_{z \in \mathcal{B}^{c}(\Delta)} \pi\left(z \mid z_{-1}\right)\left(1+r^{b}(\Delta)\right)(k-a)
\end{aligned}
$$

with $\mathcal{B}(\Delta)$ the set of values $z$ for a given state vector $\Delta$ for which the entrepreneur bankrupts and $\mathcal{B}^{c}(\Delta)$ is the complement for which she repays. Note that if the entrepreneur's cash on hand is too low and that $\pi_{r}<0$, the creditor can only recover what the entrepreneur actually has, that is, only the amount $(1-\chi) k+\pi_{r}$.

Bankruptcy has several roles in this model. First, it prevents poor entrepreneurs from entering a credit contract because the charged interest rate would be too high for them to borrow. Second, while the entrepreneur's upper borrowing limit is identical between agents $(k \leq(1+\lambda) a)$, the option to default generates different behavior among different ability group of entrepreneurs. Finally, bankruptcy may interact with our policy experiments. In particular, the reforms could modify the default incentive. ${ }^{34}$

\subsubsection{Excluded entrepreneur}

An entrepreneur excluded from the credit market runs her business using only her own wealth. She has a probability $\phi$ of reentering the credit market in the next period. Her recursive program after the realization of the shock $z$ is thus:

$$
\begin{aligned}
\hat{E}(a, k, \theta, z, j)=\max _{\substack{c>0, a^{\prime} \geq 0, s_{w} \geq 0}} u\left(c, s_{w}, 0\right)+\beta \mathbb{E}_{\theta^{\prime}, y^{\prime}, j^{\prime}, e^{\prime} \mid \theta, j, e=C}\left\{\pi_{w} \max \left\{W^{\prime}, E_{j^{\prime}}^{\prime}\right\}\right. & \left.+\left(1-\pi_{w}\right) \max \left\{U_{j^{\prime}}^{\prime}, E_{j^{\prime}}^{\prime}\right\}\right\} \\
\text { s.t. } \quad c+a^{\prime}=\pi_{r}^{C}+\mathbb{1}_{\{j=i\}} b_{e}\left(\theta, \pi_{r}^{C}\right)+a+r^{d}(a-k) \mathbb{1}_{\{k \leq a\}} & \\
& \pi_{r}^{C}=z g(\theta)(k)^{\nu}-\delta k
\end{aligned}
$$

Therefore, the excluded entrepreneur decides the amount $k$ invested in her firm in order to maximize her expected value with respect to the shock $\mathrm{z}$, as expressed below:

$$
E\left(a, \theta, z_{-1}, e=C, j\right)=\max _{k \in[0, a]}\left\{\sum_{z \in \mathcal{Z}} \pi\left(z \mid z_{-1}\right) \hat{E}(a, k, \theta, z, j)\right\}
$$

\footnotetext{
${ }^{34}$ In section $\mathrm{G}$ of the online appendix, we show that bankruptcy as we model it does not alter our qualitative results, but slightly impact their magnitude.
} 


\subsection{Policy reforms: insurance and entry subsidy}

We now detail the Self Employment Assistance (SEA) reform that extends the baseline economy. This policy only concerns eligible agents: formerly unemployed individuals with outstanding UI rights. We recall that an entrepreneur entering this programs after a period of unemployment is expected to have a future value $\mathcal{E}_{i}^{\prime}$ as an entrepreneur. Depending on whether the reform is implemented, we define this value using the indicator $\Psi$ :

$$
\mathcal{E}_{i}^{\prime}=\mathbb{E}_{z}[\underbrace{(1-\Psi) E\left(a^{\prime}, \theta^{\prime}, z, e^{\prime}, j=n\right)}_{\text {baseline }}+\underbrace{\Psi E\left(a^{\prime}, \theta^{\prime}, z, e^{\prime}, j=i\right)}_{\text {SEA reform }}]
$$

where $\Psi=0$ defines the baseline economy and $\Psi=1$ the reformed economy.

SEA reform The major policy reform we introduce is a type dependent entrepreneurial insurance in the spirit of entrepreneurial policies active in France, Germany, and some US states. An eligible entrepreneur entering this program will continue to benefit from her UI rights, even after starting a business activity. The UI provision will depend on the realized entrepreneurial income. Specifically, the additional amount $b_{e}\left(\theta, \pi_{r}\right)$ is given to the entrepreneur, depending on her current entrepreneurial income $\pi_{r}$ and the UI benefits she could have claimed as anemployed individual. When the entrepreneurial income is negative (i.e., $\pi_{r}<0$ ), an entrepreneur can fully claim her unemployment benefits. Otherwise, the UI supplement diminishes proportionally with the realized entrepreneurial income. The policy is characterized with the couple of parameters $(f, \bar{q})$, where $f \in[0,1]$ is a downside risk insurance (DRI) replacement parameter ${ }^{35}$ and $\bar{q}$ the maximum insurance duration. The rule governing $b_{e}\left(\theta, \pi_{r}\right)$ is given by:

$$
b_{e}\left(\theta, \pi_{r}\right)=\left\{\begin{array}{ccc}
b(\theta) & \text { if } & \pi_{r}<0 \\
b(\theta)-(1-f) \pi_{r} & \text { if } & 0 \leq \pi_{r} \leq \frac{b(\theta)}{1-f} \\
0 & \text { if } & \pi_{r}>\frac{b(\theta)}{1-f}
\end{array}\right.
$$

where $b(\theta)=\left(1-\tau_{w}\right) h(\theta) w \mu$ is the full UI benefit that the entrepreneur could have claimed if she was only unemployed. Figure 3 illustrates this policy with an example. The higher the $f$, the higher is the amount of insurance provided in case of a positive but low profit. Moreover, the higher the $f$, the higher is the fraction of entrepreneurs insured. Indeed, the maximum level of entrepreneurial income $\pi_{r}$ for which some UI benefits are provided is equal to $\frac{b(\theta)}{1-f}$. By increas-

\footnotetext{
${ }^{35} f$ lets the entrepreneur's income be larger than her UI payment, but the compensation $b_{e}\left(\theta, \pi_{r}\right)$ cannot exceed her UI rights. Even when $f=0$, the insurance is effective as shown later.
} 
ing the DRI parameter $f$, entrepreneurial incomes are covered up to a higher threshold value. Therefore the insurance mechanism displays three regions: (i) a supplement that guarantees at least the UI benefits if the entrepreneurial income is positive but low; (ii) an insurance-subsidy which provides an additional supplement even if the entrepreneurial income is greater than the UI benefits; and (iii) in case of a negative entrepreneurial income the full extent of the UI benefit. On top of the above, our benchmark SEA scheme lets the insured entrepreneur return to the unemployment pool and keep claiming her outstanding UI benefits.

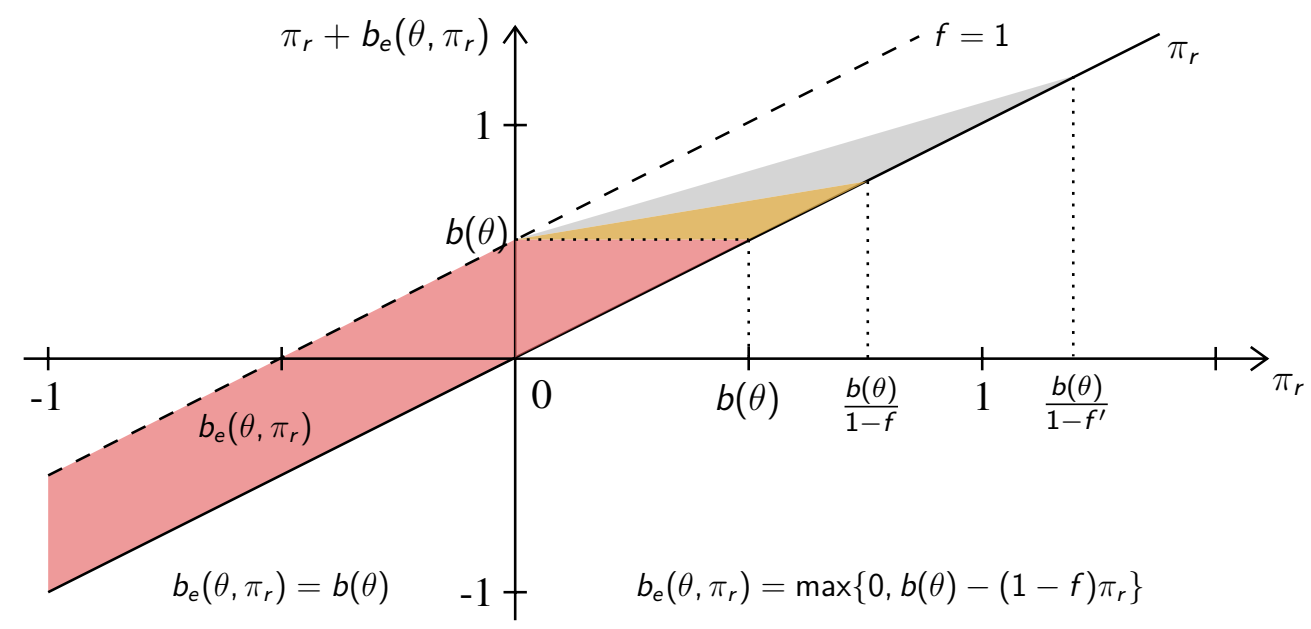

Figure 3. SEA reform. The red (darkest) region corresponds to a minimal case where $f=0$ (entrepreneur gets at least $b(\theta)$ when $b(\theta)>\pi_{r}>0$ ). Note that if current entrepreneurial income $\pi_{r}<0$, this zone will be the same whatever the value of $f$. The orange (lighter) zone refers to a case where $f=0.3$ : entrepreneurs will get at least the red zone and the extra orange zone depending on their income. The grey (lightest) zone is a case where $f=0.45$. Finally, the white zone between the grey zone and the upper dashed line is the case where $f \rightarrow 1$ (entrepreneur always gets $b(\theta)$ ).

An unemployed individual starting a business and who does not use all her outstanding UI in the form of SEA payments must keep her UI rights as long as they are unused. To model this feature, we let the probabilistic policy duration $q\left(\pi_{r}\right)$ vary endogenously with $\pi_{r}$, such that:

$$
q\left(\pi_{r}\right)=\bar{q} \frac{b_{e}\left(\theta, \pi_{r}\right)}{b(\theta)}
$$

In particular, in the case where $\pi_{r}>\frac{b(\theta)}{1-f}$, the government does not provide any compensation, $b_{e}\left(\theta, \pi_{r}\right)=0$, and the probability $q\left(\pi_{r}\right)$ equals zero, a lower bound: the entrepreneur keeps all her remaining UI rights. Contrastingly, an entrepreneur with $\pi_{r}<0$ will receive all of her SEA payments and lose her rights with the upper bound probability $\bar{q}$. When $\pi_{r} \in\left(0, \frac{b(\theta)}{1-f}\right)$, this probability, $q\left(\pi_{r}\right)$, lies in $(0, \bar{q})$, depending on the amount of compensation provided. 


\subsection{Government}

In all considered economies, the government runs an UI system that covers the pool of short-term unemployed individuals. Under the reforms, the government extends the UI program to unemployed individuals starting a business activity and finances the programs using labor income taxes $\tau_{w} \cdot{ }^{36}$ Total government revenues ( $T$ ) are (with a slight abuse of notations): $T=$ $\int_{\mathbf{x}_{o_{w}, u}}\left(\tau_{w} h(\theta) w y d \Gamma\left(\mathbf{x}_{o_{w}}\right)+\tau_{w} h(\theta) w \mu d \Gamma\left(\mathbf{x}_{o_{u}}\right)\right)$, with $\mathbf{x}_{o}$ and $\Gamma\left(\mathbf{x}_{o}\right)$ respectively the individual's state vector and the mesure of individuals in occupation $o$. Total government expenditures $G$ are equal to distributed UI benefits plus the reform's cost: $G=\int_{\mathbf{x}_{o_{u, e, e u}}}\left(h(\theta) \mu w d \Gamma\left(\mathbf{x}_{o_{u}}\right)+\right.$ $\left.\Psi b_{e}\left(\theta, \pi_{r}\right) d \Gamma\left(\mathbf{x}_{o_{e}^{j}}\right)\right)$, where $\Gamma\left(\mathbf{x}_{o_{e}^{j}}\right)$ is the measure of insured entrepreneurs coming from the pool of unemployed individuals with outstanding UI rights.

\subsection{Equilibrium}

Given $\mathbf{x}=(a, y, \theta, z, j, e) \in A \times \mathcal{Y} \times \Theta \times \mathcal{Z} \times\{i, n\} \times\{A, C\}$, a stationary recursive equilibrium in this economy consists of a set of value functions $W(\mathbf{x}), U(\mathbf{x}), E(\mathbf{x})$, policy rules over asset holdings $a^{\prime}(\mathbf{x})$, consumption $c(\mathbf{x})$, job search effort $s_{w}(\mathbf{x})$, business search effort $s_{e}(\mathbf{x})$, business investment $k(\mathbf{x})$, bankruptcy decision, occupational choice, prices $(r, w \in \mathbb{R})$, tax parameters $\left(\tau_{w} \in \mathbb{R}\right)$ and a stationary measure over individuals $\Gamma(\mathbf{x})$, such that:

(1) Given prices $(r, w)$ and tax $\tau_{w}$, the policy rules and value functions solve household individual programs and the zero profit condition of competitive creditors is respected; (2) The wage $w$ and the interest rate $r$ are equal to the marginal products of the respective production factor in the corporate sector; (3) Goods and factor markets clear: (a) capital: $\int a^{\prime}(\mathbf{x}) d \Gamma(\mathbf{x})=K+K^{E}$, with aggregate entrepreneurial capital $K^{E}=\int k\left(\mathbf{x}_{o_{e}}\right) d \Gamma\left(\mathbf{x}_{o_{e}}\right)$, (b) the measure of corporate workers $\int d \Gamma\left(\mathbf{x}_{o_{w}}\right)$ is equal to corporate labor demand; (4) $\Gamma(\mathbf{x})$ is the stationary measure of individuals induced by the decision rules and the exogenous Markov processes; (5) $\tau_{w}$ balances the government budget $(T=G)$.

This model has no analytical solution and must be solved numerically. We detail our numerical implementation for this problem in section $\mathrm{F}$ of the online appendix.

\footnotetext{
${ }^{36}$ In France, the PARE entrepreneurial insurance program is an extension of the UI system and this insurance is only available after contributing enough as a former worker.
} 


\section{Parameterization}

We parameterize the model to be consistent with key features on occupational mobility, entrepreneurship and the wealth distribution in the US. We compute moments related to mobility using the basic CPS from 2001 to 2008 and those related to the wealth distribution using SCF 2001, 2004 and 2007. The model period is the quarter.

\subsection{Fixed parameters}

Technology, preferences and demography The share of capital in the corporate production function $\alpha$ is set to 0.33 . The depreciation rate $\delta$ is set to 0.015 . We use the following CRRA and power functions to describe utility of consumption and disutility of search: $u\left(c, s_{w}, s_{e}\right)=$ $\frac{c^{1-\sigma}}{1-\sigma}-s_{w}^{\psi_{w}}-s_{e}^{\psi_{e}}$. The coefficient of relative risk aversion $\sigma$ is set to 1.5 and $\psi_{w}$ and $\psi_{e}$ are calibrated. Each period, a fraction $\zeta$ of individuals retires and is replaced by $\zeta$ unemployed individuals without UI rights. $\zeta$ is set to $0.5 \%$, corresponding to the average entry rate of young individuals into the working population each quarter in the CPS.

Labor income processes and UI The labor income process has persistent components $h(\theta)$ (individual labor productivity) and $y$ (match-quality), each following an AR(1) process in logs. We set the individual productivity component such that $h(\theta)=\theta$ and the persistence $\rho_{\theta}$ is 0.975 , corresponding to 10 years in the model. The variance of the innovation of the individual productivity process $\sigma_{\theta}^{2}$ is 0.24 and is chosen to generate a Gini index for the earnings distribution of about 0.38 , as in (Cagetti and De Nardi (2006)). For the match-quality, $\rho_{y}$ is set to 0.75 , corresponding to a persistence of about a year. The variance of the innovation $\sigma_{y}^{2}$ is set to 0.0225 . We document a linear relationship for the transition from employment to unemployment with respect to earnings using the CPS. We therefore specify the layoff probability $\eta$ as a linear function of the working ability $h(\theta)$, such that $\eta(\theta)=\alpha_{\eta}+\beta_{\eta} w h(\theta)$, where $\alpha_{\eta}$ and $\beta_{\eta}$ are estimated. Earning quantiles are used as a proxy for $w h(\theta)$. Home production income $m$ is set to 0.04. ${ }^{37}$ The US Joint Federal-State Unemployment Compensation program, established under the Social Security Act of 1935, provides regular UI benefits for 26 weeks. Additionally, since 1993, the Federal-State Extended Benefits program extends the duration up to 20 weeks in states with especially high unemployment. We choose the least generous UI duration and set

\footnotetext{
${ }^{37}$ By increasing the agent's current income and lowering the incentive to search for either a job or a business idea, this value helps to generate a realistic unemployment rate.
} 
the probability $\rho$ of falling in uninsured unemployment to 0.5 , corresponding to about 26 weeks of benefits. The replacement rate $\mu$ is set to 0.4 according to Shimer (2005). ${ }^{38}$

Credit market The probability $\phi$ of reentering the credit market after an exclusion is set to $4.2 \%$, corresponding to a period of 6 years. The intermediation cost $v$ translating the transaction cost banks face when lending is set to $0.4 \%$ per quarter, which is in the range of the literature. ${ }^{39}$ The recovery rate of a bankrupt entrepreneur is set to $77 \%$ of the capital invested in the firm, according to data from the World Bank 2009 Doing Business report. The bankruptcy cost $\chi$, however, is calibrated endogenously to generate a realistic default rate. Finally, we set the maximum leverage ratio $\lambda$ to $50 \%$ following Kitao (2008).

\begin{tabular}{llllll}
\hline Parameter & Symbol & Value & Parameter & Symbol & Value \\
\hline Capital share & $\alpha$ & 0.33 & Home production & $\mathrm{m}$ & 0.04 \\
Depreciation rate & $\delta$ & 0.015 & UI replacement rate & $\mu$ & 0.4 \\
Relative risk aversion & $\sigma$ & 1.5 & UI duration & $\rho$ & 0.5 \\
Match-quality persistence & $\rho_{y}$ & 0.75 & Bankruptcy recovery rate & $\xi$ & 0.77 \\
Match-quality variance & $\sigma_{y}^{2}$ & 0.0225 & Maximum leverage ratio & $\lambda$ & 0.5 \\
Individual productivity persistence & $\rho_{\theta}$ & 0.975 & Credit market wedge & $v$ & 0.004 \\
Individual productivity variance & $\sigma_{\theta}^{2}$ & 0.24 & Probability of reentering credit market & $\phi$ & 0.042 \\
Fraction retiring & $\zeta$ & 0.005 & Layoff rates (in \%) & $\eta(\theta)$ & $3.2,2.2,1.2$ \\
TFP & $A$ & 1 & & & \\
\hline \hline
\end{tabular}

Table. 4. Fixed parameters

\subsection{Endogenously calibrated parameters and targeted moments}

Entrepreneurial abilities The literature does not provide clear indications as to how entrepreneurial abilities evolve over time. The estimation procedure for such abilities is challenging since: (1) the contribution of the entrepreneur's skills to the business returns is generally unobservable; and (2) entrepreneurial income could be the sum of different income sources (business income, wage or capital income). Some authors, for instance, Kitao (2008), parameterize this ability using the entrepreneur's income Gini. However, this assumes that entrepreneurial and working abilities are uncorrelated. We instead stress that working and entrepreneurial abilities are correlated and can generate the observed U-shaped relationship in the transition from paid-employment to entrepreneurship by earning quantiles. We use this relation to indirectly infer the mapping between working and entrepreneurial individual productivity. To do so, we

\footnotetext{
${ }^{38}$ In section 6.3, we study policy effects under various UI systems with longer durations and higher benefits.

${ }^{39}$ For instance, Mankart and Rodano (2015) set a wedge of $1 \%$ for secured debt and $4 \%$ for unsecured debt. Bassetto, Cagetti and De Nardi (2015) report a spread of about $1.5 \%$ annually (i.e. $0.37 \%$ quarterly).
} 
divide the labor income distribution into 3 quantiles and compute in each the ratio of workers starting a business over the average ratio of workers starting a business in the economy. This measure tells us how likely is a worker in a given quantile to start a business as compared to the average worker. Depending on the period and the definition considered, we find that workers in the bottom and the top quantiles are $0 \%$ to $15 \%$ more likely to start a business than the average worker whereas in the middle quantile they are 10\% - 20\% less likely. Therefore, we estimate entrepreneurial abilities $g(\theta)=\left\{g_{1}, g_{2}, g_{3}\right\}$ such that the resulting transition ratios by earning quantiles in the model are close to their data counterparts. ${ }^{40}$

Business productivity While preceding papers assuming iid shocks (for instance Mankart and Rodano (2015) or Herranz, Krasa and Villamil (2015)), the idiosyncratic business shock we use is characterized by an $\operatorname{AR}(1)$ process with variance $\sigma_{z}$ and persistence parameter $\rho_{z}$. In the model, a persistent business shock generates an incentive to exit entrepreneurship (and search for a job) when an individual falls into a bad state. Therefore, unlike many entrepreneurship models (for instance Cagetti and De Nardi (2006), among others), exit in our model arise endogenously as an optimal decision. $\left(\sigma_{z}, \rho_{z}\right)$ are pinned down endogenously and capture the high entrepreneurial exit rate and the fraction of entrepreneurs with zero or negative earnings.

Other parameters After setting the above parameters, other structural parameters have to be pinned down. The discount factor $\beta$ helps to generate a realistic annual capital-output ratio of 2.65. ${ }^{41}$ The return to scale parameter in the entrepreneurial sector $\nu$ lets us fit the ratio of median net worth between workers and entrepreneurs. The probabilities of getting a business idea or a job opportunity depend on search efforts. Exit probabilities are thus: $\pi_{e}\left(s_{e}\right)=1-e^{-\kappa_{e} s_{e}}$ and $\pi_{w}\left(s_{w}\right)=1-e^{-\kappa_{w} s_{w}}$. The matching parameters $\left(\kappa_{w}, \kappa_{e}\right)$, the persistence of the process $z$ and the search elasticities, $\psi_{w}$ and $\psi_{e}$ (with the restriction $\psi_{w}=\psi_{e}$ ), are used to obtain consistent masses and transitions between occupations in the model. We target a fraction of entrepreneurs in the economy of $8.8 \%$, which is close to the CPS estimate and equal to the average observed rate in the SCF. We target an unemployment rate of 5\%, which is roughly the US average between 2001 and 2008. We target an entrepreneurship exit rate of about $6 \%$ and a fraction of (previously

\footnotetext{
${ }^{40}$ Notice that we could also take the ratio by educational attainment, however, in the model, there is no state variable summarizing education exactly. $\theta$ reflects education, but also experience, professional training, etc.

${ }^{41}$ As Kitao (2008), we follow Quadrini (2000) and choose a capital-output ratio without taking into account public capital. Capital in the model refers to equipment and structures, inventories, land and residential structures, which is 2.65 of total output annually.
} 
unemployed) new entrepreneurs of $20 \%$, as approximately observed in the CPS. The variance of the innovation of the process $z$ lets us match a fraction of entrepreneurs with zero or negative earnings of about 10\%, following Hamilton (2000), who uses self-employed individuals and his own annual entrepreneurial earnings measure and controls for under-reporting using the SIPP. ${ }^{42}$ Finally, we let the bankruptcy cost $\chi$ adjust in order to generate a realistic default rate of $0.57 \%$ following Mankart and Rodano (2015). ${ }^{43}$ Note that while some parameters mainly affect some moments, changing one parameter affects the whole set of generated moments. In order to estimate those parameters, we use a simulated method of moments (SMM) ${ }^{44}$ Let $\mathbf{p}$ represents the vector of parameters to be endogenously estimated. The parameter vector is chosen to minimize the squared difference between simulated and empirical moments: $\hat{\mathbf{p}}=$ $\arg \min _{\mathbf{p}} \sum_{k=1}^{10}\left(m_{k}-m_{k}(\mathbf{p})\right)^{2}$, where $m_{k}(\mathbf{p})$ represents the $k$-th simulated moment and $m_{k}$ its data counterpart. ${ }^{45}$ The resulting estimated parameter set and targeted moments are summarized in Table $5 .{ }^{46}$

We find a low value for the discount factor of 0.974. As in other entrepreneurial models (for instance Cagetti and De Nardi (2006) who find 0.86 to 0.88 at a yearly frequency) the existence of wealthy entrepreneurs reduce the need to give extra incentives to save through a higher discount factor to match the capital-output ratio. The implied quarterly lending interest rate, $r^{d}+\nu$, is of $2 \% .{ }^{47}$ For the idiosyncratic business process $z$, the persistence is 0.87 , which is close to the estimated profit persistency reported in Gschwandtner (2012) (at an annual frequency) and corresponds approximately to a shock every 2 years.

\footnotetext{
${ }^{42}$ Astebro and Chen (2014) report a fraction of self-employed households with zero and negative annual earnings of 7\%. However, they do not distinguish household and individual earnings. Moreover, according to the 2016 Annual Survey of Entrepreneurs, $18.5 \%$ of businesses with paid-employees experienced a profit loss. Because this number is subject to a debate, in section $\mathrm{G}$ of the online appendix, we recalibrate the model with the arbitrary much lower fraction of zero or negative earnings of $3 \%$ as a robustness check. The qualitative results of the paper remain unchanged.

${ }^{43}$ Some papers assume a bankruptcy cost close to $7 \%$ according to existing estimation. However, this does not generate enough bankruptcy in our setting. As shown in section $G$ of the online appendix, models recalibrated with alternative bankruptcy specifications do not alter the qualitative results of the paper.

${ }^{44}$ To be more precise, we use a version of the Control Random Search (CRS) algorithm with a set of starting points generated via Sobol sequences along a dimension of 11 parameters.

${ }^{45}$ Minimizing this function is computationally intensive since it requires solving policy functions and all equilibrium outcomes for each set of parameters.

${ }^{46} \mathrm{We}$ also present the resulting policy functions and distributions in the section $\mathrm{D}$ of the online appendix.

${ }^{47}$ This corresponds to an annual interest rate of $8.2 \%$, which is a bit higher than the average lending rate from 1993 to 2008 of $7.44 \%$, as computed by the IMF.
} 


\begin{tabular}{|c|c|c|c|c|c|}
\hline \multicolumn{3}{|c|}{ Parameters } & \multicolumn{3}{|l|}{ Targets } \\
\hline Parameter & Symbol & Value & Moment & Target & Model \\
\hline Discount factor & $\beta$ & 0.9742 & Capital-output ratio (annual) & 2.65 & 2.6 \\
\hline Business return to scale & $\nu$ & 0.79 & Ratio of net worth E/W & 8.0 & 8.07 \\
\hline Matching parameter & $\kappa_{e}$ & 0.267 & Share of entrepreneurs (in \%) & 8.8 & 8.8 \\
\hline Matching parameter & $\kappa_{w}$ & 0.855 & Entrepreneurial exit rate (in \%) & 6.0 & 5.9 \\
\hline Search elasticities & $\psi_{e}, \psi_{w}$ & 2.41 & Unemployment rate (in \%) & 5.0 & 5.0 \\
\hline$z$ process persistence & $\rho_{z}$ & 0.869 & New entrepreneurs from unemp. (in \%) & 20 & 18.9 \\
\hline$z$ process variance & $\sigma_{z}^{2}$ & 0.185 & Entrepreneur with earnings $\leq 0$ (in \%) & 10 & 10.8 \\
\hline Bankruptcy cost & $\chi$ & 0.0238 & Entrepreneurial bankruptcy rate (in \%) & 0.57 & 0.57 \\
\hline Entrepreneurial productivity & $g_{1}$ & 0.0679 & W to E flow in quantile $Q_{1} /$ avg rate $(\%)$ & 1.075 & 1.075 \\
\hline Entrepreneurial productivity & $g_{2}$ & 0.0775 & W to E flow in quantile $Q_{2} /$ avg rate (\%) & 0.85 & 0.85 \\
\hline Entrepreneurial productivity & $g_{3}$ & 0.1026 & W to E flow in quantile $Q_{3} /$ avg rate $(\%)$ & 1.075 & 1.075 \\
\hline
\end{tabular}

Table. 5. Endogenously calibrated parameters and targeted moments.

\section{Properties of the quantitative model}

We now detail the properties of the calibrated quantitative model for occupational mobility and other moments related to entrepreneurship. Compared to the existing literature on occupational flows, this model better reproduces the aggregate flows while using less exogenous mechanisms. Here, all flows emerge as the aggregation of optimal decisions to search and exit to a new occupation, with the exception of the flow from worker to unemployment that we pin down to the data. The aggregate flows reported in Table 6 are very close to their CPS counterparts despite the facts that we are left with one degree of freedom after the calibration and that the entry of a fraction $\zeta$ of newborn unemployed agents somewhat disconnects the model masses from transitional flows. ${ }^{48}$ In particular, our model captures the fact that unemployed individuals are 4 to 5 times more likely than workers to start a business. As in the data, the model captures the high entrepreneurial exit rate into paid-employment. Two forces lead to this high rate. First, a bad business shock $z$ generates low future expected profits and encourage entrepreneurs to search a job on-the-business. Second, a sizable fraction of unemployed individuals started their business out-of-necessity. Since the option to work in the corporate sector is better for those individuals, they continue to search for a job on-the-business and exit as soon as a job is found.

\footnotetext{
${ }^{48}$ As we calibrated the model to match two occupational masses and three transitions, we are left with one degree of freedom. Theoretically, the invariant distribution of the model flows generates model masses. Therefore, if we omit $\zeta$, targetting masses also indirectly target some flows. In the data, there are always some mismatches between the observed masses and the invariant distribution generated with the observed flows due to the transition to Not in the Labor Force (NLF), death and various other reasons.
} 


\begin{tabular}{cccccc}
\hline & \multicolumn{2}{c}{ Masses (\%) } & \multicolumn{3}{c}{ Flow: Model (Data) $(\%)$} \\
& Target & Model & $W$ & $E$ & $U$ \\
\hline$W$ & 86.2 & 86.2 & $97.36(97.35)$ & $0.53(0.50)$ & $2.11(2.15)$ \\
$E$ & 8.8 & 8.8 & $5.19(4.80)$ & $94.07(94.22)$ & $0.74(0.99)$ \\
$U$ & 5.0 & 5.0 & $45.07(47.36)$ & $2.14(2.40)$ & $52.79(50.25)$ \\
\hline \hline
\end{tabular}

Table. 6. Flow between occupations during a quarter (data counterpart between braces). Data sources: authors' computations using CPS data from 2001 to 2008. We restrict our sample to individuals aged between 20 to 65 years old.

In Figure 4, we report how the model matches the shapes of the flows from a given occupation to another as compared to the CPS data. The flows in the model are computed with respect to individual productivity (ability) levels and educational attainment is taken as a proxy in the data. ${ }^{49}$ In order to compare the alternative definitions of entrepreneurship, we simultaneously display the flows for self-employed individuals and self-employed business owners. Among those flow patterns, only the decreasing shape of the paid-employment to unemployment flow is somewhat more explicitly imposed in the model as we set the layoff probability with a decreasing dependence to the ability level $\theta$. We also recall that we imposed in the calibration step that the model match the $U$-shape of the flow between paid-employment and entrepreneurship by earnings quantiles. The shape of this flow by educational attainment is similarly $U$-shaped in the data for self-employed individuals and flatter on the left for self-employed business owners. All the other patterns are endogenously generated by the model. A number of flow shapes are well-reproduced under our parsimonious assumptions concerning search frictions and business shocks across ability groups: we capture the decreasing pattern of the entrepreneurship to unemployment flow as well as the increasing shape of the reverse flow. We also capture the hump-shape of the flow from unemployment to paid-employment despite the fact the model is unable to match the exact magnitude of this flow. This hump-shape is explained in the following way in the model: low-skilled unemployed individuals search for a job with a lower incentive than other groups since the difference of value between employment and unemployment for this category is smaller. This is not true for unemployed individuals in the high skilled group

\footnotetext{
${ }^{49}$ Matching ability groups with education groups might not be the most obvious way to compare data and model simulations. However, the CPS data does not allow many options on the subject. Although they are probably the best to recover the flow dynamics at high frequency, CPS data does not provide any information about wealth or business earnings and unemployment compensation. The included family income variable is rather imprecise and its range is too small. Education is the best directly available element comparable to the model. However, we still tried to match by indirect means: in section $\mathrm{E}$ of the online appendix, we report flows by reconstructed wages using a fitted wage that takes age, education, etc.
} 
although they tend to also switch toward paid-employment less often. But, this group of individuals has a large incentive to switch toward self-employment, consistently with the data, lowering the transition to paid-employment. Finally, the flow shape the model captures the least is the $S$-shape from entrepreneurship to paid-employment. We still capture the increasing part of this flow for $H S$ to $M$ groups but not the highly non-linear extremes. ${ }^{50}$ In the model, highskilled entrepreneurs exit more often since they have better outside opportunities in corporate jobs, without any business risk: this results in a higher incentive to search for a job. ${ }^{51}$
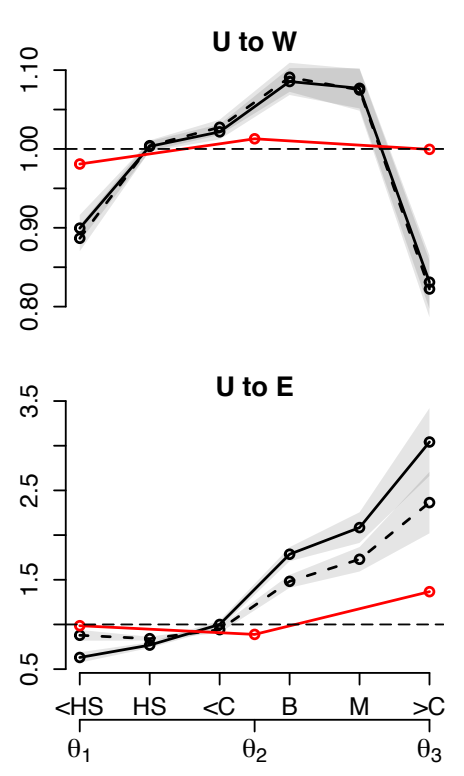

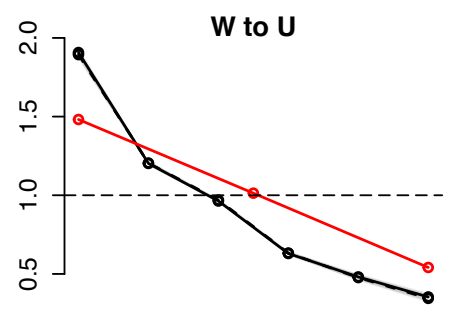

W to $E$

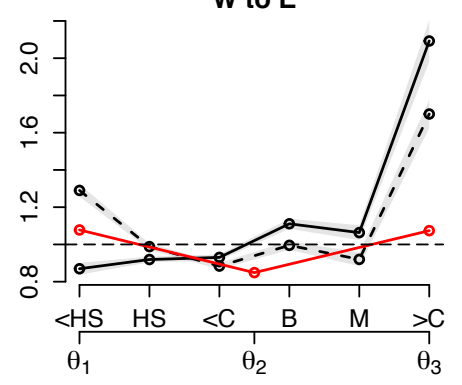

$E$ to $U$

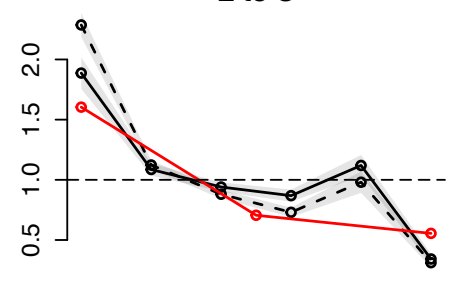

E to W

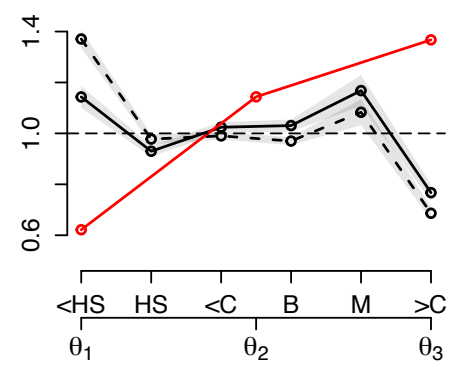

Figure 4. Quarterly occupational flows by CPS educational attainment (black, top horizontal axis) and model ability level $\theta$ (red, bottom horizontal axis). The solid lines (resp. dashed lines) refer to self-employed business owners (resp. self-employment only). Legend: $U$ : unemployment, $W$ : paidemployment, $E$ : entrepreneurship. In grey: confidence interval for the CPS means at a $95 \%$ confidence level. Data sources: authors' own computations using CPS data from 2001 to 2008.

As argued above, the model is based on the two minimal dimensions of ability and wealth and individual search efforts play an important role in shaping the flows between occupations. We find that unemployed agents and entrepreneur's job search efforts are decreasing both in wealth and ability. ${ }^{52}$ For the business search efforts, the policy functions are hump-shaped. Wealth poor individuals, most likely to be constrained, do not find it interesting to run very small firms and thus provide very small effort. As wealth increases, individuals are willing to

\footnotetext{
${ }^{50}$ According to the BLS, groups $>C$ and $<H S$ together represent fewer than $15 \%$ of the working population.

${ }^{51}$ In the online appendix section A, we show that this $S$-shape becomes a hump-shaped curve at a yearly frequency for self-employed business owners. At the higher quarterly frequency, we might also capture movements that may mainly concern the lowest educated group potentially running more unstable businesses in the short-run.

${ }^{52}$ For the sake of brevity, the search policy functions of unemployed, workers and entrepreneurs in the baseline model are plotted in section D of the online appendix.
} 
invest larger amounts in their businesses and the effort increases. At some point, search costs become larger than the benefit of additional capital in the business and search efforts decrease.

We also capture a number of other moments related to the labor market and entrepreneurship that are not explicitly targeted but that are still reasonably well matched. The necessity share, which is the fraction of entrepreneurs who started businesses because of a lack of job opportunities is equal to $7.4 \%$ in our model and is evaluated by Ali et al. (2008) in 2008 to be $4.7 \%$ of early-stage entrepreneurs for men and $21.4 \%$ for women, representing $10 \%$ in total. ${ }^{53}$ Therefore, in line with Caliendo and Kritikos (2009), among the 20\% new entrepreneurs who were previously unemployed, a substantial fraction enters entrepreneurship out-of-necessity.

Concerning entrepreneurial earnings, we obtain a fraction of $10.8 \%$ of the entrepreneurs with zero or negative earnings (profits in the model). If we consider only those who do not exit entrepreneurship at the end of the period, this fraction falls to $9.5 \%$. This means that despite the realization of bad shocks, a substantial number of entrepreneurs persist in their activity. As argued by Hamilton (2000) or more recently by Astebro and Chen (2014), a number of entrepreneurs (about 35\% in the model) create and keep running a business although they would earn more in a paid job. In the model, expectations of a better business shock $z$ and frictions induce some entrepreneurs to keep running a bad business while others search for a job opportunity and exit as soon as possible. The model generates heterogeneity in entrepreneurial earnings through different firm sizes, ability, and business shocks. The implied Gini coefficient for entrepreneurial earnings in the model is 0.58 against 0.65 in the SCF. Now considering all forms of income (including accrued interests from savings and realized profits), the fraction of entrepreneurs with zero or negative income falls to $2.7 \%$ in the model, and between 0 and $2.8 \%$ in the SCF. Finally, concerning the cross-sectional variance of earnings between occupations, we find a ratio of the standard deviation of entrepreneurial earnings with respect to wage earners of 3.5 in the model, while it is typically 3 to 4 in the US according to Astebro and Chen (2014). ${ }^{54}$

The model does also match well the crucial relative wealth between occupations and the associated saving characteristics. First, it is worth noting that the median ratio of entrepreneurial net worth relative to the one held by the whole population is equal to 6.2 in the model against 6.6

\footnotetext{
${ }^{53}$ We define the necessity share as unemployed agents starting a business while $\mathbb{E}[W(\mathbf{x})]>\mathbb{E}[E(\mathbf{x})]>U(\mathbf{x})$.

${ }^{54}$ While the mean and the median ratio of entrepreneurial earnings with respect to wage earners is subject to a debate, it is recognized that the ratio of standard deviations is high, even controlling for mismeasurement. In the model, the median ratio of entrepreneur's earnings (business and wage) over worker's earnings is equal to 1.5 in the model, against 1.6 in the SCF, at the household level.
} 
in the SCF. Additionally, the ratio of median debt to income ranges from 0.95 to 1.6 between SCF waves, whereas it is 0.93 in our model. Moreover, the median ratio of entrepreneurial (resp. worker's) income (including capital gains) to net worth (i.e. total assets minus debt) is 0.11 (resp. 0.63) in the model, while it is 0.13 (resp. 0.68) in the data. Finally, the fraction of zero (or negative) net worth is roughly $10 \%$ in the SCF, whereas it is $4 \%$ in our model, and the fraction of total wealth held by entrepreneurs is $30 \%$ in the data, against $29.4 \%$ in the model.The model, however, underestimates the wealth Gini: we find 0.63 compared to 0.82 in the SCF. However, we do not target this statistic and our model abstracts from a bequest motive, which has been shown to play an important role in replicating the right tail of the wealth distribution.

Finally, we compare the entrepreneurial survival rate with records available for surviving establishments. The fraction of entrepreneurs surviving after 2 years and 4 years are respectively $59 \%$ and $43 \%$ in the model, whereas the average establishment rates are respectively $66 \%$ and 44\% in the data (see Knaup and Piazza (2007)). However, the empirical data excludes two-thirds of the observations, as it does not account for sole-proprietorship who might survive less. ${ }^{55}$ Overall, we potentially underestimate the true survival rate, however, as evidenced by Figure 5, we capture well the usual shape of the survival rate. That is, the largest exit rates occur during first and second years and, after the fourth year, the probability of exit is considerably reduced. In the model, as non-entrepreneurs have no prior knowledge of their business productivity, some entrepreneurs start with an unfavorable business shock and rapidly exit entrepreneurship.

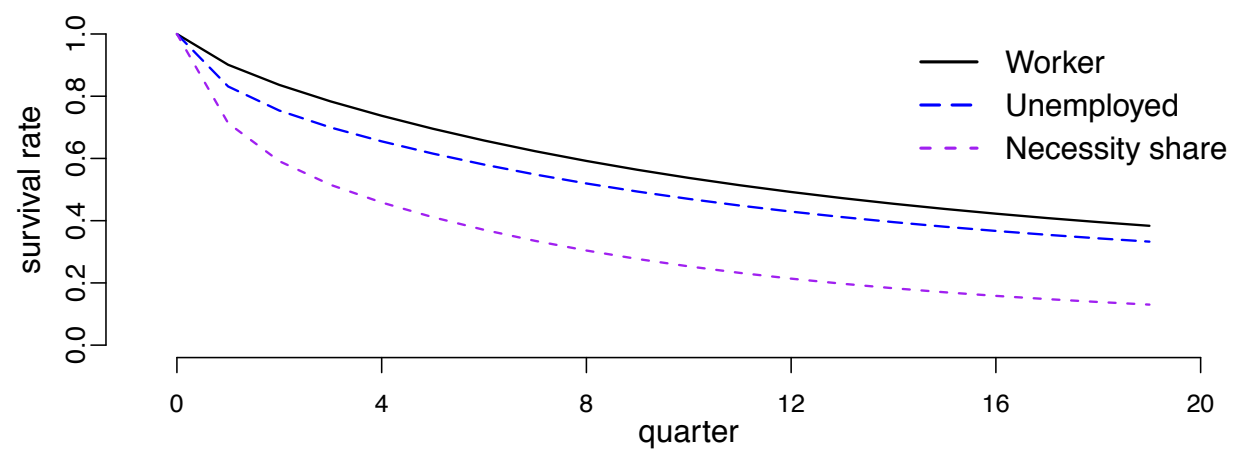

Figure 5. Survival rate of new entrepreneurs depending on their previous situation.

Overall, despite the few limitations that we underlined, the model is well suited to capture

\footnotetext{
${ }^{55}$ It is worth noting that establishment dynamics might be somewhat different from the actual firm and entrepreneurial dynamics. As another comparison, using the Panel Study of Entrepreneurial Dynamics (PSED), Reynolds (2017) finds that $48 \%$ of firms survive after 4 years, taking the first transaction as a measure for firm birth.
} 
occupational flow dynamics and key features expected from a rich entrepreneurial framework.

\section{Policy experiment: self-employment assistance programs}

This section studies the introduction of various entrepreneurial assistance programs as an extension to the existing UI program. For our reference SEA program, denoted SEA*, we use the US UI duration of 26 weeks, corresponding to $\bar{q}=\rho=0.5$ and a DRI replacement parameter of $f=0.3$, corresponding to the French PARE case. This SEA policy includes three key features: type dependency, business income dependency and the option to return to unemployment as an insured unemployed agent. This policy is compared to two alternative specifications. First, by setting $f=1$, we study a non business income dependent SEA policy, denoted $\mathbf{S E A _ { \mathbf { N B } }}$, closely resembling the existing US SEAP or the German Bridging Allowance policies. Under this policy, new entrepreneurs continue to perceive their type dependent UI benefits, irrespectively of their profit, and can return to the unemployment pool and claim UI in case of failure. Under the second alternative experiment, denoted $\mathbf{S E A}_{\mathbf{L S}}$, entrepreneurs receive a periodic lump-sum amount that is neither type dependent nor business income dependent, as in the German Existenzgrundungszuschuss start-up subsidy or the UK NEA policy. Here, the DRI parameter remains at $f=1$ but $b_{e}\left(\theta, \pi_{r}\right)=\overline{b_{e}}$. ${ }^{5}$ Additionally, entrepreneurs cannot return to the insured unemployment situation when stopping their business. All policies are only available to eligible entrepreneurs. We focus on the effects of these alternative insurance reforms on production, unemployment, mobility, entrepreneurial composition, and performances, as well as welfare.

\subsection{Steady-state outcomes}

Mobility effects Table 7 reports the aggregate steady-state effects of the reforms. In all three experiments, the additional support the SEA scheme provides to early-stage eligible entrepreneurs leads to significant mobility effects. The fraction of unemployed individual starting a business increases between 11 and 19\%. Consequently, the fraction of entrepreneurs increases by $1.5 \%$ for $\mathbf{S E A}^{*}$ and $\mathbf{S E A} \mathbf{A}_{\mathbf{L S}}$ and by $2 \%$ for $\mathbf{S E A _ { \mathbf { N B } }}$, implying that the number of newly created firms per year goes up by respectively $2.6,3.2$ and $4.6 \% .{ }^{57}$. Mobility effects are thus stronger un-

\footnotetext{
${ }^{56} \mathrm{We}$ assume, as in the German system, that the lump-sum amount is lower than the lowest possible unemployment benefit such that $\overline{b_{e}}=\vartheta b\left(\theta_{1}\right)$. We arbitrarily set $\vartheta=0.9$ but adjust the policy duration $\bar{q}$ in order to generate the same share of entrepreneurs as in SEA* ${ }^{*}$. We obtain a duration of 1.5 years.

${ }^{57}$ We normalize this number in the baseline model to 500.000 new businesses creation as in the US. A firm in the model corresponds to an entrepreneur.
} 
der $\mathbf{S E A}_{\mathbf{L S}}$ and $\mathbf{S E A _ { \mathbf { N B } }}$, mostly because benefits are provided to entrepreneurs independently of their business performances under these policies: the systematic support mechanism of these two policies dominates the downside risk insurance mechanism found in SEA* However, these experiments select very different types of entrepreneurs, both in terms of ability and wealth, as detailed in the next section. Interestingly, by reducing the bias of the baseline UI system in favor of paid-employment, all the reforms significantly reduce the fraction of necessity entrepreneurs, that is to say, entrepreneurs that would have been better off working in the corporate sector. Our results suggest a decrease of about $20 \%$ of the necessity share.

\begin{tabular}{lcccc}
\hline & Baseline & SEA $^{*}$ & SEA & \multicolumn{2}{c}{ SEA $_{\text {NB }}$} \\
DRI replacement rate $f$ & - & 0.3 & 1.0 & 1.0 \\
Type & - & type-dep & lump-sum & type-dep \\
\hline Fraction of entrepreneurs (in \%) & 8.800 & 8.929 & 8.928 & 8.970 \\
Fraction unemployed starting businesses (in \%) & 2.144 & 2.381 & 2.428 & 2.544 \\
Entrepreneurship exit rate (in \%) & 5.934 & 6.015 & 6.052 & 6.105 \\
Insured entrepreneurs over total entrepreneurs (in \%) & - & 2.920 & 1.595 & 0.700 \\
Unemployment rate (in \%) & 5.000 & 4.992 & 4.987 & 4.984 \\
Corporate jobs (in \%) & 86.200 & 86.078 & 86.085 & 86.046 \\
New firm per year (in thousands) & 500 & 513 & 516 & 523 \\
Bankruptcy rate per quarter (in \%) & 0.569 & 0.584 & 0.578 & 0.581 \\
Necessity share (in \%) & 7.411 & 5.886 & 5.701 & 5.950 \\
Total production & 1.957 & 1.959 & 1.958 & 1.960 \\
Corporate sector capital & 3.585 & 3.582 & 3.582 & 3.581 \\
Entrepreneurial sector capital & 1.495 & 1.515 & 1.509 & 1.520 \\
\hline Tax rate $\tau_{w}$ (in \%) & 0.902 & 0.921 & 0.919 & 0.927 \\
Consumption equivalent variation $\left(\right.$ cev $\left.^{*}\right)($ in \%) & - & 0.061 & 0.066 & 0.088 \\
\hline \hline
\end{tabular}

Table. 7. Summary statistics: steady-states outcomes.

Unemployment, production, and prices In contrast to the empirical literature (see among other Caliendo and Künn (2011), Ejrnæs and Hochguertel (2014) or Hombert et al. (2017)) that studies country-specific SEA policies in partial equilibrium without endogenous occupational choices, we do not find significant effects on the unemployment rate. In the model, the response of the unemployment rate to the reforms is determined by the magnitude of two opposing forces. On the one hand, a positive change in the expected value of being an entrepreneur relative to the value of being a worker leads to a shift in the cutoff point along the two-dimensions of assets and abilities at which unemployed individuals start businesses. This leads to the entry of new entrepreneurs and an increase in the search effort to find a business idea, with both effects reducing either unemployment or corporate employment. On the other hand, the policy 
also improves the value of staying unemployed and lowers the incentive to search for a job, potentially leading to an increase in unemployment. Our results tend to show that overall the reforms encourage unemployed individuals to exit unemployment, but this is mostly detrimental to corporate jobs. Finally, the effects on production and prices are relatively small, in part because the increased capital invested in the entrepreneurial sector crowd out capital invested in the corporate sector and because the targeted unemployed population is a relatively small group.

Steady-state welfare and costs Interestingly, implementing any of the SEA programs improve the steady-state welfare measured in terms of ex ante consumption equivalent variations $\left(\operatorname{cev}^{*}\right)$, despite the higher labor income taxes (labor income taxes increase between $1.8 \%$ and $2.7 \%){ }^{58}$ This is explained by the fact that eligible entrepreneurs are much better off under the policies since they obtain a minimum income level with $\mathbf{S E A _ { \mathbf { N B } }}$ and $\mathbf{S E A _ { \mathbf { L S } }}$ or are directly insured against the downside risk under SEA*. Moreover, insured unemployed individuals also directly benefit from the policies, but welfare gains mostly go to those with sufficient wealth to run a valuable business. On the other hand, costs are small and spread widely among the masses of corporate workers and unemployed. The steady-state welfare is higher with $\mathbf{S E A}_{\mathbf{L S}}$ than with SEA* $^{*}$ but the largest gain comes from SEA $\mathbf{A}_{\mathbf{N B}}$, where benefits are the highest irrespectively of the business outcomes, even if this policy is more expensive.

\subsection{Selection effects}

Selection by ability To understand this selection mechanism and the change in the composition of the pool of entrepreneurs, the crucial element is whether or not the reform induces the entry of low-skilled entrepreneurs. Since regular UI benefits are proportional to the working ability, highly productive workers receive higher UI compensation when laid off than those with low productivity. Therefore, the insurance mechanism generated by the compensation $b_{e}\left(\theta, \pi_{r}\right)$ in the two experiments $\mathbf{S E A}^{*}$ and $\mathbf{S E A} \mathbf{A}_{\mathbf{N B}}$ are type-dependent. Contrastingly, $\mathbf{S E A}_{\mathbf{L S}}$ provides an additional amount of income that is unrelated to previous earnings and entrepreneurs cannot recover UI rights in case of failure. This policy is thus fully independent of an agent's ability $\theta$. Contingent on whether they are type dependent or not, very different entrepreneurs are likely to be selected by the policies. Table 8 displays the increase in the share of entrepreneurs by ability

\footnotetext{
${ }^{58} \mathrm{Ex}$ ante $\mathrm{cev}^{*}$ computes the constant percentage change in per period consumption, $c$, that equates the discounted expected sum of lifetime utility under the baseline economy and under the reform. It measures whether an agent, taking into account all the uncertainty, would rather be born in an economy with or without the reform.
} 
groups for each policy in simple differences to the baseline economy.

\begin{tabular}{lccc}
\hline Ability & $\theta_{1}$ & $\theta_{2}$ & $\theta_{3}$ \\
SEA $^{*}$ & +0.131 & +0.125 & +0.136 \\
SEA $_{\mathbf{N B}}$ & +0.166 & +0.165 & +0.183 \\
SEA $_{\mathbf{L S}}$ & +0.199 & +0.112 & +0.089 \\
\hline \hline
\end{tabular}

Table. 8. Increase (relative to the baseline economy) in the share of entrepreneurs by ability groups.

Qualitatively, results can be stated as follows: type-dependent policies favor the entry of more able entrepreneurs while a lump-sum SEA program encourages the entry of low-skilled individuals. Because they have to give up on relatively high UI benefits, highly skilled unemployed individuals are less likely to enter entrepreneurship under $\mathbf{S E A}_{\mathbf{L S}}$ as compared to other reforms. Indeed, the lump-sum amount $\overline{b_{e}}$ is too low to resorb the opportunity cost coming from the loss of their original UI benefits for this population. ${ }^{59}$ These composition effects could also be related to incumbent entrepreneurs by maintaining the activity of those who would have left without the reforms. Figure 6 shows that entry effects are undoubtedly a driver of the results. Highly-skilled (resp. low-skilled) unemployed individuals are more likely (resp. less likely) to start a business under both type-dependent reforms and less likely to take a job opportunity, while under $\mathbf{S E A}_{\mathbf{L S}}$ the selection into entrepreneurship is closer to what is observed in the baseline economy.
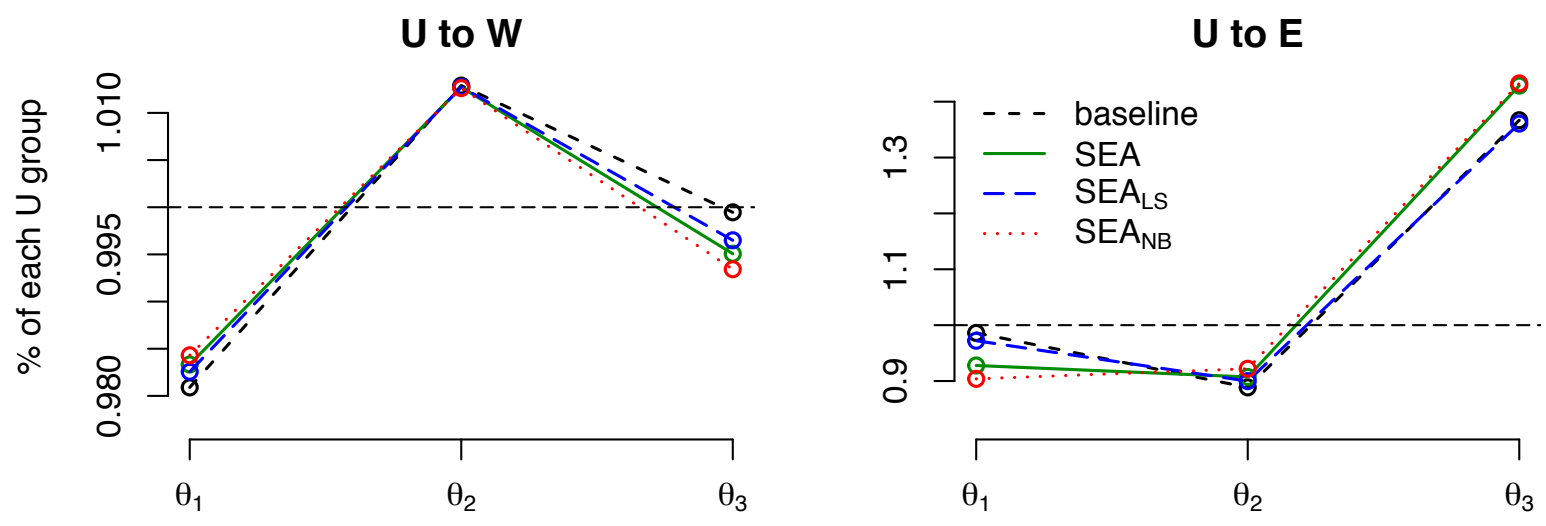

Figure 6. Flows (relative to the average transition rate) from unemployment toward paid-employment and entrepreneurship by ability group.

\footnotetext{
${ }^{59}$ Our findings corroborate results in the empirical literature. In Germany, the 2003 start-up subsidy is similar to a lump-sum SEA and has been shown to significantly increase the entry of unemployed individuals into entrepreneurship, especially for lowly educated individuals (see Caliendo and Künn (2011)). Additionally, Hombert et al. (2017) show that the DRI introduced in France in 2002 - 2003 did not lower the quality of new entrepreneurs, especially in terms of education. Finally, in Table 2 of Caliendo et al. (2015), the selection by education in a type-dependent SEA policy implemented in Germany after 2006 is also found to have more homogenous effects.
} 
Selection by wealth Turning to the wealth distribution, the effects mirror the observations made by ability. The left panel of Figure 7 displays the difference in the mass of entrepreneurs with respect to the baseline case under both $\mathbf{S E A}^{*}$ and $\mathbf{S E A} \mathbf{A S}_{\mathbf{L S}}$. Compared to a lump-sum SEA, the steady-state distribution under the type-dependent policy has richer entrepreneurs. These individuals are more likely to run bigger businesses and increase aggregate production. Contrastingly, the small increase in the leftmost bin shows that even under this assistance mechanisms, financial constraints prevent very poor individuals from running valuable businesses. The right panel of Figure 7 demonstrates that both policies lead to a significant and similar reduction in the necessity share. By removing part of the bias generated by the current UI system, the SEA reforms magnify the value of being an entrepreneur and reduce the number of unemployed individuals entering entrepreneurship due to a lack of job opportunities.

Entrepreneurs

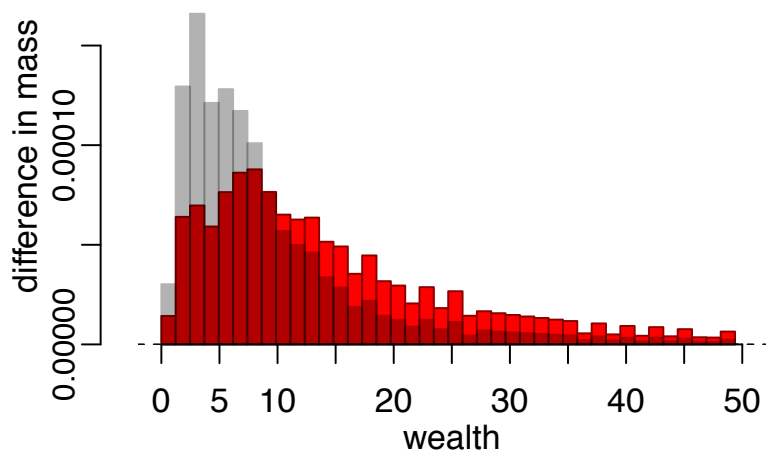

Necessity share

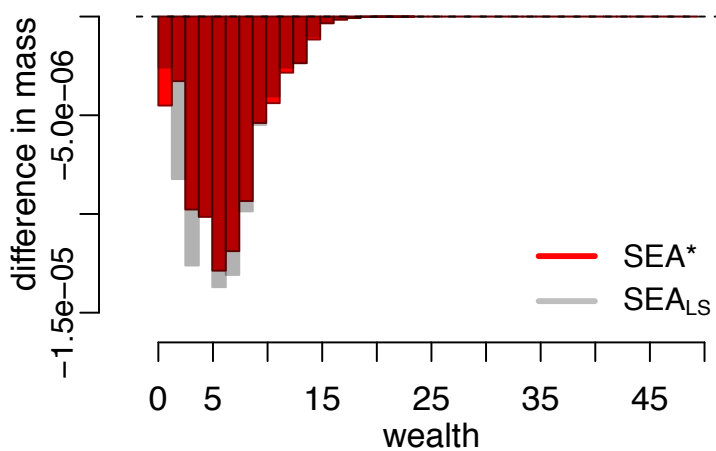

Figure 7. Difference in the mass of entrepreneurs (left panel) and the necessity share (right panel) relative to the baseline economy for the $\mathbf{S E A}{ }^{*}$ and $\mathbf{S E A} \mathbf{A}_{\mathbf{L S}}$ reforms.

Selection and performances A natural question when implementing a program fostering entrepreneurship is how eligible new entrepreneurs perform under the policies. In particular, as pointed out by Caliendo and Künn (2011), these entrepreneurs could have entered and performed similarly without the reform, resulting in important deadweight losses. These losses are even stronger if the reforms generate moral hazard effects and reduce the incentives to run and expand a business. These effects are usually hard to estimate empirically. We use our model to evaluate the performance of eligible entrepreneurs on production, invested capital, bankruptcy rate, skills, and survival rate, in the quarters and years after their entry under SEA* and $\mathbf{S E A} \mathbf{A}_{\mathbf{L S}}$ as compared to the same group under the baseline economy. We, therefore, separate new entrepreneurs into two groups: (i) the intensive margin group (IMG) composed of those 
who would have entered entrepreneurship even without the reforms, (ii) an extensive margin group (EMG) with those who started a business essentially because the program was available. The IMG lets us compare the performances and behaviors implied by the reforms relative to the baseline economy, without selection effects: we mark individuals becoming entrepreneurs in the baseline economy, before providing them with each reform and measuring their average performances. The EMG sheds light on the performance of new eligible entrepreneurs that entered due to the reforms. In the model, the share of recipients who would have started a new business even in the absence of the policy is $69 \%$ under SEA* and 64\% under SEA LS. $^{*}{ }^{60}$ Table 9 summarizes the average performances of both groups over 5 years.

The IMG shows a reduction in the average capital invested, resulting in lower production and accumulated wealth over the five years. This is indicative of a moral hazard issue. That effect is stronger under $\mathbf{S E A}_{\mathbf{L S}}$ for two reasons. First, that policy provides a minimum amount of benefits irrespectively of the business performance, resulting in a lower incentive to invest in the business. Second, it provides benefits for a longer period as compared to SEA*, reinforcing the first effect. However, since the latter policy allows entrepreneurs to claim their remaining UI benefits in case of business failure, recipients tend to bankrupt more often.

\begin{tabular}{lccccc}
\hline 5 years average & Baseline & \multicolumn{2}{c}{ Intensive margin group } & \multicolumn{2}{c}{ Extensive margin group } \\
& & SEA $^{*}$ & SEA $_{\mathbf{L S}}$ & SEA $^{*}$ & SEA $_{\mathbf{L S}}$ \\
\hline$g(\theta)$ (skill) & 0.079 & 0.079 & 0.079 & 0.083 & 0.078 \\
Wealth & 12.063 & 12.050 & 11.626 & 10.081 & 8.094 \\
Production & 0.825 & 0.812 & 0.786 & 0.821 & 0.654 \\
Capital invested & 12.699 & 12.466 & 12.149 & 11.522 & 9.339 \\
Bankruptcy rate (in \%) & 1.006 & 1.174 & 0.872 & 2.326 & 1.478 \\
Marginal productivity of labor (MPL) & 0.298 & 0.302 & 0.292 & 0.370 & 0.292 \\
\hline \hline
\end{tabular}

Table. 9. Performance and quality of entrepreneurs after 5 years for the intensive vs. extensive margin groups. Notes: all values are an average over 5 years.

Concerning the EMG, SEA* selects higher skilled and richer unemployed individuals than the $\mathbf{S E A}_{\mathbf{L S}}$, and this persists over the 5 years. This is similar to our previous observation. The resulting average production under $\mathbf{S E A}^{*}$ is close to the baseline case and $26 \%$ higher than under $\mathbf{S E A}_{\mathbf{L S}}$. Because this increased entrepreneurial production does not necessarily mean higher aggregate production, we compute the (virtual) average marginal productivity of labor (MPL) that translates the marginal production that an additional worker in each considered group would

\footnotetext{
${ }^{60}$ While hard to measure empirically, our numbers seem to be comparable to those estimated in the empirical literature according to Caliendo (2016) who reports a fraction between $20 \%$ and $60 \%$ depending on the country.
} 
have generated if she was employed in the corporate sector. ${ }^{61}$ We find that the corporate production loss implied by the entry of more skilled individuals under the SEA* is largely compensated by the increased production of those individuals in the entrepreneurial production sector.

Finally, figure 8 depicts the survival rate of entrepreneurs in the IMG (left panel) and the EMG (right panel). Entrepreneurs in the IMG are significantly more likely to survive as compared to the same group in the baseline economy. On the other hand, an average of about $20 \%$ of the EMG survives after 5 years. In the end, both policies are able to foster a number of long-lasting businesses.
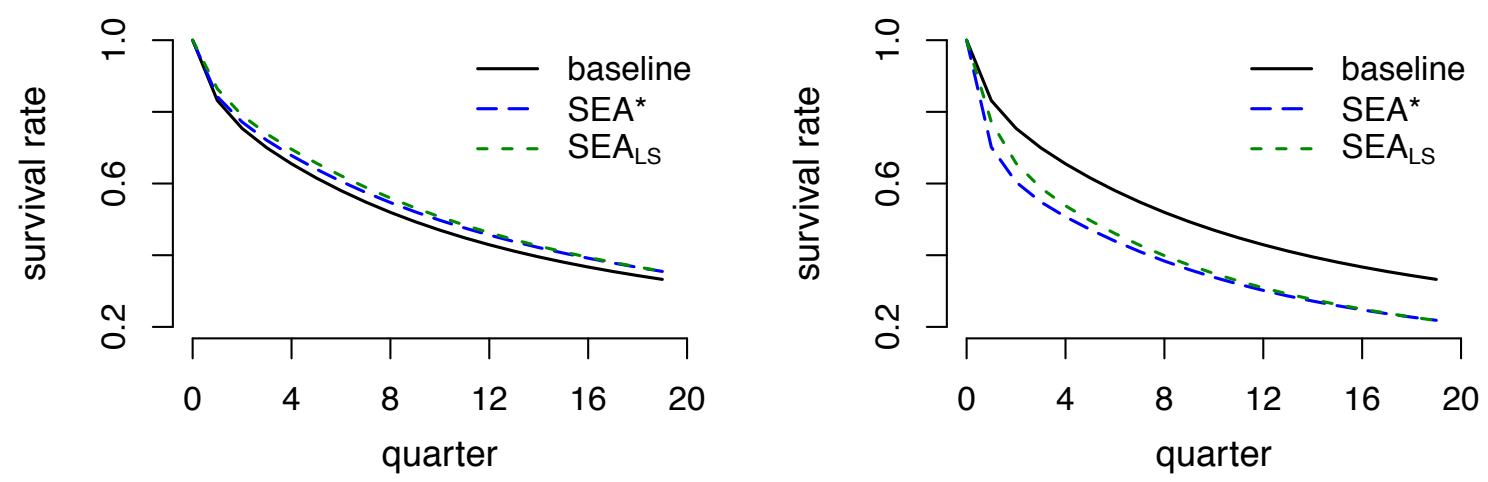

Figure 8. Survival rate for the IMG (left panel) and the EMG (right panel).

\subsection{Insurance effects and the UI system}

SEA decomposition Three reasons explain why insured unemployed individuals would not start a business in the model: it requires some business search effort costly in terms of utility; it is risky, and; it implies losing UI benefits. To support unemployed individuals in starting businesses, the SEA* combines three insurance components: (1) in case of business failure, the option of claiming any outstanding UI rights after returning to the unemployment pool; (2) a compensation that guarantees at least UI benefits in case of low but positive entrepreneurial income; (3) the provision of a supplementary income that, depending on $f$, can let them earn more than their initial UI rights. In Table 10, we disentangle the various components of this insurance policy by inspecting the effects of two alternative partial entrepreneurial insurances. Provided they were unemployed with UI rights before, the first insurance only lets entrepreneurs return to the unemployment pool if necessary and keep claiming any outstanding UI rights. As this insurance does not pay any compensation or supplement, we call it the 0-compensation

\footnotetext{
${ }^{61}$ We abstract from the additional production coming from the entrepreneur's wealth that would have been also invested in the corporate sector, especially since it represents a very small amount.
} 
case. The second partial insurance is simply a SEA with $f=0$ : the supplementary income part is removed. ${ }^{62}$

\begin{tabular}{lccc}
\hline & \multicolumn{3}{c}{ SEA policy } \\
\cline { 2 - 4 } & SEA $^{*}$ & $f=0$ & 0-compensation \\
\hline$(\Delta \%)$ Fraction entrepreneurs & 1.48 & 1.37 & 0.59 \\
$(\Delta \%)$ Fraction unemployed & -0.16 & -0.14 & 0.02 \\
$(\Delta \%)$ Fraction unemployed $\rightarrow$ new business & 11.2 & 10.0 & 8.3 \\
$(\Delta \%)$ Tax rate $\tau_{w}$ & 2.09 & 2.05 & 0.5 \\
Consumption equivalent variation $(c e v *)($ in $\%)$ & 0.061 & 0.053 & 0.021 \\
\hline \hline
\end{tabular}

Table. 10. Effect of the entrepreneurial insurance policy under SEA * and two partial insurances with respect to the baseline. Note: $(\Delta \%)$ means deviation in percent from the baseline case.

Under both partial insurances, the fraction of entrepreneurs and the fraction of unemployed individuals starting a new business increase significantly. Obviously, the effects are smaller in the 0 -compensation case: the fraction of unemployed individuals starting businesses increases by $8.3 \%$ relative to the baseline, against $11.2 \%$ with the compensation. In the $f=0$ case, the government does not provide any extra supplementary assistance when the business income is above UI benefits: this same fraction goes up by $10 \%$ and the share of entrepreneurs is reduced only by $0.11 \%$. Therefore, this subsidy part does not play a crucial role in the total effect. It is rather the insurance compensation component and the right to claim UI benefits after returning to the unemployment pool that make the SEA * effective. In particular, we stress that allowing entrepreneurs to return to the unemployment pool and keep claiming UI rights is a substantially beneficial policy for resorbing the distortion generated by a UI system favoring paid-employment, with virtually no costs. This single component accounts for $40 \%$ of the increase in the share of entrepreneurs under the SEA * , with significant occupational mobility.

The role of the UI system The specification of UI programs itself can change. For instance, the US experienced several such reforms, especially during recessions. ${ }^{63}$ We now study the interplay between alternative UI systems and the provision of SEA. In the model, both the duration of UI and the level of benefits directly affect the decision to start a business. First, the more generous the UI system (i.e. longer duration or larger benefits), the lower the incentive to exit unemployment (reflected in lower search efforts). Second, the more generous the UI system,

\footnotetext{
${ }^{62}$ This is close to the Finnish and Dutch SEA, where business income is fully deducted from UI benefits.

${ }^{63}$ As an example, in late 2009 , the UI duration was extended several times beyond the normal 26 weeks, up to a maximum of 99 weeks. Such a reform usually has a controversial effect on the unemployment rate by potentially lowering the incentive to search for a job. Here, we argue that it could also largely impact the share of entrepreneurs.
} 
the higher the opportunity cost of starting a business, since previously unemployed new entrepreneurs have to give up larger UI claims, reinforcing the bias for paid-employment. Third, a more generous UI system lets unemployed individuals accumulate more wealth in order to start their own business. ${ }^{64}$ This last effect goes in the opposite direction to the other two but our quantitative results suggest that incentive effects dominate the wealth channel. Table 11 reports the impact of alternative UI systems on occupational decisions: (1) variations of the UI $(\rho)$ and SEA $(\bar{q})$ durations from 26 weeks to either one year or 99 weeks; (2) variations of the replacement rate $(\mu)$ from $40 \%$ to either $60 \%$ or $80 \% .^{65}$

\begin{tabular}{lccccccccc}
\hline & Baseline & \multicolumn{3}{c}{ Extended UI duration } & \multicolumn{3}{c}{ Increased UI benefits } \\
\cline { 2 - 11 }$(\rho$ or $\bar{q}, \mu)$ & $(0.5,0.4)$ & \multicolumn{2}{c}{$(0.25,0.4)$} & \multicolumn{2}{c}{$(0.132,0.4)$} & \multicolumn{2}{c}{$(0.5,0.6)$} & \multicolumn{2}{c}{$(0.5,0.8)$} \\
& - & Ini. & SEA & Ini. & SEA & Ini. & SEA & Ini. & SEA \\
\hline Frac. of entrepreneurs (\%) & 8.8 & 8.63 & 8.86 & 8.49 & 8.96 & 8.6 & 8.80 & 8.41 & 8.68 \\
$\quad$ - \% increase & - & - & 2.57 & - & 4.20 & - & 2.2 & - & 3.2 \\
$\quad$ - \% insured & - & - & 5.46 & - & 8.50 & - & 2.81 & - & 2.82 \\
Frac. of unemployed (\%) & 5.0 & 5.19 & 5.17 & 5.38 & 5.36 & 5.09 & 5.07 & 5.18 & 5.15 \\
Frac. of workers (\%) & 86.2 & 86.18 & 85.97 & 86.13 & 85.68 & 86.31 & 86.13 & 86.41 & 86.17 \\
Frac. of U $\rightarrow$ E (\%) & 2.14 & 1.98 & 2.25 & 1.84 & 2.16 & 2.08 & 2.39 & 2.03 & 2.43 \\
Frac. of U $\rightarrow$ W $(\%)$ & 45.07 & 43.49 & 43.32 & 41.91 & 41.73 & 44.36 & 44.16 & 43.63 & 43.39 \\
Total production & 1.957 & 1.949 & 1.955 & 1.943 & 1.954 & 1.949 & 1.953 & 1.942 & 1.948 \\
Labor income tax (\%) & 0.902 & 1.133 & 1.173 & 1.311 & 1.381 & 1.362 & 1.391 & 1.827 & 1.870 \\
Welfare gains $\left(\mathrm{cev}^{*}\right)$ & - & - & 0.115 & - & 0.182 & - & 0.096 & - & 0.139 \\
\hline \hline
\end{tabular}

Table. 11. Effects of alternative UI systems with and without SEA * Ini. is the baseline economy without the SEA policy but with the considered change to the UI system.

When the UI duration is extended, most of the resulting unemployment rate increase is compensated by a smaller entrepreneurial fraction while corporate jobs are only very slightly reduced. On top of that, starting a business is also riskier, since it means giving up larger outstanding UI benefits while business profits are still uncertain. Consequently, the number of newly created firms and production are also reduced. Alternatively, increasing UI benefits produces a somewhat different effect: while the unemployment rate increases and the fraction

\footnotetext{
${ }^{64}$ There are also general equilibrium effects, such as increased taxes and wages, but our quantitative investigations suggest that those effects are small because unemployed agents account for a small share of the population.

${ }^{65} 26$ weeks correspond to a $\rho$ and a $\bar{q}$ set at 0.5 while a year is 0.25 and 99 weeks is 0.132 . More generous UI systems sometimes lead to $W(a, \theta, y, e)<U(a, \theta, e, i)$ for low values of $y$. We still assume that an insured unemployed individual receiving a job offer switch to paid-employment. This could reflect the fact that they can not refuse a job offer, otherwise, they lose their UI rights and get $U(a, \theta, e, n)<W(a, \theta, y, e)$. Notice also that $\mathbb{E}_{y}[W(a, \theta, y, e)]>U(a, \theta, e, i)$, therefore, they still search a job with high intensity. Alternatively, we could let agents refuse some offers, and the unemployment rate would be even larger under a very generous UI system. For simple comparison with the benchmark results, we do not explore this issue.
} 
of entrepreneurs is reduced, the share of corporate jobs increases. Indeed, higher UI benefits considerably improve the value of having a job relative to creating a business, compelling the poorest entrepreneurs into stopping their activity to search for a job. The incentives to exit unemployment are still high as the UI duration remains at 26 weeks. In the end, production is lower as there are fewer entrepreneurial firms. Under both reforms, taxes considerably increase.
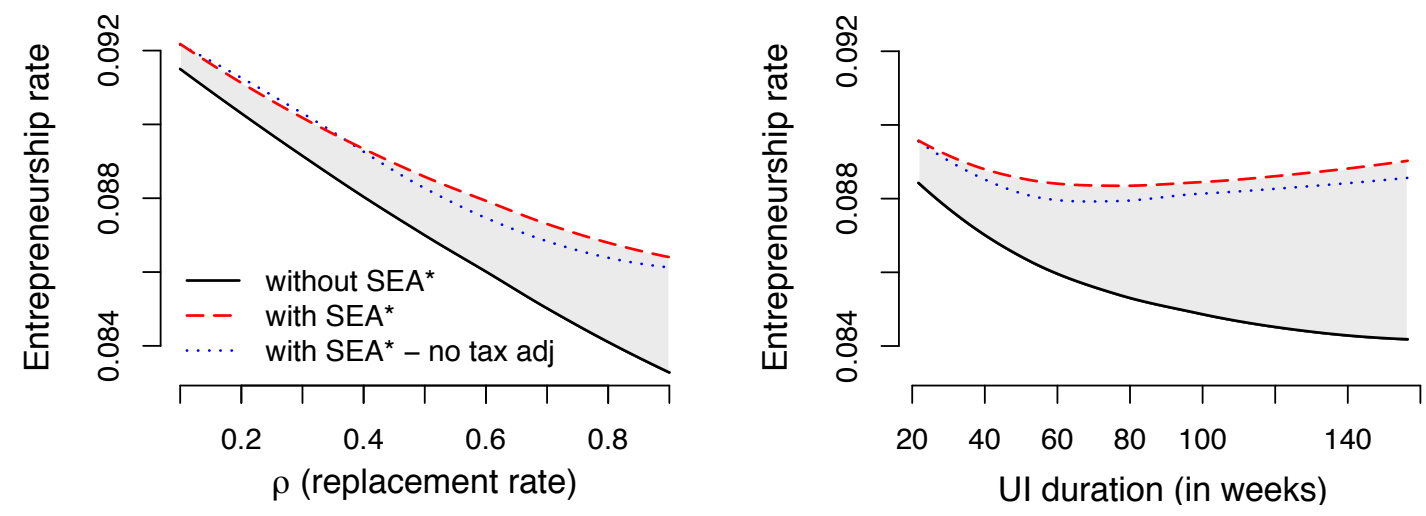

Figure 9. Effects of a more generous UI system on the entrepreneurship rate, with/without SEA*.

When the SEA is implemented, entrepreneurship, occupational mobility, and production are strongly increased as the UI system becomes more generous. Indeed, because the distortion arising from favoring paid-employment becomes stronger, the larger is the effectiveness of the SEA. Figure 9 demonstrates the interplay between the UI design and the SEA implementation. Starting from a duration of 20 weeks, increasing the UI duration (right panel) first reduces the entrepreneurship rate: at this stage, the value of unemployment (and indirectly the value of employment) is increased more than the value of entrepreneurship. However, if the UI duration is increased further, the entrepreneurship rate starts rising: the insurance value provided by the SEA over this longer period increases the value of entrepreneurship enough to compensate for the increase in the value of unemployment. This specific interaction does not appear when increasing the replacement rate as evidenced by the left panel of this Figure: the entrepreneurship rate is decreasing monotonically in that case even under the SEA. This suggests that more than the amount of insurance, it is the possibility of obtaining a regular amount over a longer duration that matters the most for entry into entrepreneurship. ${ }^{66}$ Those conclu-

\footnotetext{
${ }^{66}$ The empirical literature also seems to support the larger impact of a SEA on occupational decisions when UI is more generous. For instance, taking the case of France that has a specially more generous UI duration of 3 years (around 156 weeks), we find that SEA ${ }^{*}$ implies an increase of $6 \%$ of the share of entrepreneurs and around $11 \%$ of the entrepreneurs are insured (against $1.5 \%$ and $3 \%$ in the baseline). This corroborates the finding of Hombert et al. (2017) on the large magnitude of the DRI in France, with an increase of about $12 \%$ of the number of newly created firms. The difference can also be accounted for by a much larger unemployment rate in France as well as
} 
sions remain valid even when we do not adjust for labor income taxes. In that case, government spendings are not balanced, which lowers the value of working in the corporate sector relative to a self-employment situation. Finally, in line with the findings above, implementing a SEA program under the considered UI reforms largely enhances steady-state welfare.

\subsection{Transitional dynamics and robustness}

As it is standard in the literature with policy experiments, we compute the transition path of the economy between steady states, following a sudden and unexpected introduction of the reforms. Figure 10 depicts the dynamics. At the time of the reform, the share of entrepreneurs and labor income taxes sharply rise under all the considered reforms, while the number of corporate jobs and the unemployment rate are reduced. After 5 years, $60 \%$ of the occupational adjustment has taken place under SEA $\mathbf{L S}$ against $47 \%$ under SEA* ${ }^{*}$, and production has increased in all reforms.
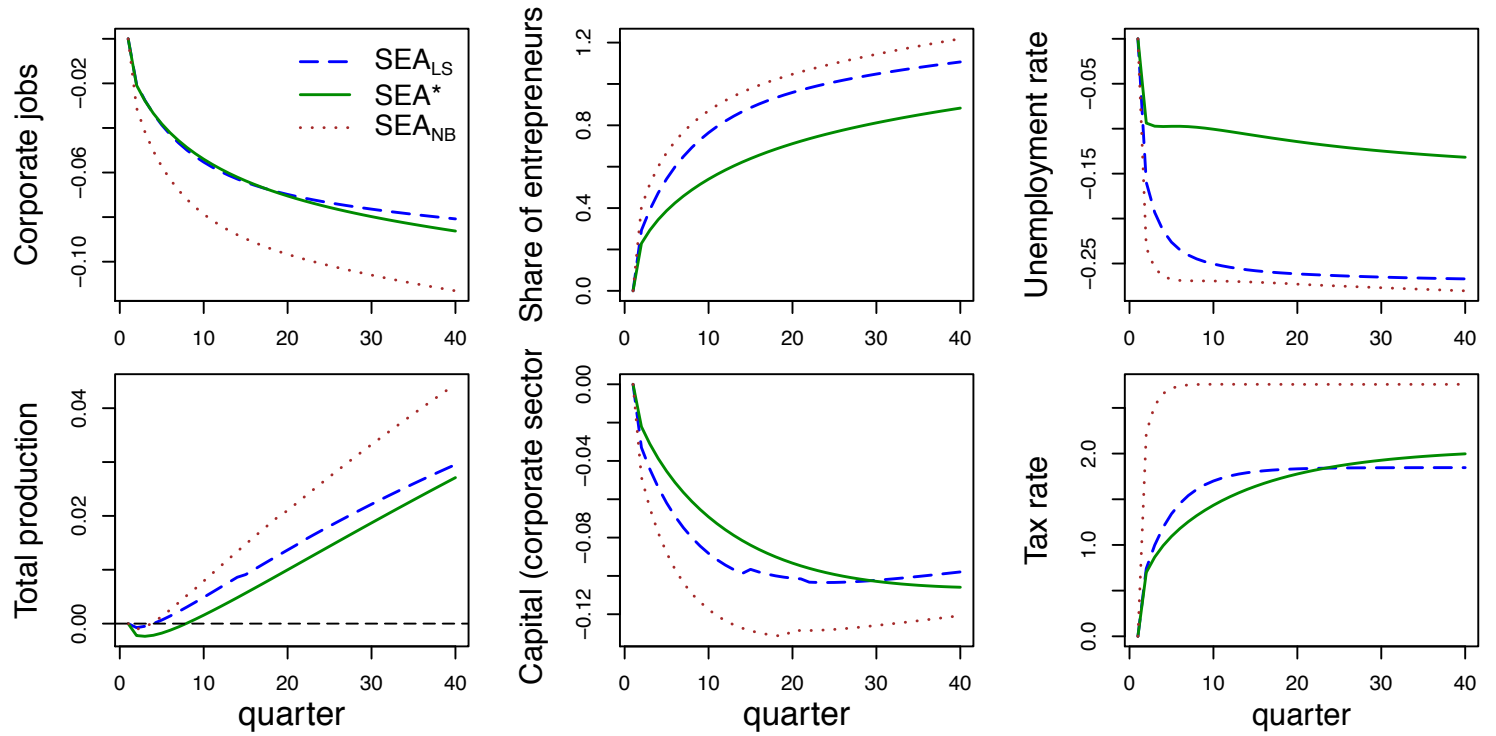

Figure 10. Transitional dynamics after an unexpected introduction of the policies.

Welfare along the transition We quantify welfare gains and losses along the transition as the ex post consumption equivalent variation $\left(\operatorname{cev}_{i}\right)$ : it quantifies whether individuals alive at the time of the reforms and with perfect knowledge about the future would prefer experiencing them

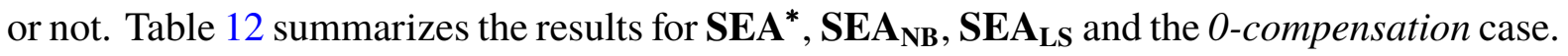
Welfare along the transition mirrors the steady-state findings. Under all reforms, richer individuals (and the least constrained to start a business) are better-off. Concerning ability, it appears a larger UI replacement rate. 
that $\mathbf{S E A}_{\mathbf{L S}}$ favors much more the low-skilled individuals, while type-dependent SEA impacts all three ability levels in a similar way, with a slight advantage for the high-skilled. Under all reforms, workers who suffer from higher taxes are less likely to support the reforms. Interestingly, because they disfavor poor and constrained individuals with larger marginal propensity to consume, the reforms do not appear to be supported by a majority. Nevertheless, the 0 compensation and the $\mathbf{S E A}_{\mathbf{L S}}$ cases, that benefits more to the (on average poorer) unskilled group, are better accepted. Overall, relative to steady-state welfare, transitional welfare gains and losses are quite small.

\begin{tabular}{|c|c|c|c|c|c|c|c|c|}
\hline \multirow{3}{*}{$\begin{array}{l}\text { Type } \\
\text { Median wealth }\end{array}$} & \multicolumn{6}{|c|}{ Ability dependent } & \multirow{2}{*}{\multicolumn{2}{|c|}{$\begin{array}{c}\text { Lump-sum } \\
\text { SEA }_{\text {LS }}\end{array}$}} \\
\hline & \multicolumn{2}{|c|}{ SEA $^{*}$} & \multicolumn{2}{|c|}{ SEA $_{N B}$} & \multicolumn{2}{|c|}{ O-compensation } & & \\
\hline & $\leq$ med. & $>$ med. & $\leq$ med. & $>$ med. & $\leq$ med. & $>$ med. & $\leq$ med. & $>$ med. \\
\hline \multicolumn{9}{|l|}{ Occupation } \\
\hline Worker & -0.016 & 0.002 & -0.024 & 0.011 & -0.007 & 0.001 & -0.016 & 0.012 \\
\hline Entrepreneur & -0.012 & 0.007 & -0.017 & 0.014 & -0.005 & 0.003 & -0.010 & 0.015 \\
\hline Unemployed & -0.016 & 0.006 & -0.024 & 0.020 & -0.007 & 0.002 & -0.016 & 0.020 \\
\hline All & -0.016 & 0.003 & -0.024 & 0.012 & -0.007 & 0.001 & -0.016 & 0.013 \\
\hline \multicolumn{9}{|l|}{$\operatorname{Ability}(\theta)$} \\
\hline Low-skilled & -0.017 & 0.004 & -0.027 & 0.012 & -0.008 & 0.003 & -0.017 & 0.026 \\
\hline Middle-skilled & -0.016 & 0.002 & -0.024 & 0.009 & -0.007 & 0.001 & -0.016 & 0.012 \\
\hline High-skilled & -0.011 & 0.005 & -0.014 & 0.014 & -0.003 & 0.001 & -0.009 & 0.010 \\
\hline All & \multicolumn{2}{|c|}{-0.006} & \multicolumn{2}{|c|}{-0.007} & \multicolumn{2}{|c|}{-0.003} & \multicolumn{2}{|c|}{-0.002} \\
\hline Fraction (in $\%$ ) cev $_{i}>0$ & \multicolumn{2}{|c|}{29.2} & \multicolumn{2}{|c|}{37.5} & \multicolumn{2}{|c|}{37.1} & \multicolumn{2}{|c|}{41.4} \\
\hline
\end{tabular}

Table. 12. Welfare over the transition (in $\% \operatorname{cev}_{i}$ ). Note: $\leq$ med. and $>$ med. refer to population masses below and above the median wealth level in the economy.

Robustness check We also considered alternative model specifications: a broader definition of entrepreneurship, preventing bankruptcy in equilibrium, an alternative specification of the business process $z$ and we find that our results are robust to these changes. For the sake of brevity, we leave the robustness discussions to the online appendix section G.

\section{Conclusion}

In this paper, we develop an incomplete markets heterogeneous agents general equilibrium model with risky entrepreneurship and search frictions to characterize occupational choices and occupational flows between entrepreneurship, paid-employment, and unemployment. The model accounts for the main empirical features about occupational flows, macroeconomic ag- 
gregates and key entrepreneurial features in the US. Both wealth and ability are major determinants of occupational choices and the model matches the magnitude of exits and entries in and out of occupations with more endogenous incentives than the literature. We extend our baseline economy to simulate a number of large scale ALMP designed to foster entrepreneurship, referred to as Self-Employment Assistance programs. The assistance provided under these reforms is shown to help reduce the bias towards paid-employment of current UI systems in the US and other countries while producing important shifts in occupational choices. As a consequence, a type-dependent and a non type-dependent SEA select very different new entrepreneurs, with the former facilitating the entry of (on average richer) higher-skilled individuals. We finally show that these reforms interplay with the UI system itself and isolate the effects of extending UI duration on the share of entrepreneurs. We point out that this model could be used to tackle a number of related questions. A careful analysis of optimal UI design accounting for entrepreneurship and SEA programs seems promising for future research. Also, simple experiments suggest that shocks affecting both the job destruction and the job finding rates in our model can account for the observed changes in occupational flows during the Great Recession.

\section{References}

Ali, Abdul, I. Elaine Allen, Candida Brush, William D. Bygrave, Julio De Castro, Julian Lange, Heidi Neck, Joseph Onochie, Ivory Phinisee, Edward Rogoff, and Albert Suhu. 2008. "What Entrepreneurs Are Up To.” Global Entrepreneurship Monitor, GERA.

Arenius, Pia, and Maria Minniti. 2005. "Perceptual Variables and Nascent Entrepreneurship." Small Business Economics, 24(3): 233-247.

Astebro, Thomas, and Jing Chen. 2014. "The entrepreneurial earnings puzzle: Mismeasurement or real?" Journal of Business Venturing, 29(1): 88-105.

Bassetto, Marco, Marco Cagetti, and Mariacristina De Nardi. 2015. "Credit Crunches and Credit Allocation in a Model of Entrepreneurship." Review of Economic Dynamics, 18(1): 53-76.

Buera, Francisco J., and Yongseok Shin. 2013. "Financial Frictions and the Persistence of History: A Quantitative Exploration.” Journal of Political Economy, 121(2): 221-272.

Cagetti, Marco, and Mariacristina De Nardi. 2006. "Entrepreneurship, Frictions, and Wealth.” Journal of Political Economy, 114(5): 835-870. 
Cagetti, Marco, and Mariacristina De Nardi. 2009. "Estate Taxation, Entrepreneurship, and Wealth." American Economic Review, 99(1): 85-111.

Caliendo, Marco. 2016. "Start-up subsidies for the unemployed: Opportunities and limitations." IZA World of Labor, , (200).

Caliendo, Marco, and Alexander Kritikos. 2009. “"I Want to, But I Also Need to": Start-Ups Resulting from Opportunity and Necessity." Institute for the Study of Labor (IZA) IZA Discussion Papers 4661.

Caliendo, Marco, and Steffen Künn. 2011. "Start-up subsidies for the unemployed: Long-term evidence and effect heterogeneity." Journal of Public Economics, 95(3-4): 311-331.

Caliendo, Marco, Jens Hogenacker, Steffen Künn, and Frank Wießner. 2015. "Subsidized startups out of unemployment: a comparison to regular business start-ups.” Small Business Economics, 45(1): 165-190.

Chatterjee, Satyajit, Dean Corbae, Makoto Nakajima, and José-Víctor Ríos-Rull. 2007. “A Quantitative Theory of Unsecured Consumer Credit with Risk of Default." Econometrica, 75(6): 1525-1589.

D'Erasmo, Pablo N., and Hernan J. Moscoso Boedo. 2012. "Financial structure, informality and development." Journal of Monetary Economics, 59(3): 286 - 302.

Ejrnæs, Mette, and Stefan Hochguertel. 2014. "Insurance, Entrepreneurial Start-Up, and Performance.” Tinbergen Institute Tinbergen Institute Discussion Papers 14-040/V.

Evans, David, and Linda S Leighton. 1989. “Some Empirical Aspects of Entrepreneurship.” American Economic Review, 79(3): 519-35.

Fairlie, Robert W., Kanika Kapur, and Susan Gates. 2011. "Is employer-based health insurance a barrier to entrepreneurship?" Journal of Health Economics, 30(1): 146 - 162.

Gschwandtner, Adelina. 2012. "Evolution of profit persistency in the USA: evidence from three periods." The Manchester School, 80(2): 172-209.

Hamilton, Barton H. 2000. "Does entrepreneurship pay? An empirical analysis of the returns to selfemployment.” Journal of Political economy, 108(3): 604-631.

Herranz, Neus, Stefan Krasa, and Anne P. Villamil. 2015. "Entrepreneurs, Risk Aversion, and Dynamic Firms.” Journal of Political Economy, 123(5): 1133 - 1176. 
Hombert, Johan, Antoinette Schoar, David Sraer, and David Thesmar. 2017. "Can Unemployment Insurance Spur Entrepreneurial Activity? Evidence from France.” HEC Paris Research Paper Working Paper FIN-2013-1020.

Hurst, Erik, and Benjamin Wild Pugsley. 2011. "What Do Small Businesses Do?” Brookings Papers on Economic Activity, 42(2 (Fall)): 73-142.

Kitao, Sagiri. 2008. "Entrepreneurship, taxation and capital investment." Review of Economic Dynamics, 11(1): 44-69.

Knaup, Amy E., and Merissa C. Piazza. 2007. "Business Employment Dynamics data: survival and longevity, II." Monthly Labor Review.

Landier, Augustin, and David Thesmar. 2008. "Financial Contracting with Optimistic Entrepreneurs." The Review of Financial Studies, 22(1): 117.

Mankart, Jochen, and Giacomo Rodano. 2015. "Personal bankruptcy law, debt portfolios, and entrepreneurship." Journal of Monetary Economics, 76: 157-172.

Poschke, Markus. 2013. "Who becomes an entrepreneur? Labor market prospects and occupational choice." Journal of Economic Dynamics and Control, 37(3): 693-710.

Quadrini, Vincenzo. 2000. "Entrepreneurship, Saving and Social Mobility.” Review of Economic Dynamics, 3(1): 1-40.

Reynolds, Paul Davidson. 2017. "When is a Firm Born? Alternative Criteria and Consequences.” Business Economics, 52(1): 41-56.

Røed, Knut, and Jens Fredrik Skogstrøm. 2013. "Unemployment Insurance and Entrepreneurship." Institute for the Study of Labor (IZA) IZA Discussion Papers 7121.

Schoar, Antoinette. 2010. "The Divide between Subsistence and Transformational Entrepreneurship." Innovation Policy and the Economy, Volume 10, 57-81. University of Chicago Press.

Shimer, Robert. 2005. "The Cyclical Behavior of Equilibrium Unemployment and Vacancies.” American Economic Review, 95(1): 25-49.

Thurik, A. Roy, Martin A. Carree, AndrÃ@ $\Subset$ van Stel, and David B. Audretsch. 2008. "Does selfemployment reduce unemployment?" Journal of Business Venturing, 23(6): 673 - 686. The Economics of Entrepreneurship. 


\section{Entrepreneurship, Labor Market Mobility and the Role of Entrepreneurial Insurance}

\section{Online Appendix}

\author{
Alexandre Gaillard \\ Toulouse School of Economics
}

\author{
Sumudu Kankanamge \\ Toulouse School of Economics
}

The online appendix is organized as follows. Section A provides additional facts about entrepreneurship relative to section 2 of the paper. Section B details the data source and the associated variables used to construct the flows between occupations, the masses of occupation and the targeted moments. Section $\mathrm{C}$ provides a full characterization of the model and section D displays the associated policy functions and the resulting stationary distributions. Section E provides additional properties of the baseline model. The full numerical implementation is detailed in section F. Finally, the robustness of our results is discussed in section G.

\section{A Facts about entrepreneurship}

\section{A.1 Fear of failure}

Figure 1 plots the relation between the fear of failure index and the self-employment rate in the US as evidenced by the data collected by the Global Entrepreneurship Monitor. This relation is discussed in section 2.1 of the paper. Additionally, Figure 2 displays the cross-sectional correlation between the fear of failure index and self-employment rate across countries.

\section{A.2 Entrepreneurial income}

Figure 3 shows that entrepreneurial income is not distributed normally but is rather extremely right-skewed. Most entrepreneurs are concentrated below and around the median income (normalized to unity here) but some of them perform extremely well while others have negative incomes. Whether we consider business or total income, the main idea is that there are potentially important risks associated with an entrepreneurial occupation. 


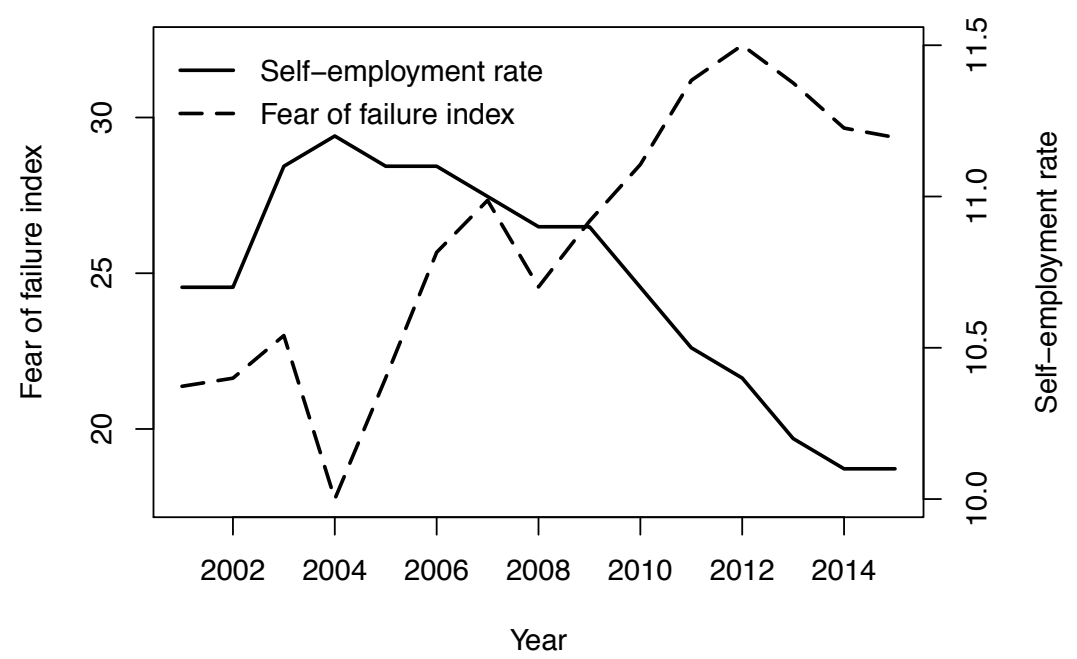

Figure 1. Fear of failure index and self-employment rate in the US. Source: Global Entrepreneurship Monitor and The Bureau of Labor Statistics (BLS). The Fear of Failure index measures the 18-64 old population perceiving good opportunities to start a business while indicating that the fear of failure would prevent them from doing so. The self-employment rate (over the working population) is the fraction of the 20-65 old population declaring themselves as self-employed (incorporated or not).

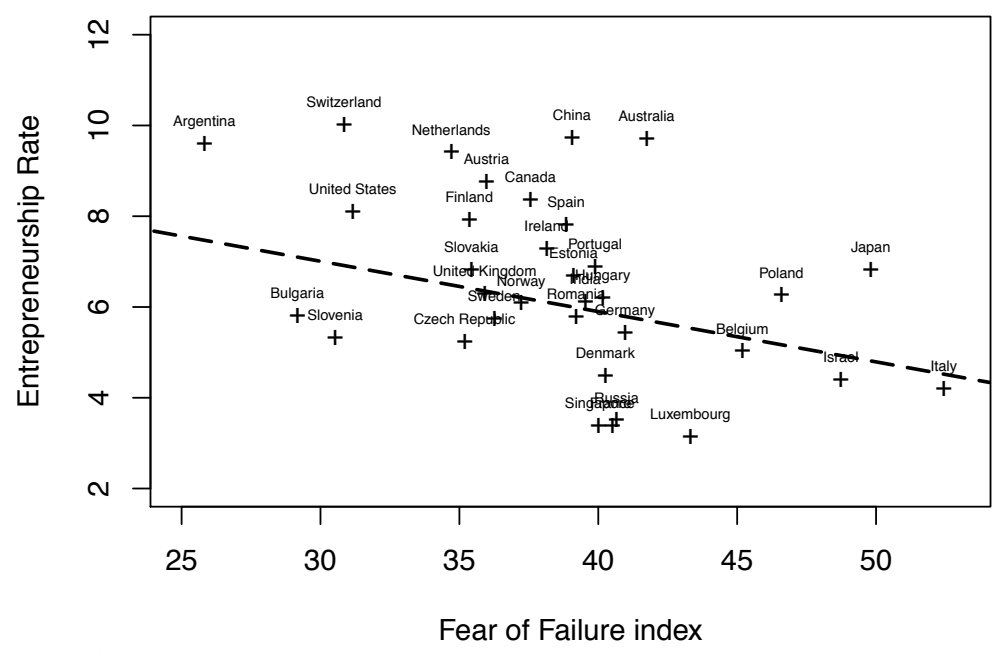

Figure 2. Fear of failure index and self-employment rate across countries.

\section{A.3 Additional occupational flows}

Figures 4, 5, 6 and 7 below provide additional occupational flow evidence from the CPS in addition to the flow plot provided and discussed in section 2.2 of the paper. Figure 4 considers the period from 2001 to 2015 and Figure 5 considers the alternative data period 2012-2015 (excluding the 2009 - 2011 unemployment peak). Figure 6 only considers full-time occupation and discards part-time occupied households from the characterization. The shapes are quite similar to the one in the core paper. We notice however that the transition from paid-employment to en- 


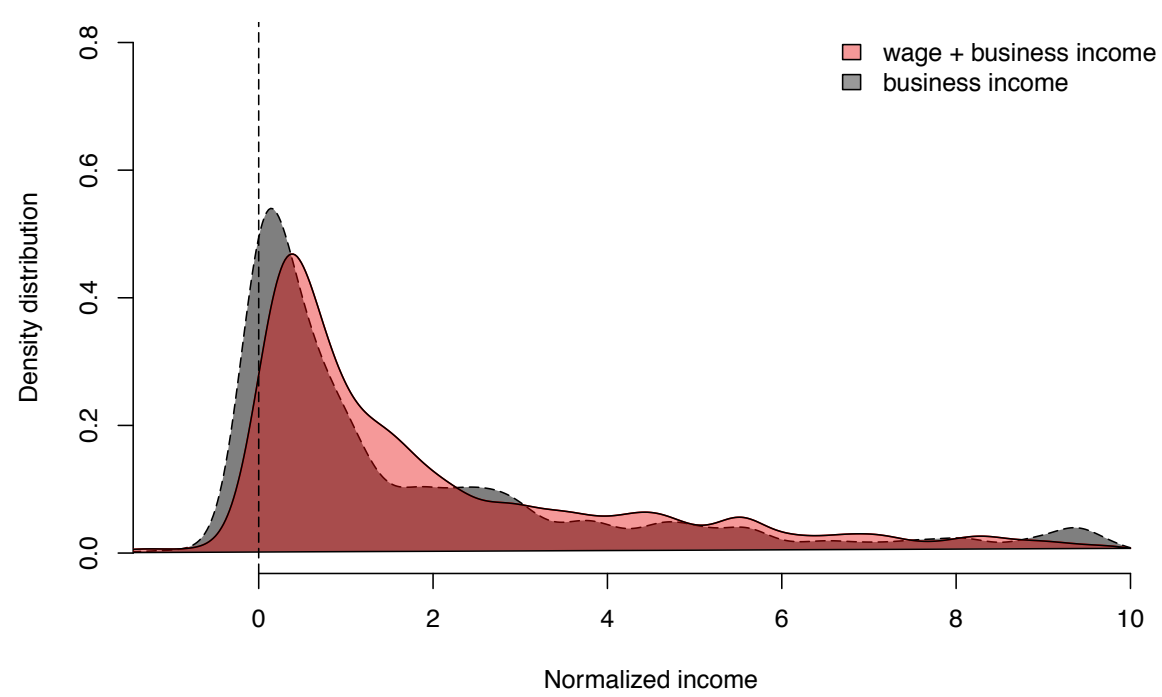

Figure 3. Entrepreneurial income normalized with respect to the median. Legend: dashed line refers to only business income and solid line to all entrepreneurial income. Source: SCF 2007.

trepreneurship is $U$-shaped in the two dimensions of wage and educational attainment for these 3 figures. Finally, in figure 7 we display the yearly transitions. It appears that when considering only self-employed business-owners, the $S$-shape of the transition from entrepreneurship to paid-employment becomes a hump-shape decreasing only for college graduates. This could be due to the fact that large movements occur at a high frequency (quarterly frequency), suggesting that many lower than high-school individuals try to run a business but fail relatively quickly (before one year). We also did compute these transitions at a monthly frequency. Shapes are similar to those at a quarterly frequency. 

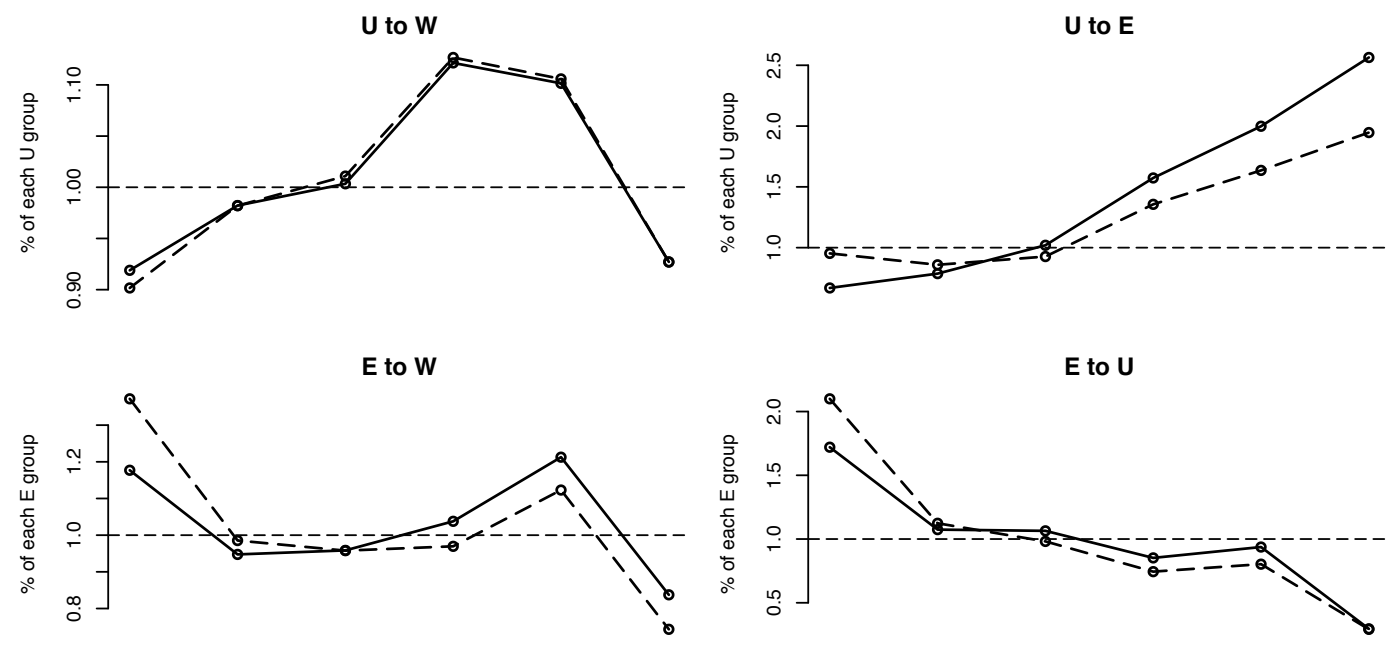

W to E
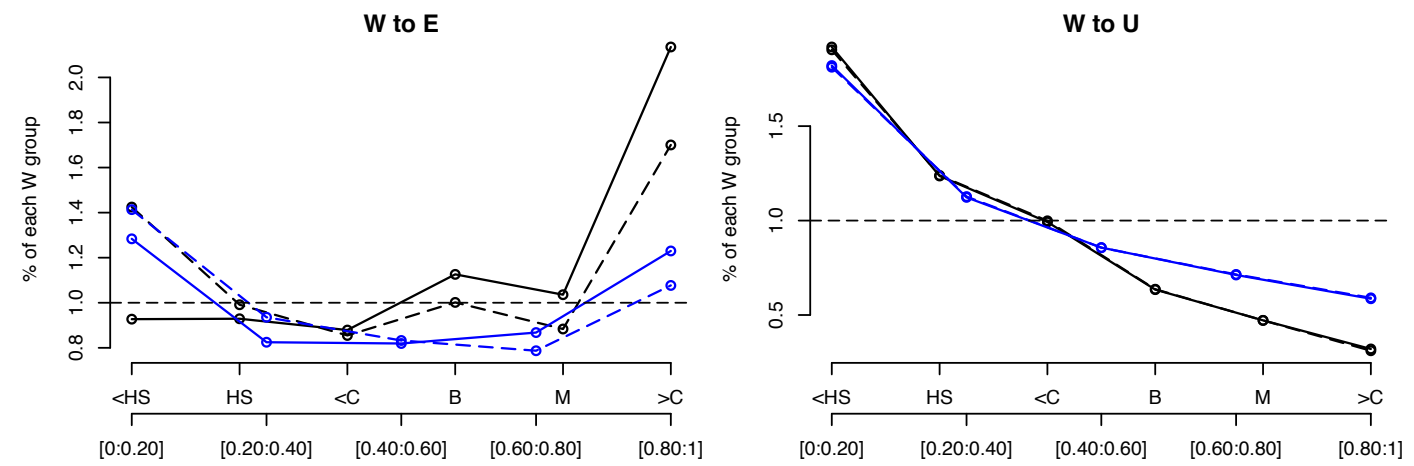

Figure 4. Quarterly flows from a given occupation to another by educational attainment (black) and wage earnings (blue), from 2001 to 2015. A dashed lines refer to self-employment only while a solid line to only self-employed business owners. Data sources: monthly basic CPS. 

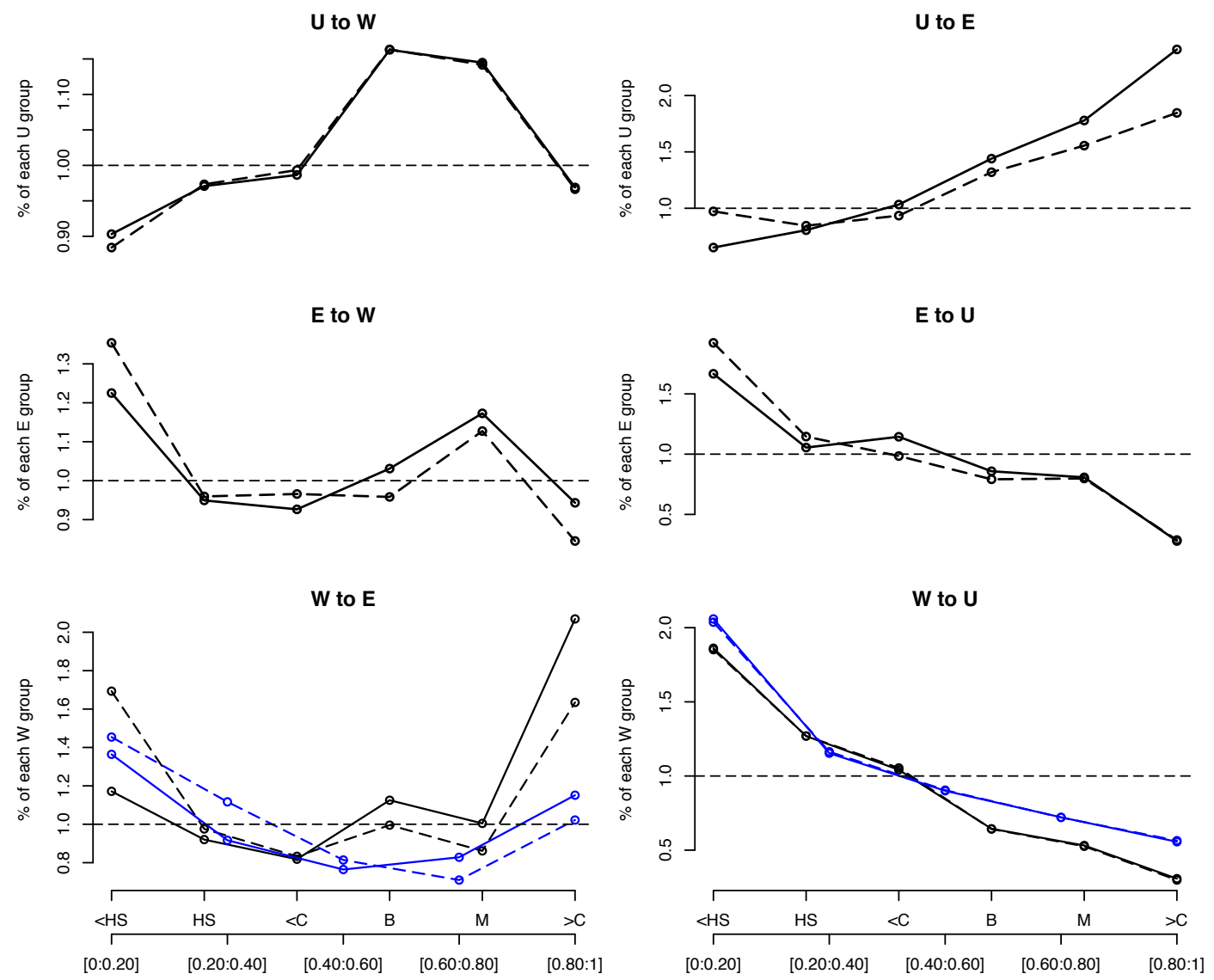

Figure 5. Quarterly flows from a given occupation to another by educational attainment (black) and wage earnings (blue), from 2012 to 2015. A dashed lines refer to self-employment only while a solid line to only self-employed business owners. Data sources: monthly basic CPS. 

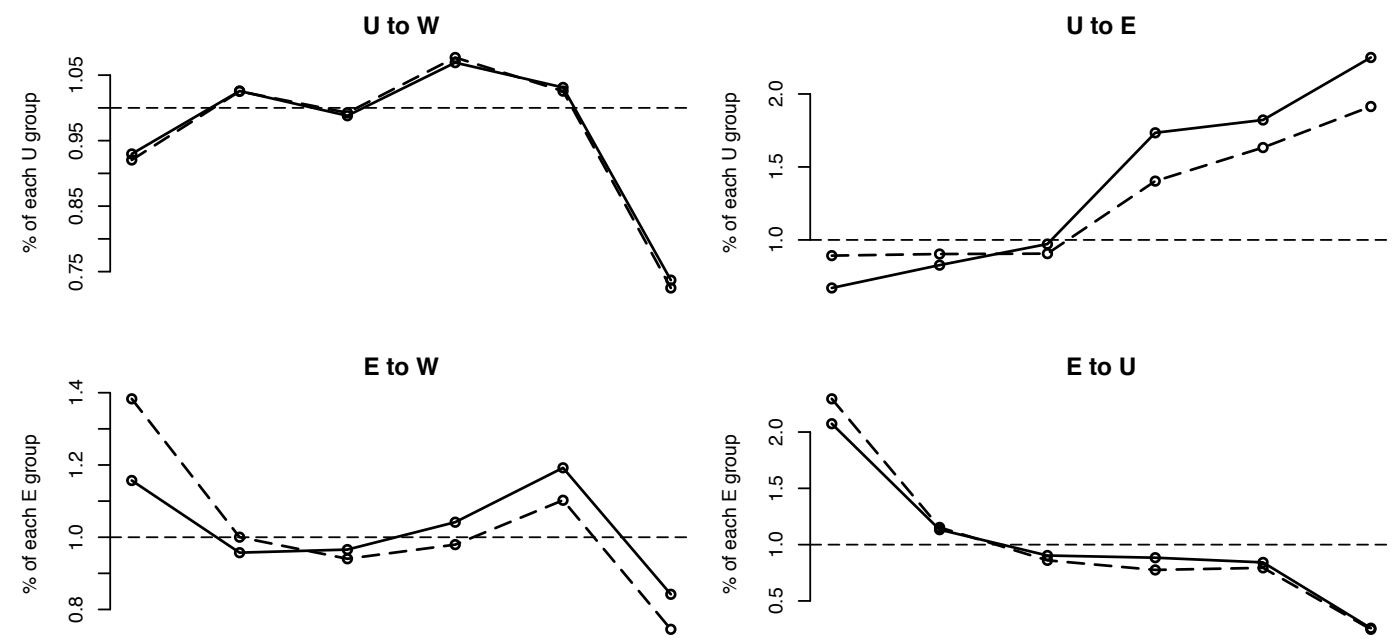

W to $E$
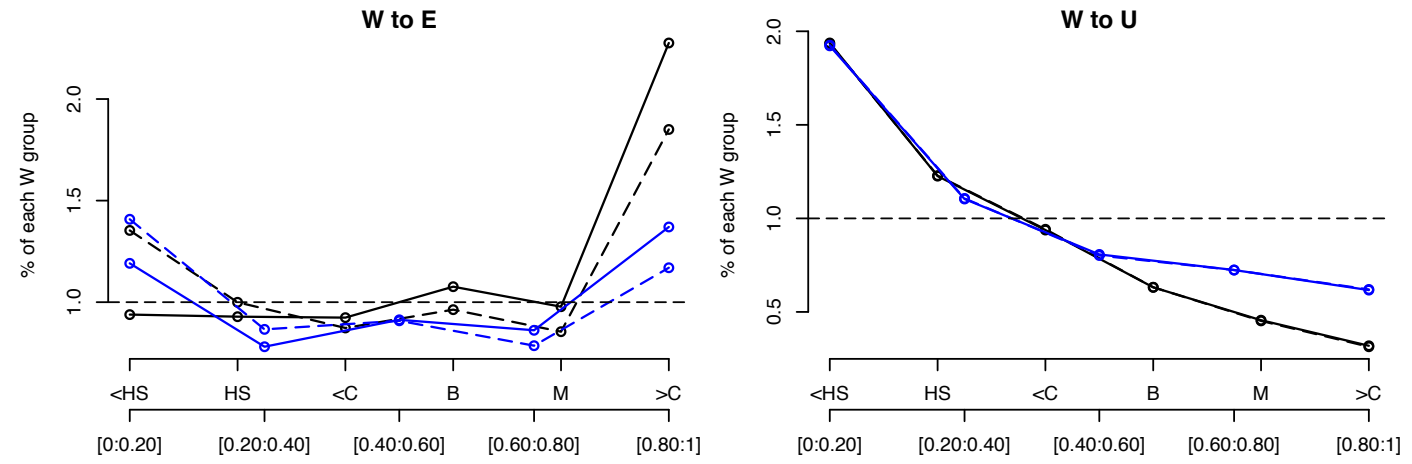

Figure 6. Quarterly flows from a given occupation to another by educational attainment (black) and wage earnings (blue), restricting to full-time movements. A dashed lines refer to self-employment only while a solid line to only self-employed business owners. Data sources: monthly basic CPS from 2001 to 2008. 

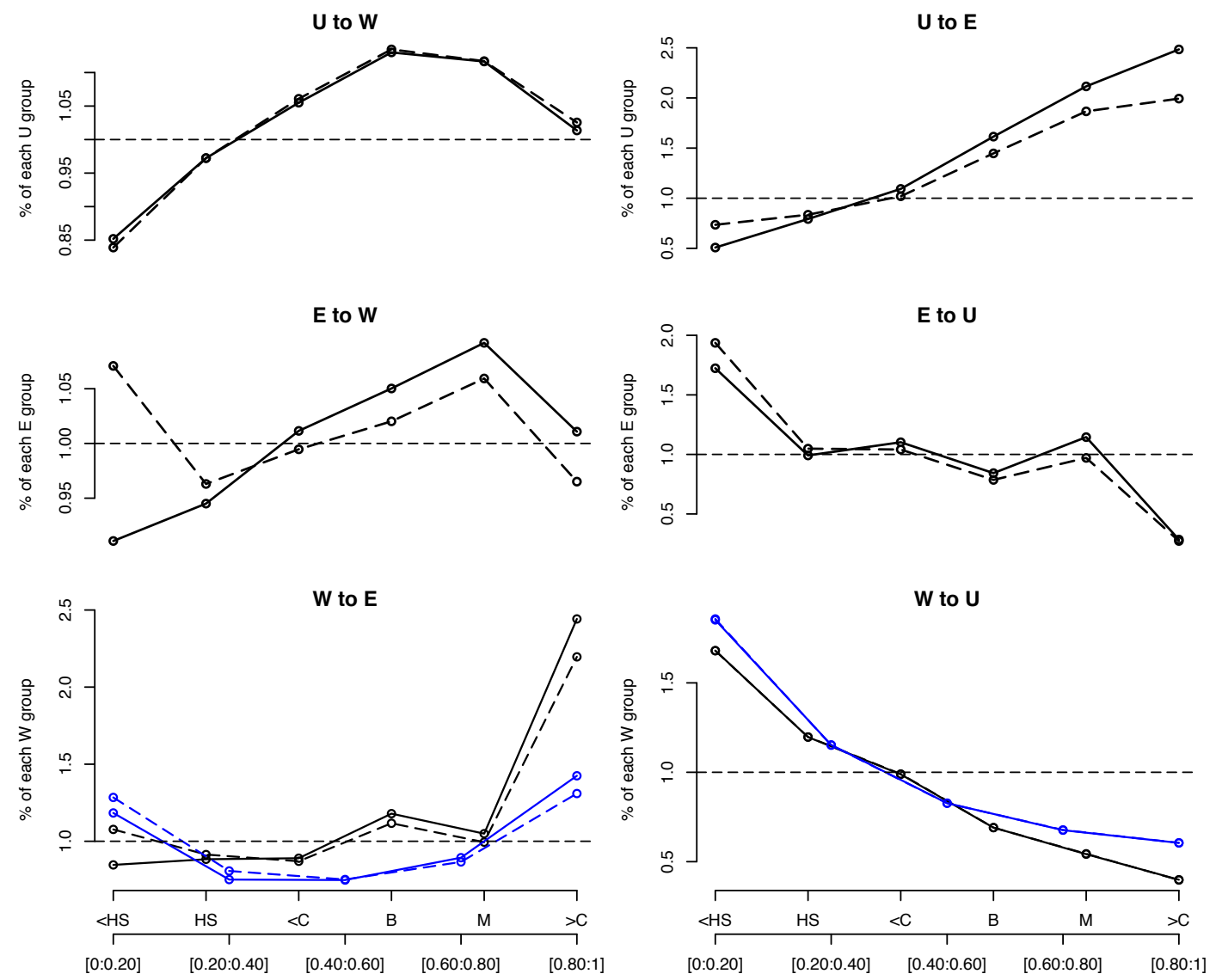

Figure 7. Yearly flows from a given occupation to another by educational attainment (black) and wage earnings (blue). A dashed lines refer to self-employment only while a solid line to only self-employed business owners. Data sources: monthly basic CPS from 2001 to 2015. 


\section{A.4 Yearly occupational flows}

Using the CPS, we also compute the yearly occupational flows from 2001 to 2008. Table 1 summarizes the results. As a comparison, Cagetti and De Nardi (2009) obtain a yearly entrepreneurial exit rate toward paid-employment of about $22 \%$ within their model and a yearly worker exit rate toward entrepreneurship of about $2.4 \%$. We find quite similar flows using our definition of an entrepreneur.

\begin{tabular}{l|ccc}
\hline & $W$ & $E$ & $U$ \\
\hline$W$ & 94.6 & 2.2 & 3.2 \\
$E$ & 21.6 & 76.9 & 1.5 \\
$U$ & 56.0 & 3.7 & 40.3 \\
\hline \hline
\end{tabular}

Table. 1. Flows between occupations during a year. Data sources: authors' computations using CPS data from 2001 to 2015 . We restrict our sample to individuals aged between 20 to 65 years old.

\section{A.5 Flows from entrepreneurship to employment and conversely by activ- ity sector and education}

In Table 2, we detail flows from employment to entrepreneurship and from entrepreneurship to employment by origin CPS main occupation and educational attainment. The majority of the lowly educated individuals leaving paid employment for entrepreneurship were occupied in the production sector or the services sector. We find the same type of flows from entrepreneurship to paid employment. However, the picture is quite different for highly educated individuals: a majority of the movers originate in the professional and related sector with management activities coming in second ${ }^{1}$. Mid education groups such as individuals with a bachelor's degree or less than a college degree seem to bridge the gap with more diverse origin sectors. This seems to suggest that individuals with different educational attainments are selected in different activity sectors associated with different performances and growth expectations.

\footnotetext{
${ }^{1}$ Professional and related occupations refer to engineers, architects, surveyors, mathematical and computer scientists, teachers, lawyers, judges etc. A complete definition is available in the BLS documentation.
} 


\begin{tabular}{lrrrrrr}
\hline Employment to entrepreneurship flow (\%) & $<$ HS & HS & $<$ C & B & M & $>$ C \\
\hline Professional and related & 1 & 6 & 15 & 29 & 51 & 77 \\
Management, business, and financial occupations & 6 & 9 & 16 & 29 & 29 & 16 \\
Sales and related & 9 & 11 & 15 & 18 & 10 & 4 \\
Service & 25 & 19 & 16 & 6 & 4 & 2 \\
Production, maintenance, and repair & 40 & 31 & 17 & 6 & 2 & 0 \\
Transportation and material moving & 10 & 8 & 6 & 2 & 0 & 0 \\
Others & 9 & 16 & 15 & 10 & 6 & 1 \\
\hline Entrepreneurship to employment flow (\%) & $<\mathrm{HS}$ & $\mathrm{HS}$ & $<\mathrm{C}$ & $\mathrm{B}$ & $\mathrm{M}$ & $>\mathrm{C}$ \\
\hline Professional and related & 1 & 4 & 11 & 19 & 35 & 72 \\
Management, business, and financial occupations & 16 & 22 & 24 & 33 & 35 & 17 \\
Sales and related & 10 & 15 & 19 & 24 & 16 & 5 \\
Service & 24 & 16 & 17 & 7 & 4 & 1 \\
Production, maintenance, and repair & 31 & 25 & 16 & 8 & 5 & 3 \\
Transportation and material moving & 11 & 7 & 3 & 2 & 2 & 1 \\
Others & 7 & 11 & 10 & 6 & 5 & 2 \\
\hline \hline
\end{tabular}

Table. 2. Flows from employment to entrepreneurship and from entrepreneurship to employment by origin sector educational attainment. Data sources: authors' own computations using CPS data from 2001 to 2008, defining entrepreneurs as self-employed business owners. Category "others" refers to individuals meeting no other condition and office and administrative support.

\section{B Data: additional elements}

In this section, we detail additional elements about our sample selection. The main discussion about data elements is conducted in section 2 and Appendix A of the core paper.

\section{B.1 Current Population Survey: sample details}

We use the CPS from 2001 to 2008 to compute masses and transitions between occupations. We restrict our sample to the population aged between 20 and 65 years old. Quarterly probability to exit a given occupation to another one is computed using all months from 2001 to 2008 in order to boost sample sizes. We end up with a panel of around 7 millions of matched individuals. In order to control for false matches, we construct a specific individual identifier that controls for age, sex and US state. Probabilities are multiplied by the first-month respondent weight (PWCMPWG) to generate a numeric value for the fraction of individuals in a specific occupation leaving to another occupation. Finally, we take the weekly earnings as a measure of wage.

Worker We classify as a worker an individual who currently work in a job or who declares being temporarily absent from a job (PEMLR $=1$ or 2 , and PEIO1COW $=1: 5$ or 8 ). 
Unemployed individual Individuals classified as unemployed are those who do not have a job, but have actively looked for one in the preceding 4 weeks (except for temporary illness), and are currently available for work. According to the Bureau of Labor Statistics (BLS), actively looking for work may consist in contacting an employer, a university or an employment center (job interviews, submitting resumes, answering job advertisements, checking unions or professional registers, etc.). Workers expecting to be recalled from temporary layoffs are counted as unemployed whether or not they have engaged in a specific job seeking activity (PEMLR $=3$ or 4 ). We also count as unemployed all individuals marginally attached to the labor force. Those individuals declare wanting a job (PRWNTJOB $=1)$, are currently available for work (PEDWAVL $=1$ ), have looked for a job in the last 12 months (even if they did not actively search in the 4 weeks preceding the interview for various reasons) (PRJOBSEA $=1,2$ or 3). Such individuals are likely to be represented in our model, since we account for individuals that could search a relatively small amount of time, which may classify them as not in the labor force following the BLS definition.

Entrepreneur In the case of an entrepreneur, we use a definition similar to Cagetti and De Nardi (2006). Using the CPS, we define an entrepreneur as a self-employed (incorporated or unincorporated) worker (PEIO1COW $=6$ or 7$)$, who currently work $($ PEMLR $=1$ or 2$)$ and own his business (HUBUS =1). We control business ownership by creating a specific variable that indicates whether or not the individual was owning his firm from 2001 to 2008, allowing us to control for measurement errors arising in the survey ${ }^{2}$. The share of entrepreneurs varies between $8.5 \%$ to $11 \%$ (relative to the population of workers, entrepreneurs and unemployed) depending of the assumption considered and the period.

\section{B.2 Survey of Consumer Finance}

We use the SCF 2001, 2004 and 2007 waves in order to compute various moments relative to entrepreneurship. To be consistent with our CPS sample, we restrict the definition of an entrepreneur to individuals declaring being self-employed and owning a business (that they

\footnotetext{
${ }^{2}$ If we do not construct this additional variable, the flow from entrepreneurship to paid-employment during a quarter jump to $16 \%$, which is inconsistent with yearly flows (see Cagetti and De Nardi (2006)). Therefore, our definition captures a part of self-employment that is not business ownership, but this is more consistent with resulting flows.
} 
actively work in) with at least $5000 \$$ invested in $\mathrm{it}^{3}$. In table 3, we report those SCF moments that can be compared to those obtained with the model.

\begin{tabular}{l|ccc|c|c}
\hline X / SCF & $\mathbf{2 0 0 1}$ & $\mathbf{2 0 0 4}$ & $\mathbf{2 0 0 7}$ & Average & Model \\
\hline Share of entrepreneurs (in \%) & 8.8 & 8.5 & 9.1 & 8.8 & 8.8 \\
Fraction of unemployed (in \%) & 4.2 & 5.2 & 5.2 & 4.9 & 5.0 \\
Ratio of median net worth (entrepreneur to worker) & 7.3 & 8.7 & 7.5 & 7.8 & 8.1 \\
Ratio of median net worth (entrepreneur to all population) & 6.2 & 7.2 & 6.6 & 6.7 & 6.2 \\
Ratio of median income (entrepreneur to worker) & 1.71 & 1.67 & 1.57 & 1.65 & 1.66 \\
Fraction of pop. with net worth < 1/10 of median (in \%) & 21.1 & 22.2 & 23.43 & 22.2 & 15.2 \\
Gini coefficient - wealth & 0.81 & 0.82 & 0.82 & 0.82 & 0.63 \\
Fraction of capital hold by entrepreneurs (in \%) & 28.5 & 30 & 31.5 & 30 & 29.4 \\
Ratio of median entrepreneurs' debt to entrepreneurs' earnings & 0.95 & 1.37 & 1.59 & 1.3 & 0.93 \\
Ratio of median ent. income to ent. net worth (in \%) & 0.166 & 0.128 & 0.11 & 0.134 & 0.106 \\
Ratio of median worker income to worker net worth (in \%) & 0.72 & 0.73 & 0.60 & 0.68 & 0.63 \\
\% of entrepreneurs with zero or negative income (in \%) & 0.05 & 0.8 & 2.8 & 1.2 & 2.7 \\
\hline \hline
\end{tabular}

Table. 3. Various moments using different SCF waves as compared to the baseline model.

\section{B.3 Part-time versus full-time movements}

We display in table 4 the full transition matrix accounting for full and part-time occupations. We class an individual in a part-time occupation when she is working less than 20 hours per week. It appears that individuals working part-time are likely to remain in a part-time occupation (the probability is around 60\%). Nonetheless, full-time workers are unlikely to become parttime workers or entrepreneurs whereas full-time entrepreneurs have a chance to become a parttime entrepreneurs. This could be driven, for instance, by a lack of production opportunities forcing entrepreneurs to only work part-time. Overall, the flows of full-time entrepreneurs and workers do not seem to be affected when we distinguish part-time and full-time.

\begin{tabular}{cccccc}
\hline & \multicolumn{5}{c}{ Transition (\%) } \\
& $W_{F}$ & $W_{P}$ & $E_{F}$ & $E_{P}$ & $U$ \\
\hline$W_{F}$ & 95.34 & 2.23 & 0.39 & 0.05 & 1.98 \\
$W_{P}$ & 32.99 & 61.38 & 0.48 & 0.74 & 4.42 \\
$E_{F}$ & 4.00 & 0.32 & 90.44 & 4.42 & 0.82 \\
$E_{P}$ & 4.33 & 3.67 & 31.34 & 58.5 & 2.16 \\
$U$ & 39.68 & 7.67 & 1.70 & 0.69 & 50.25 \\
\hline \hline
\end{tabular}

Table. 4. Flows between occupations for different definitions of entrepreneurship per quarter. Data sources: authors' own computations using CPS data from 2001 to 2008.

\footnotetext{
${ }^{3}$ The magnitude of the moments are quite similar under different assumptions for this value. We impose a restriction of $5000 \$$ to reduce misreporting effects and to be more consistent with our CPS sample. Moreover, note that this definition of an entrepreneur selects individuals that are on average better off than the average of all self-employed.
} 


\section{B.4 Not in the labor force (NLF)}

In the baseline model, we are computing the flows between three occupations: entrepreneurship, paid-employment and unemployment. We therefore abstract from non-participation. This assumption might create a bias. Table 5 reports the flows between occupations accounting for NLF individuals. There are two main observations. First, entrepreneurial and worker flows are relatively unchanged when we take into account the NLF population. Concerning the unemployment flows, we note that a substantial fraction of unemployed individuals falls into a NLF status for various reasons (discouragement, not actively searching for a job, not directly available for work, etc.). At the same time, an important fraction of the NLF population seems to switch between employment and unemployment. This may indicate that some of them are still attached to the labor force if an opportunity of work becomes available. This could be due to recently graduated young individuals or long-run and discouraged unemployed individuals who finally find a job, without actively looking for it.

\begin{tabular}{l|ccc|ccc|c}
\hline & \multicolumn{3}{|c}{ Transition (without NLF) } & \multicolumn{4}{c}{ Transition (with NLF) } \\
& $W$ & $E$ & $U$ & $W$ & $E$ & $U$ & $N L F$ \\
\hline$W$ & 97.35 & 0.50 & 2.15 & 94.17 & 0.48 & 2.08 & 3.27 \\
$E$ & 4.8 & 94.22 & 0.99 & 4.62 & 90.67 & 0.95 & 3.76 \\
$U$ & 47.36 & 2.4 & 50.25 & 36.61 & 1.85 & 38.84 & 22.70 \\
\hline$N L F$ & - & - & - & 8.50 & 1.08 & 3.66 & 86.77 \\
\hline \hline
\end{tabular}

Table. 5. Flows in percentage between occupations during a quarter, taking into account not in the labor force (NLF) individuals. Data sources: flows computed using the monthly basic CPS from 2001 to 2008. We restrict our sample to individuals aged between 20 to 65 .

\section{Detailed model characterization}

In this section, we provide detailed value functions characterizations to support the more compact form used in sections 3.3, 3.4 and 3.5 of the core paper. For convenience, we note $W$ the value function associated with a worker, $U$ with an unemployed individual and $E$ an entrepreneur. We characterize here the credit status with the superscript $e$ and the insurance status with the subscript $j$, except for a worker who is by definition always insured. The future values of those value functions are respectively noted:

$$
W^{e \prime}=W\left(a^{\prime}, \theta^{\prime}, y^{\prime}, e^{\prime}\right), \quad U_{j}^{e \prime}=U\left(a^{\prime}, \theta^{\prime}, e^{\prime}, j\right), \quad E_{j}^{e \prime}=E\left(a^{\prime}, \theta^{\prime}, z^{\prime}, e^{\prime}, j\right)
$$


As with the simplified notations of the model, the continuation value $\mathcal{E}_{j}^{e \prime}$ defines the future value of a new entrepreneur starting a business with insurance status $j$ and credit status $e$.

Workers Following the notations of the paper, we can write the value function of a worker in details as follows:

$$
\begin{aligned}
\begin{array}{l}
W(a, \theta, y, e)=\max _{c, a^{\prime}, s_{e}} u\left(c, 0, s_{e}\right)+\beta \sum_{\theta^{\prime} \in \Theta} \sum_{y^{\prime} \in \mathcal{Y}} \pi\left(y^{\prime} \mid y\right) \pi\left(\theta^{\prime} \mid \theta\right) \\
\left\{( \mathbb { 1 } _ { e = A } + \phi \mathbb { 1 } _ { e = C } ) \left[(1-\eta)\left(\pi_{e} \max \left\{W^{A \prime}, \mathcal{E}_{n}^{A \prime}\right\}+\left(1-\pi_{e}\right) W^{A \prime}\right)\right.\right. \\
\left.+\eta\left(\pi_{e} \max \left\{U_{i}^{A \prime}, \mathcal{E}_{i}^{A \prime}\right\}+\left(1-\pi_{e}\right) U_{i}^{A \prime}\right)\right] \\
+(1-\phi) \mathbb{1}_{e=C}\left[(1-\eta)\left(\pi_{e} \max \left\{W^{C \prime}, \mathcal{E}_{n}^{C \prime}\right\}+\left(1-\pi_{e}\right) W^{C \prime}\right)\right. \\
\left.\left.+\eta\left(\pi_{e} \max \left\{U_{i}^{C \prime}, \mathcal{E}_{i}^{C \prime}\right\}+\left(1-\pi_{e}\right) U_{i}^{C \prime}\right)\right]\right\}
\end{array}
\end{aligned}
$$

\section{s.t. (2), (3), (4)}

Notice that when $e=A$, then $\pi_{c}\left(e^{\prime}=A \mid e=A\right)=1$. Hence a worker with access to the credit market remains non excluded next period. In the other case, if $e=C$, then $\pi_{c}\left(e^{\prime}=A \mid e=\right.$ $C)=\phi$. The simplified notations combines those probability in the expectation operator.

Unemployed individual Following the notations of the paper, we can write the value function of an unemployed individual in details as follows:

$$
\begin{aligned}
U(a, \theta, e, j)=\max _{c, a^{\prime}, s_{w}, s_{e}} u\left(c, s_{w}, s_{e}\right)+\beta \sum_{\theta^{\prime} \in \Theta} \sum_{y^{\prime} \in \mathcal{Y}} \Pi_{y}\left(y^{\prime}\right) \pi\left(\theta^{\prime} \mid \theta\right) \\
\left\{( \mathbb { 1 } _ { e = A } + \phi \mathbb { 1 } _ { e = C } ) \left[\pi_{w}\left(\left(1-\pi_{e}\right) W^{A \prime}+\pi_{e} \mathcal{U}_{j}^{A}(W, E)\right)\right.\right. \\
\left.\quad+\left(1-\pi_{w}\right)\left(\pi_{e} \mathcal{U}_{j}^{A}(U, E)+\left(1-\pi_{e}\right) \mathcal{U}_{j}^{A}(U)\right)\right] \\
+(1-\phi) \mathbb{1}_{e=C}\left[\pi_{w}\left(\left(1-\pi_{e}\right) W^{C \prime}+\pi_{e} \mathcal{U}_{j}^{C}(W, E)\right)\right. \\
\left.\left.+\left(1-\pi_{w}\right)\left(\pi_{e} \mathcal{U}_{j}^{C}(U, E)+\left(1-\pi_{e}\right) \mathcal{U}_{j}^{C}(U)\right)\right]\right\}
\end{aligned}
$$


s.t.

$$
\begin{aligned}
& \mathcal{U}_{j}^{e \prime}(W, E)=\mathbb{1}_{\{j=i\}}\left((1-\rho) \max \left\{W^{e \prime}, \mathcal{E}_{i}^{e \prime}\right\}+\rho \max \left\{W^{e \prime}, \mathcal{E}_{n}^{e \prime}\right\}\right)+\mathbb{1}_{\{j=n\}} \max \left\{W^{e \prime}, \mathcal{E}_{n}^{e \prime}\right\} \\
& \mathcal{U}_{j}^{e \prime}(U, E)=\mathbb{1}_{\{j=i\}}\left((1-\rho) \max \left\{U_{i}^{e \prime}, \mathcal{E}_{i}^{e \prime}\right\}+\rho \max \left\{U_{n}^{e \prime}, \mathcal{E}_{n}^{e \prime}\right\}\right)+\mathbb{1}_{\{j=n\}} \max \left\{U_{n}^{e \prime}, \mathcal{E}_{n}^{e \prime}\right\} \\
& \mathcal{U}_{j}^{e \prime}(U)=\mathbb{1}_{\{j=i\}}\left((1-\rho) U_{i}^{e \prime}+\rho U_{n}^{e \prime}\right)+\mathbb{1}_{\{j=i\}} U_{n}^{e \prime}
\end{aligned}
$$

$(6),(7),(3),(4)$

With $\rho$ the probability that an unemployed individual loses her UI rights next period. The probability of getting the transitory shock $y^{\prime}$ is given by the invariant probability distribution $\Pi_{y}$ and the shock is known before the decision to take the job.

\section{Non excluded entrepreneur - repayment case}

$$
\begin{aligned}
R(a, k, \theta, z, j)=\max _{c, a^{\prime}, s_{w}} u\left(c, s_{w}, 0\right)+\beta \sum_{\theta^{\prime} \in \Theta} \sum_{y^{\prime} \in \mathcal{Y}} \Pi_{y}\left(y^{\prime}\right) \pi\left(\theta^{\prime} \mid \theta\right) \\
\quad\left\{\left(\mathbb{1}_{\{j=i\}} q+\mathbb{1}_{\{j=n\}}\right)\left(\pi_{w} \max \left\{W^{A \prime}, E_{n}^{A \prime}\right\}+\left(1-\pi_{w}\right) \max \left\{U_{n}^{A \prime}, E_{n}^{A \prime}\right\}\right)\right. \\
\left.\quad+\mathbb{1}_{\{j=i\}}(1-q)\left(\pi_{w} \max \left\{W^{A \prime}, E_{i}^{A \prime}\right\}+\left(1-\pi_{w}\right) \max \left\{U_{i}^{A \prime}, E_{i}^{A \prime}\right\}\right)\right\}
\end{aligned}
$$

s.t. (3), (7), (11), (12)

Such an entrepreneur keeps her access to the credit market next period.

\section{Non excluded entrepreneur - bankruptcy case}

$$
\begin{aligned}
B(a, k, \theta, z, j)=\max _{c, a^{\prime}, s_{w}} u\left(c, s_{w}, 0\right)+\beta \sum_{\theta^{\prime} \in \Theta} \sum_{y^{\prime} \in \mathcal{Y}} \Pi_{y}\left(y^{\prime}\right) \pi\left(\theta^{\prime} \mid \theta\right) \\
\left\{\pi_{w} W^{C \prime}+\left(1-\pi_{w}\right)\left(\left(\mathbb{1}_{\{j=i\}} q+\mathbb{1}_{\{j=n\}}\right) U_{n}^{C \prime}+\mathbb{1}_{\{j=i\}}(1-q) U_{i}^{C \prime}\right)\right\}
\end{aligned}
$$

s.t. (3), (7), (14), (15)

Such an entrepreneur is excluded from the credit market next period. 


\section{Excluded entrepreneur}

$$
\begin{aligned}
\hat{E}(a, k, \theta, z, j)=\max _{c, a^{\prime}, s_{w}} u\left(c, s_{w}, 0\right)+\beta \sum_{\theta^{\prime} \in \Theta} \sum_{y^{\prime} \in \mathcal{Y}} \Pi_{y}\left(y^{\prime}\right) \pi\left(\theta^{\prime} \mid \theta\right) & \\
\left\{\left(\mathbb{1}_{\{j=i\}} q+\mathbb{1}_{\{j=n\}}\right)(\right. & (1-\phi)\left[\pi_{w} \max \left\{W^{C \prime}, E_{n}^{C \prime}\right\}+\left(1-\pi_{w}\right) \max \left\{U_{n}^{C \prime}, E_{n}^{C \prime}\right\}\right] \\
& \left.\quad+\phi\left[\pi_{w} \max \left\{W^{A \prime}, E_{n}^{A \prime}\right\}+\left(1-\pi_{w}\right) \max \left\{U_{n}^{A \prime}, E_{n}^{A \prime}\right\}\right]\right) \\
+\mathbb{1}_{j=i}(1-q)( & (1-\phi)\left[\pi_{w} \max \left\{W^{C \prime}, E_{i}^{C \prime}\right\}+\left(1-\pi_{w}\right) \max \left\{U_{i}^{C \prime}, E_{i}^{C \prime}\right\}\right] \\
& \left.\left.+\phi\left[\pi_{w} \max \left\{W^{A \prime}, E_{i}^{A \prime}\right\}+\left(1-\pi_{w}\right) \max \left\{U_{i}^{A \prime}, E_{i}^{A \prime}\right\}\right]\right)\right\}
\end{aligned}
$$

Subject to: (3), (7), (20), (21)

$\phi$ is the probability to recover the access to the credit market.

\section{Policy functions and resulting distributions}

\section{D.1 Search policy functions}

In figure 8 and 9, we report the search policy functions of workers, entrepreneurs and unemployed individuals generated by the baseline model and discussed in section 5 of the core paper.
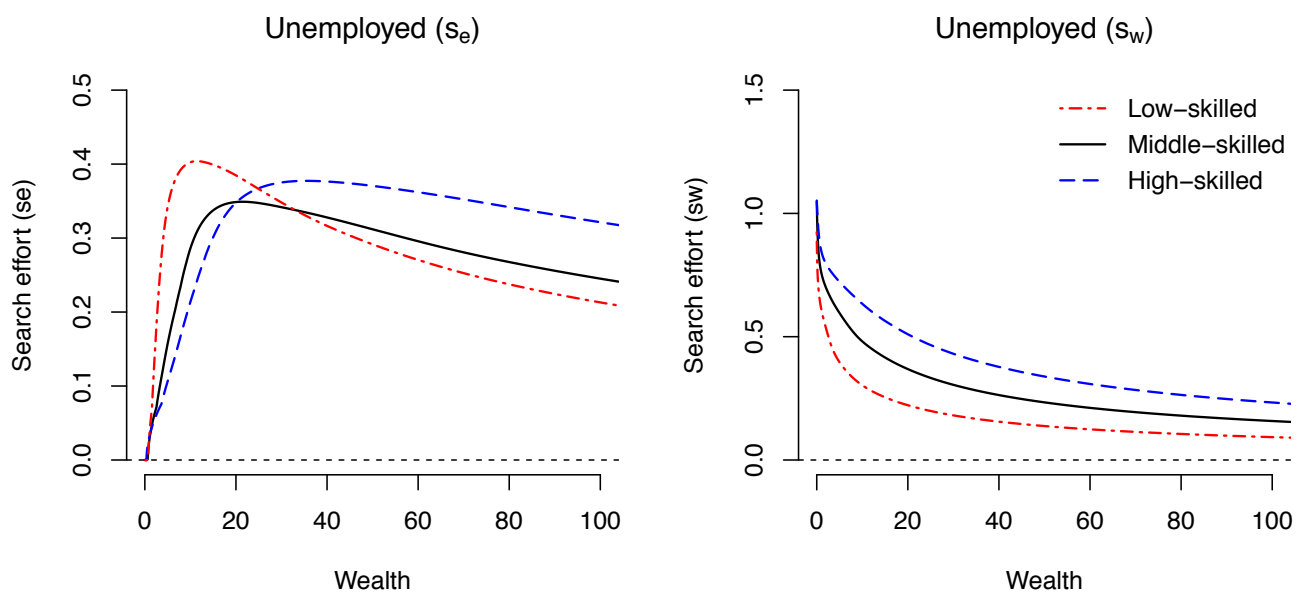

Figure 8. Business (left) and job (right) optimal search efforts for insured unemployed individuals. 
Worker $\left(\mathrm{s}_{\mathrm{e}}\right)$

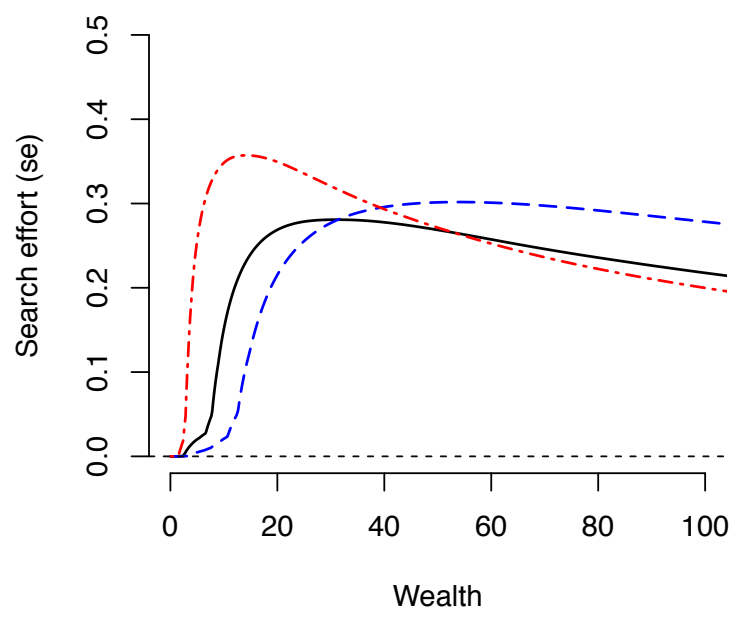

Entrepreneur $\left(\mathrm{s}_{\mathrm{w}}\right)$

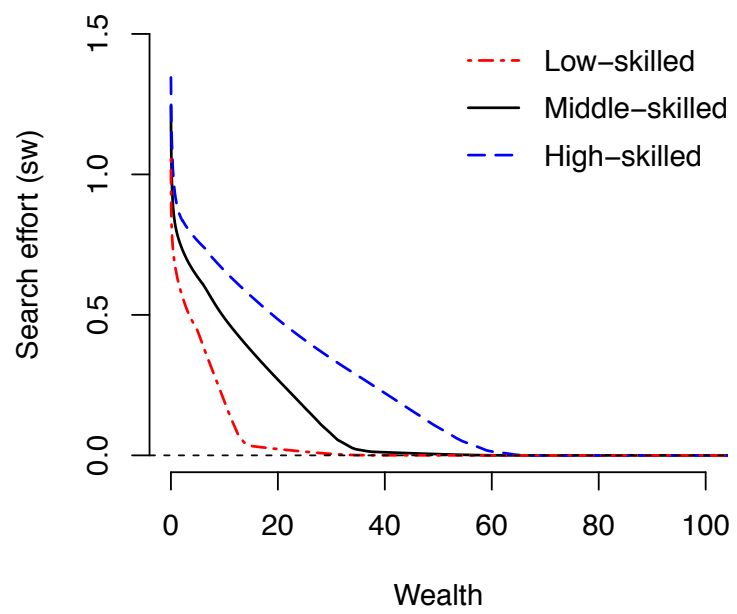

Figure 9. Workers' optimal business search effort (left) and entrepreneurs' optimal job search effort (right). Note: these are optimal policies under the non-exclusion case. For workers we choose $y=y_{3}$ and for entrepreneurs we take $z_{-1}=z_{1}$.

\section{D.2 Endogenous spreads and borrowing constraints}

In the baseline model, an entrepreneur will default only when the business shock $z$ is too small. This is because, in such a case, an entrepreneur generates a small loss and expected future profits are small. Because the external creditor perfectly anticipates this behavior, it charges a higher price to risky entrepreneurs, with a higher incentive to default. The resulting interest rate depends on the entrepreneur's states. In particular, entrepreneurs with sufficient levels of wealth would never default. Indeed, for those entrepreneurs, bankruptcy costs (fees and expected losses from credit market exclusion) are high as compared to the benefits of renegotiating their debt. The incentive to default is also strongly related to the business shock $z_{-1}$ realized during the previous period. Entrepreneurs who experienced a bad shock have a higher probability of default, lowering their ability to borrow by increasing the charged interest rate.

\section{D.3 Distributions}

Figure 11 displays the distribution of the three occupations in the model. As in Cagetti and De Nardi (2006), distributions display important concentration of wealth in the hand of entrepreneurs, consistent with the data. 

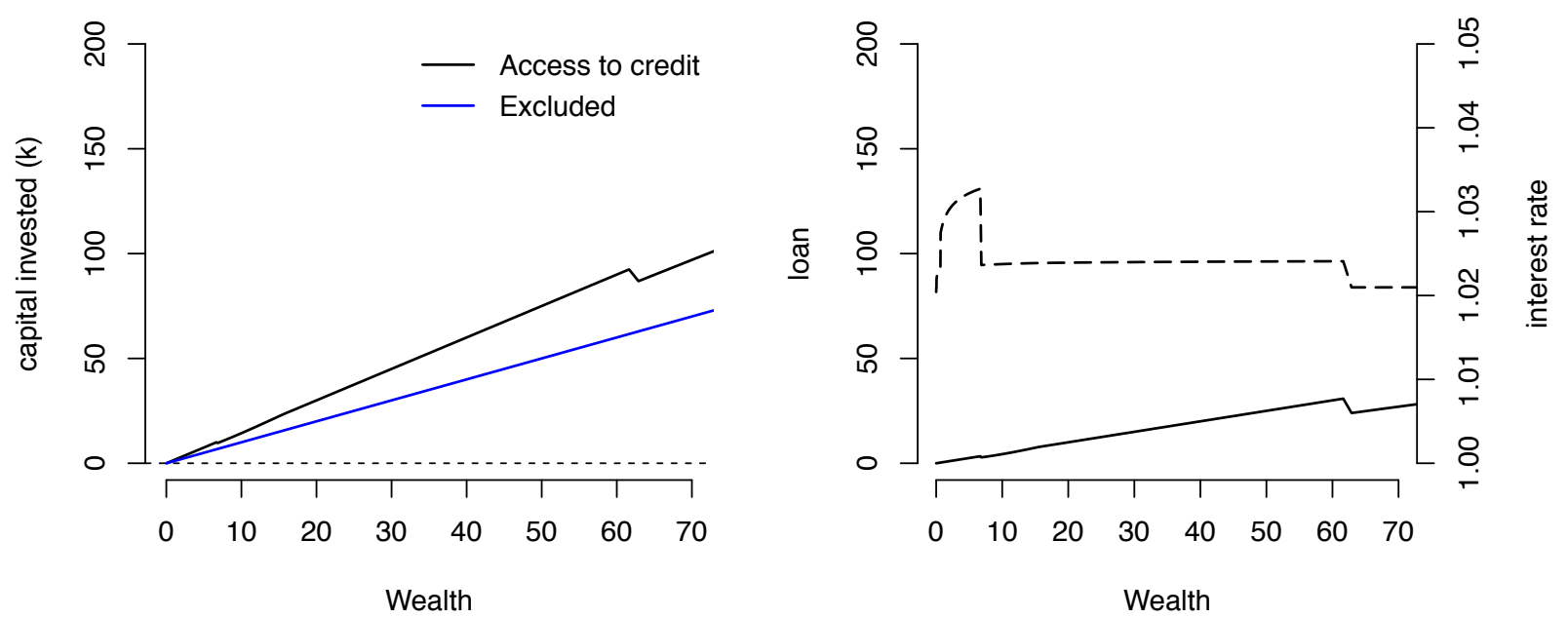

Figure 10. Entrepreneur's policy functions. Left panel: capital invested $k$, right panel: loan $k-a$ and resulting interest rate $r(\Phi, k)$ for non-excluded entrepreneurs. Plot correspond to $\theta=\theta_{2}$ and $z=z_{6}$.
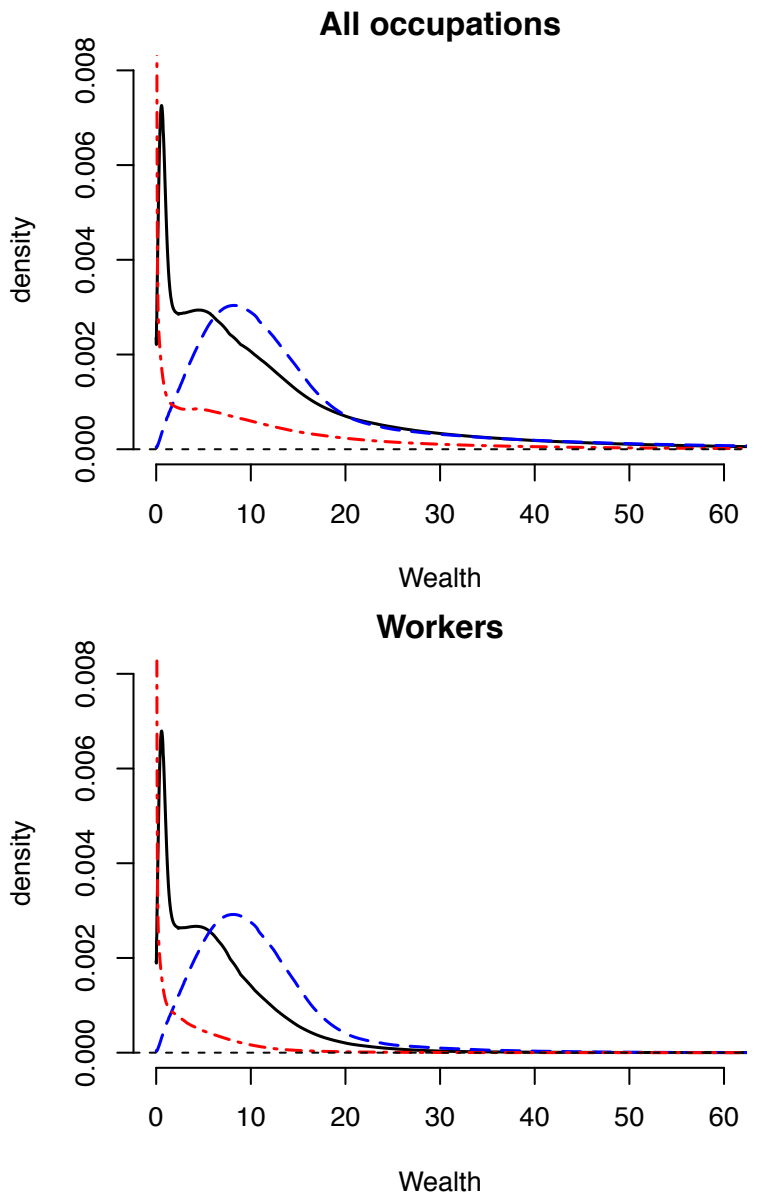

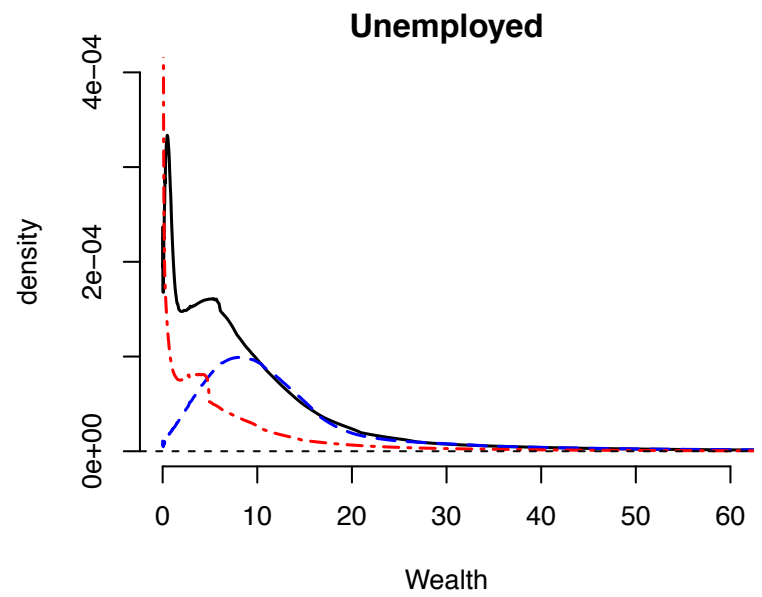

Entrepreneurs

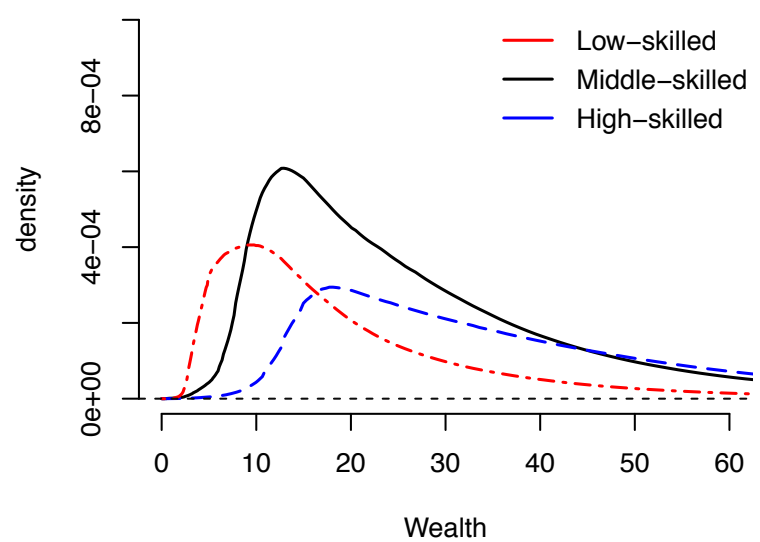

Wealth

Figure 11. Distribution for the three occupations. 


\section{E Additional properties of the quantitative model}

\section{E.1 Occupational flows by wage quintiles, data and model}

Figure 12 displays how the baseline model matches the shapes of the flows from a given occupation to another as compared to CPS data for fitted wages (except for the transition W to $\mathrm{U}$ and $\mathrm{W}$ to $\mathrm{E}$ where we use exact wages). In the data, information is available for the wages of employed workers but not for entrepreneurs or unemployed for obvious reasons. Thus we use a specific methodology to recover this information. We estimate a potential wage that an individual (i.e. unemployed or entrepreneurs) could have if she would have taken a job. We use age, age ${ }^{2}$, age $e^{3}$, sex, education, occupation and industry sector as covariates to fit the observed $\log$ (wage) of a worker in the data. We obtain an $R^{2}$ of about 0.37 using simple OLS. We then assign to all the individuals the potential wage using the coefficient estimates. It appears that educational attainment, that we use as the main proxy for ability in the baseline model, produce almost the same transitions except for the $\mathrm{E}$ to $\mathrm{W}$ transition which is now decreasing, a feature that we do not capture in the model.

\section{E.2 Normalized income of entrepreneurs}

Table 6 compares the fraction of entrepreneurs with an income lower than a given level of normalized income (including wage, business income, and interests from savings) in the model and in the data. The model exhibits a slightly higher concentration of total income on the left side with respect to data.

\begin{tabular}{lcccccccc}
\hline Normalized income level & $\mathbf{0 . 1}$ & $\mathbf{0 . 3}$ & $\mathbf{0 . 5}$ & $\mathbf{0 . 7}$ & $\mathbf{1 . 0}$ & $\mathbf{1 . 5}$ & $\mathbf{2 . 0}$ & $\mathbf{2 . 5}$ \\
\hline Model (\% entrepreneurs) & 4.6 & 12.7 & 25 & 36 & 50 & 66.2 & 77 & 83.9 \\
Data (\% entrepreneurs) & 3.7 & 9.9 & 20.9 & 33 & 50 & 63.2 & 73 & 79 \\
\hline \hline
\end{tabular}

Table. 6. Fraction of entrepreneurs with an income lower than a given level of normalized income. 

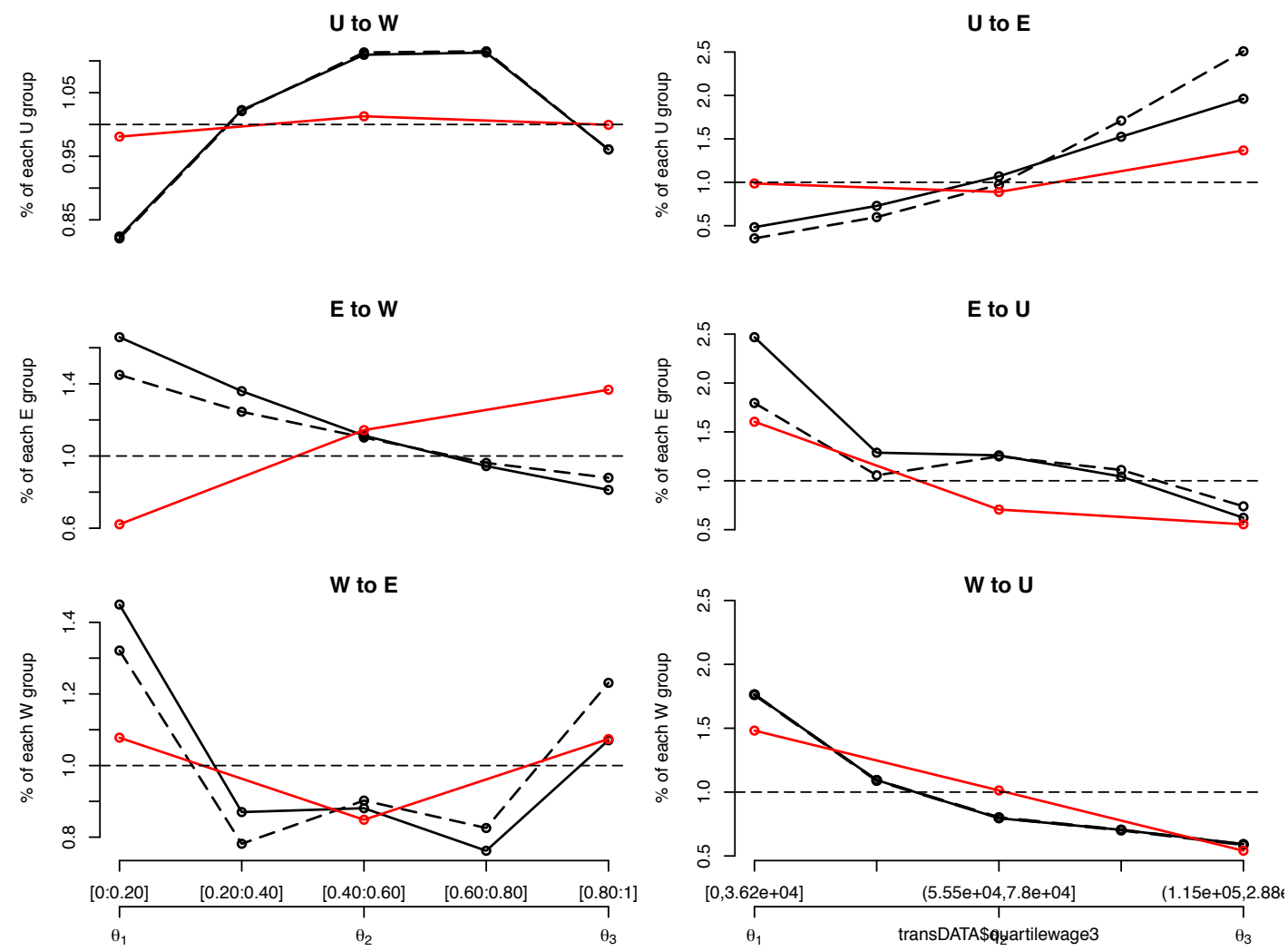

Figure 12. Quarterly flows from a given occupation to another by CPS fitted wage quintile (black) and model (red). The dashed lines refer to self-employment only while the solid line to only self-employed business owners. Wages are estimated for entrepreneurs and unemployed. Data sources: authors' own computations using CPS data from 2001 to 2008.

\section{F Numerical implementation}

State space and grid definition In our model, an household is fully characterized by a state vector $\mathbf{x}=(o, y, \theta, z, e, j, a)$ with $a \in A, y \in \mathcal{Y}, z \in \mathcal{Z}, \theta \in \Theta, o \in\{w, e, u\}, e \in\{A, C\}$ and $j \in\{i, n\}$. We compute the household problem using a grid of asset $\mathbf{a}$ of 350 points, spaced according to an exponential rule. We discretize the process $z, y$ and $\theta$ with respectively 7,5 and 3 grid points. We compute the second stage entrepreneur's problem over a grid of cash-on-hand with 350 grid points.

\section{F.1 Algorithm}

We organize the algorithm as follows.

1. Initialize a full dimension grid space composed of all different possible asset values (a), productivity level $(y)$, innate ability $(\theta)$ and entrepreneurial state $(z)$. The maximum asset level is chosen sufficiently large to get ergodicity of the policy functions. 
2. Guess initial tax rate $\tau_{w}$ and prices $\{w, r\}$.

3. Given prices, solve the consumption-saving-search (CSS) problem of a worker and an unemployed agent.

4. For the entrepreneur's problem, we proceed as follows.

- First we solve the CSS problem of the values $B, R$ and $\hat{E}$ on a grid of cash-on-hand.

- Given the solution to the previous values, set a grid of possible investment value $k$ with bound $[0, \lambda a]$.

- Separate the problem in multiple regions. Between [0, a], we apply a standard solver to find the optimal $k$. Between $[a, \lambda a]$, we apply a grid search that account for multiple solutions that could arise due to the endogenous determination of the spread $r^{b}$.

- For each $k>a$, start by providing the loan at the risk-free interest rate $r$. If the entrepreneur default for this interest rate, then compute the resulting new interest rate $r^{b}$ implied by the zero profit condition of the bank. Iterate the process until $r^{b}$ is consistent with the default probability. A loan that implies a default probability equals to 1 is not allowed.

- Save the best solutions to the problem and find the optimal $k$ level.

5. Construct the transition matrix $\mathbf{M}$ generated by $\Pi_{y}, \Pi_{z}$ and $\Pi_{\theta}, a^{\prime}(\mathbf{x}), s_{w}(\mathbf{x}), s_{e}(\mathbf{x})$ and the default decision. Compute the associated stationary measure of individuals $\Gamma(\mathbf{x})$, by first guessing an initial mass of one of households with zero asset and then by iterating on $\Gamma^{\prime}(\mathbf{x})=\mathbf{M} \Gamma(\mathbf{x})$ until $\left|\Gamma^{\prime}(\mathbf{x})-\Gamma(\mathbf{x})\right|<\mu$, with $\mu$ very small.

6. Compute the resulting total asset level, total labor supplied and total investment in the entrepreneurial sector. Total capital invested in the corporate sector is given as the difference between total savings and total capital invested in the entrepreneurial sector. Total labor used in the corporate sector is given by total labor supplied by workers.

7. Update prices $\{r, w\}$ using the marginal productivities in the corporate sector and tax rate $\tau_{w}$ to close the government budget up to a relaxation. Back to step 2 until convergence of labor income tax rate and prices. 


\section{F.2 Optimal search efforts}

We describe here the solution algorithm for computing ex-ante all the optimal search efforts. Given a set of parameter $\left(\kappa_{w}, \kappa_{e}, \psi_{e}, \psi_{w}\right)$, the solutions $s_{w}$ and $s_{e}$ for each occupation is computed only once.

In order to pre-compute the search efforts, we set up a very large grid that we call diffval $\left(\mathcal{G}_{\Delta \mathrm{V}}=[0, d \max ]\right)$, which summarizes the option values $(\Delta V)$ of interest, that are needed to compute either $s_{w}$ or $s_{e}$, as shown above. Given this grid, we solve for the optimal search efforts. We end up with grid $\mathcal{G}_{\mathbf{w}}$ and $\mathcal{G}_{\mathrm{e}}$ over optimal search efforts corresponding to values in the grid $\mathcal{G}_{\Delta \mathrm{v}}$. When solving for the household problem, we therefore compute $\Delta V$ and we find, using linear interpolation, the corresponding optimal search efforts $s_{w}(\Delta V)$ and $s_{e}(\Delta V)$.

Worker and entrepreneur search efforts The solution for the optimal search efforts of a worker and an entrepreneur (who repays) is straightforward and are given respectively by the first order conditions:

$$
\begin{aligned}
& \frac{\partial W(a, \theta, y, e)}{\partial s_{e}}=0 \\
& -\psi_{w}\left(s_{w}\right)^{\psi_{w}}+\beta \pi_{w}^{\prime}\left(s_{w}\right) \underbrace{\left[\eta \max \left\{0, \mathcal{E}_{i}^{\prime}-U_{i}^{\prime}\right\}+(1-\eta) \max \left\{0, \mathcal{E}_{n}^{\prime}-W^{\prime}\right\}\right]}_{\Delta V>0}=0 \\
& \frac{\partial R(a, k, \theta, z, j)}{\partial s_{w}}=0 \\
& -\psi_{e}\left(s_{e}\right)^{\psi_{e}}+\beta \pi_{e}^{\prime}\left(s_{e}\right) \underbrace{\left[\max \left\{W^{\prime}, E_{j^{\prime}}^{\prime}\right\}-\max \left\{U_{j^{\prime}}^{\prime}, E_{j^{\prime}}^{\prime}\right\}\right]}_{\Delta V>0}=0
\end{aligned}
$$

Unemployed individuals An individual who is currently unemployed can search at the same time a business idea and a job. A convenient way to rewrite the value function in order to solve ex-ante the optimal search efforts is to use option values as follows:

$$
\begin{array}{rl}
U(a, \theta, e, j)=\max _{c, a^{\prime}, s_{w}, s_{e}} & u\left(c, s_{w}, s_{e}\right) \\
& +\beta \mathbb{E}_{\theta^{\prime}, y^{\prime}, j^{\prime}, e^{\prime} \mid \theta, y, j, e}\left\{U_{j^{\prime}}^{\prime}+\pi_{w}\left(W^{\prime}-U_{j^{\prime}}^{\prime}\right)+\pi_{w} \pi_{e} \max \left\{0, \mathcal{E}_{j^{\prime}}^{\prime}-W^{\prime}\right\}\right. \\
& \left.+\left(1-\pi_{w}\right) \pi_{e} \max \left\{0, \mathcal{E}_{j^{\prime}}^{\prime}-U_{j^{\prime}}^{\prime}\right\}\right\}
\end{array}
$$


The job search effort solves:

$$
\begin{aligned}
& \frac{\partial U(a, \theta, e, j)}{\partial s_{w}}=0 \\
& u_{s_{w}}+\beta\left[\pi_{w}^{\prime}\left(W^{\prime}-U_{j^{\prime}}^{\prime}\right)+\pi_{w}^{\prime} \pi_{e} \max \left\{0, \mathcal{E}_{j^{\prime}}^{\prime}-W^{\prime}\right\}-\pi_{w}^{\prime} \pi_{e} \max \left\{0, \mathcal{E}_{j^{\prime}}^{\prime}-U_{j^{\prime}}^{\prime}\right\}\right]=0
\end{aligned}
$$

and the condition for the business search effort is:

$$
\begin{aligned}
& \frac{\partial U(a, \theta, e, j)}{\partial s_{e}}=0 \\
& u_{s_{e}}+\beta\left[\pi_{w} \pi_{e}^{\prime} \max \left\{0, \mathcal{E}_{j^{\prime}}^{\prime}-W^{\prime}\right\}+\left(1-\pi_{w}\right) \pi_{e}^{\prime} \max \left\{0, \mathcal{E}_{j^{\prime}}^{\prime}-U_{j^{\prime}}^{\prime}\right\}\right]=0
\end{aligned}
$$

Using the notation $\mathcal{P}\left(s_{w}\right)=\pi_{w} \max \left\{0, \mathcal{E}_{j^{\prime}}^{\prime}-W^{\prime}\right\}+\left(1-\pi_{w}\right) \max \left\{0, \mathcal{E}_{j^{\prime}}^{\prime}-U_{j^{\prime}}^{\prime}\right\}$, we get the following condition for the optimal business search effort:

$$
\pi_{e}\left(s_{e}^{*}\right)=1-\frac{\psi_{e}\left(s_{e}^{*}\right)^{\psi_{e}}}{\beta \kappa_{e} \mathcal{P}\left(\bar{s}_{w}\right)}
$$

At the optimal search effort, the probability of finding a business idea $\pi_{e}\left(s_{e}^{*}\right)$ is decreasing with the cost of the search $\psi_{e}\left(s_{e}^{*}\right)^{\psi_{e}}$ and increasing with the discount factor $\beta$, the matching parameter $\kappa_{e}$ and the value associated of being entrepreneur relative to other occupations $\mathcal{P}\left(\bar{s}_{w}\right)$. We pre-compute the optimal search effort $s_{e}^{*}$ given $\Delta V$ and $s_{w}$. We then apply a root-finding optimizer to search for the corresponding $s_{w}^{*}$ within the CSS problem.

\section{F.3 Transitional dynamics}

To solve the transition, we compute the solutions of the household problem backward, starting at the new steady-state. We then find prices that are consistent with the implied policies and we iterate until convergence. We assume that the economy is in the initial steady state in period 0 and the reform is announced and implemented in period 1. Agents did not anticipate the policy before its implementation. The economy makes a transition to reach the final steady state in period $T$. We choose $T$ large enough so that the resulting stationary distribution in period $T$ is close enough to the post-reform steady states. The algorithm for the transition dynamics is:

1. Guess a path for $\left\{\mathcal{L}_{1}, \ldots, \mathcal{L}_{T-1}\right\}$ with $\mathcal{L}_{t}=\left\{r_{t}, w_{t}, \tau_{w, t}\right\} . \mathcal{L}_{0}$ and $\mathcal{L}_{T}$ are given by initial and final steady-states.

2. Use value functions of the final steady state (period $T$ ) to solve the households' problem 
backwards starting from $T-1$ until period 1.

3. Use the distribution of the initial steady state and the resulting policy functions to compute the path of the distribution of household $\left\{\hat{\Gamma}(\mathbf{x})_{1}, \ldots, \hat{\Gamma}(\mathbf{x})_{T}\right\}$.

4. Given these distributions, compute new path $\left\{\mathcal{L}_{1}, \ldots, \mathcal{L}_{T-1}\right\}$. Iterate from step 2 until the difference between the initial path is close enough to the resulting path.

5. When convergence is achieved, check if the resulting final distribution $\hat{\Gamma}(\mathbf{x})_{T}$ is close enough to the steady-state distribution $\Gamma(\mathbf{x})_{T}$ up to a relaxation. If the two distributions are identical, then stop, else, increase the number of periods $T$.

\section{F.4 Welfare: computation and additional elements}

Between the reformed steady-state and the initial baseline economy, we follow Flodén (2001) in order to compute the ex-ante utilitarian social welfare change, by computing the premium $\omega_{V}$ that measures the percent of life-time consumption that a newborn in the economy A would need to be indifferent between economy A (without the policy) and B (with the policy).
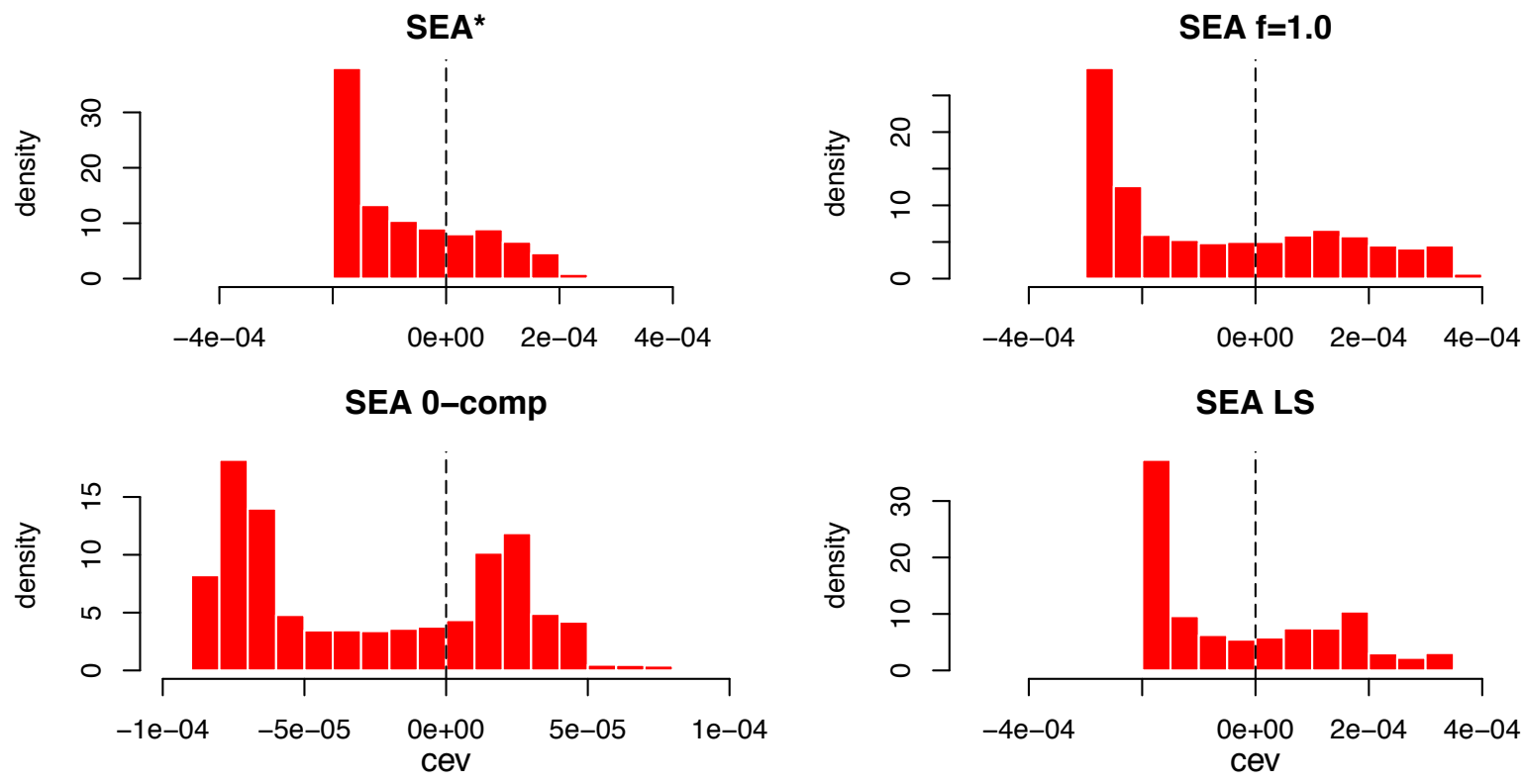

Figure 13. Distribution of welfare gains/losses over the transition.

Along the transition, we measures the constant increment in percentage of consumption in every state that has to be given to each agent so that she is indifferent between remaining in the benchmark economy and moving to another economy that makes a transition to a new steadystate implied by the reforms. Figure 13 depicts the welfare gains/losses over the transition for 
four reforms considered in the paper.

\section{G Robustness}

Reparameterization using self-employment We have parameterized again the model using self-employment as the definition for entrepreneurship and assessed the impact of the SEA* in such an economy. Table 7 summarizes the parameters and the moments of the new calibration. We target a higher exit rate and a larger fraction of entrepreneurs. We also target a different shape of the transition from paid-employment to entrepreneurship, in line with the data.

\begin{tabular}{|c|c|c|c|}
\hline A. Parameter & Symbol & & Value \\
\hline Discount factor & $\beta$ & & 0.9742 \\
\hline$z$ process (autocorrelation, variance) & $\rho_{z}, \sigma_{z}^{2}$ & & $0.8636,0.197$ \\
\hline Businesses' return to scale & $\nu$ & & 0.79 \\
\hline Search utility parameter & $\psi_{e}=\psi_{w}$ & & 2.579 \\
\hline Matching parameter & $\kappa_{e}, \kappa_{w}$ & & $0.328,0.842$ \\
\hline Bankruptcy cost & $\phi$ & & 0.0275 \\
\hline Entrepreneur's innate ability & {$\left[g_{1}, g_{2}, g_{3}\right]$} & & {$[0.0686,0.0772,0.1007]$} \\
\hline B. Targeted moments & Target & & Model \\
\hline Unemployment rate (in \%) & 5.0 & & 5.0 \\
\hline Share of entrepreneurs (in \%) & 10.5 & & 10.6 \\
\hline Entrepreneurs' exit rate (in \%) & $6.5-7.5$ & & 7.1 \\
\hline Fraction of new entrepreneurs prev. unemployed (in \%) & 20 & & 20 \\
\hline Capital-output ratio (annual) & 2.65 & & 2.66 \\
\hline Ratio of net worth E/pop & $7-8$ & & 7.6 \\
\hline Bankruptcy rate (as fraction of entrepreneurs) (in \%) & 0.57 & & 0.58 \\
\hline Fraction of entrepreneur with neg. earnings (in \%) & 10 & & 10.5 \\
\hline Flows $\mathrm{W}$ to $\mathrm{E}$ by quantiles / avg rate $(\%)$ & {$\left[\begin{array}{cc}Q 1 & Q 2 \\
1.1 & 0.85\end{array}\right.$} & $\left.\begin{array}{l}Q 3 \\
1.0\end{array}\right]$ & {$\left[\begin{array}{ccc}Q 1 & Q 2 & Q 3 \\
1.11 & 0.89 & 1.0\end{array}\right]$} \\
\hline
\end{tabular}

Table. 7. Estimated parameters and targeted moments for the alternative model with self-employment as entrepreneur's definition.

Again, the model is able to reproduce the main features concerning the observed transitions. Table 8 summarizes the aggregate transitions in the model against the data. The magnitudes found in the model are close to their data counterparts.

\begin{tabular}{l|cc|ccc}
\hline & \multicolumn{2}{|c}{ Mass (\%) } & \multicolumn{3}{c}{ Transition: Model (Data) $(\%)$} \\
& Target & Model & $W$ & $E$ & $U$ \\
\hline$W$ & 84.5 & 84.4 & $97.15(97.20)$ & $0.76(0.70)$ & $2.09(2.11)$ \\
$E$ & 10.5 & 10.6 & $6.09(6.15)$ & $92.93(92.46)$ & $0.98(1.40)$ \\
$U$ & 5.0 & 5.0 & $43.88(46.04)$ & $3.22(3.72)$ & $52.90(50.25)$ \\
\hline \hline
\end{tabular}

Table. 8. Transition between occupations during a quarter (data counterparts between braces). Data sources: authors' computations using CPS data from 2001 to 2008. We restrict our sample to individuals aged between 20 to 65 years old. 
In table 9, we summarize the results of the model under the $\mathbf{S E A}{ }^{*}$ reform. Results are quite similar to our baseline model but effects are stronger with all self-employed. Most notably, the share of entrepreneurs increases by more than $2.1 \%$ and the share of insured entrepreneurs account for $3.3 \%$ of all entrepreneurs under the $\mathbf{S E A}{ }^{*}$ in this alternative specification, against $1.8 \%$ and $2.9 \%$ when considering self-employed business owners.

\begin{tabular}{l|c|c}
\hline & Baseline & $\begin{array}{c}\text { SEA }^{*} \\
(f=0.3, \bar{q}=0.5) \\
10.79\end{array}$ \\
Fraction of entrepreneurs & 10.57 & 3.59 \\
\% unemployed starting businesses (in \%) & 3.22 & 7.16 \\
entrepreneurship exit rate (in \%) & 7.07 & 4.974 \\
unemployment rate (in \%) & 4.988 & 84.23 \\
corporate jobs (in \%) & 84.44 & 515.78 \\
new firm per year (th.) & 500 & 6.7 \\
necessity share (in \%) & 8.5 & 0.393 \\
Entrepreneurial sector production & 0.386 & 3.574 \\
Corporate sector capital & 3.58 & 1.761 \\
Entrepreneurial sector capital & 1.729 & \\
\hline \hline
\end{tabular}

Table. 9. The SEA* effects on aggregates.

Fixed start-up cost Other alternatives, such as implementing a fixed start-up cost had no significant impact on our numerical results, but of course, the parameterization is different. Notice also that we implicitly already incorporate a start-up cost since an individual has to search an idea before creating his business. Results with an entry cost suggest that the SEA* leads to a larger increase in the share of entrepreneurs while unemployed individuals are less likely to create a business as compared to the no-entry cost case. Indeed, imposing an entry cost reduces the temptation to exit entrepreneurship in case of a bad shock, since individuals would have to repay the entry cost if they want to recreate a firm.

Bankruptcy specification In the baseline economy, we have assumed that entrepreneurs could default in equilibrium but are subject to a cost component and a recovery rate. We also explore the case where no bankruptcy is allowed here. Under this assumption, we obtain a lower flow from entrepreneurship to unemployment of about $0.39 \%$ against $0.74 \%$ in the benchmark case and $0.99 \%$ in the data. Policy results are qualitatively unchanged but the magnitude of the SEA* is larger. The policy leads to a $2.2 \%$ increase in the share of entrepreneurs against $1.86 \%$ in the benchmark. Indeed, the ability to bankrupt can be viewed as an extra insurance mechanism on top of the SEA* Removing the option to default implies a larger entrepreneurial risk, which 
increases the effectiveness of the SEA*

Business shock and fraction of negative entrepreneurial earnings We also conduct some robustness on the business shock $z$. We have reduced artificially the variance of the shock to 0.12. The fraction of entrepreneurs with zero or negative earnings falls to $2.7 \%$. Under this experiment, the effect of the insurance policy is slightly lowered. This is because even with low shock $z$ variance, the insurance induces the entry of some unemployed individuals who run small firms that generate low profits. Under the SEA* ${ }^{*}$, such new entrepreneurs are compensated and receive part of their UI rights in addition to their starting low profit.

\section{References}

Cagetti, Marco, and Mariacristina De Nardi. 2006. "Entrepreneurship, Frictions, and Wealth." Journal of Political Economy, 114(5): 835-870.

Cagetti, Marco, and Mariacristina De Nardi. 2009. "Estate Taxation, Entrepreneurship, and Wealth." American Economic Review, 99(1): 85-111.

Flodén, Martin. 2001. "The effectiveness of government debt and transfers as insurance." Journal of Monetary Economics, 48(1): 81-108. 